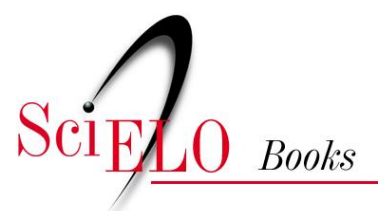

\title{
Como e por que as desigualdades sociais fazem mal à saúde
}

\author{
Rita Barradas Barata
}

\section{SciELO Books / SciELO Livros / SciELO Libros}

BARATA, RB. Como e por que as desigualdades sociais fazem mal à saúde [online]. Rio de Janeiro: Editora FIOCRUZ, 2009. Temas em Saúde collection. 120 p. ISBN 978-85-7541-391-3. Available from SciELO Books $<$ http://books.scielo.org $>$.

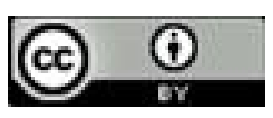

All the contents of this work, except where otherwise noted, is licensed under a Creative Commons Attribution $\underline{4.0 \text { International license. }}$

Todo o conteúdo deste trabalho, exceto quando houver ressalva, é publicado sob a licença Creative Commons Atribição 4.0.

Todo el contenido de esta obra, excepto donde se indique lo contrario, está bajo licencia de la licencia $\underline{\text { Creative }}$ Commons Reconocimento 4.0. 


\section{Como e Por Que as \\ Desigualdades Sociais Fazem Mal à Saúde}




\section{FUNDAÇÃO OSWALDO CRUZ}

Presidente

Paulo Ernani Gadelha Vieira

Vice-Presidente de Ensino, Informação e Comunicação

Nísia Trindade Lima

\section{EDITORA FIOCRUZ}

\section{Diretora}

Nísia Trindade Lima

Editor Executivo

$$
\text { João Carlos Canossa Mendes }
$$

Editores Científicos

Gilberto Hochman

Ricardo Ventura Santos

Conselho Editorial

Ana Lúcia Teles Rabello

Armando de Oliveira Schubach

Carlos E. A. Coimbra Jr.

Gerson Oliveira Penna

Joseli Lannes Vieira

Ligia Vieira da Silva

Maria Cecília de Souza Minayo

Coleção Temas em Saúde

Editores Responsáveis

Maria do Carmo Leal

Nísia Trindade Lima

Ricardo Ventura Santos 
RITA BARRADAS BARATA

\section{Como e Por Que as Desigualdades Sociais Fazem Mal à Saúde}

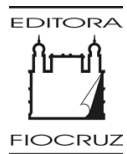


Copyright (C) 2009 da autora

Todos os direitos desta edição reservados à

FUNDAÇÃO OSWALDO CRUZ / EDITORA

ISBN: 978-85-7541-184-1

$1^{a}$ edição: 2009

$1^{\text {a }}$ reimpressão: 2012

Capa e projeto gráfico

Carlota Rios

Editoração

Robson Lima

Revisão

Cláudia Dias Sampaio

Catalogação na fonte

Instituto de Comunicação e Informação Científica e Tecnológica em Saúde/Fiocruz Biblioteca de Saúde Pública

N318s Barata, Rita Barradas

Como e Por Que as Desigualdades Sociais

Fazem Mal à Saúde. / Rita Barradas Barata. Rio de

Janeiro: Editora Fiocruz, 2009.

120 p. (Coleção Temas em Saúde)

1. Saúde Bucal. 2. Boca Edentada. 3. Atenção à Saúde. 4.

Direito à Saúde. 5. Sistema Único de Saúde.

I. Frazão, Paulo. II. Título. III. Série.

$$
\text { CDD - 21.ed. - } 617.601
$$

2012

EDITORA FIOCRUZ

Av. Brasil, 4036 - Térreo - sala 112 - Manguinhos

21040-361 - Rio de Janeiro - RJ

Tels.: (21) 3882-9039 / 3882-9041

Telefax: (21) 3882-9006

e-mail: editora@fiocruz.br

http://www.fiocruz.br 


\section{SUMÁRIO}

Apresentação

1. O que queremos dizer com desigualdades sociais em saúde?

2. A posição social e seus reflexos sobre a saúde

3. Ser rico faz bem à saúde?

4. As desigualdades étnicas necessariamente significam racismo?

5. Relações de gênero e saúde: desigualdade ou discriminação?

6. Políticas para o enfrentamento das desigualdades

Consideracões finais

Bibliografia 



\section{Apresentação}

Meu interesse pela temática das desigualdades sociais em saúde é relativamente antigo. Desde os tempos da faculdade, o interesse pelas ciências sociais e pela epidemiologia me fez buscar articular esses saberes para melhor compreender o processo saúde-doença em sua dimensão coletiva.

A temática das desigualdades sociais em saúde esteve sempre presente na minha trajetória como investigadora do campo da epidemiologia social. Ainda na etapa de elaboração da dissertação de mestrado, sob a influência da professora Cecília Donnangelo e do meu orientador, professor José da Silva Guedes, decidi estudar o comportamento de uma epidemia de doença meningocóccica, analisando o surgimento e a disseminação do processo segundo distritos da cidade de São Paulo classificados por diferentes condições de vida. O trabalho acabou virando livro ainda na década de 1980.

Na década seguinte, organizei em São Paulo um seminário ibero-americano sobre a temática das condições de vida e a situação de saúde, que resultou em uma publicação pela Abrasco dos trabalhos ali apresentados. Esta publicação teve enorme repercussão e circulação no âmbito da saúde coletiva em vários países da América Latina.

Mais recentemente, escrevi o capítulo sobre desigualdades sociais em saúde para o tratado de saúde coletiva organizado por 
Gastão Campos, Maria Cecília Minayo, Marco Akerman, Marcos Drumond e Yara Carvalho, publicado em parceria pela Abrasco e Hucitec.

Assim, pareceu-me perfeitamente natural preparar este volume para a coleção Temas em Saúde da Editora Fiocruz. Vocês verão que este texto apresenta algumas particularidades decorrentes do caráter da coleção. O livro está apresentado em um estilo mais leve, que facilite a leitura e permita, mesmo para leitores não especializados, uma visão panorâmica sobre o assunto. Também para respeitar o formato adotado tentei reduzir ao máximo as tabelas e os gráficos, normalmente mais freqüentes em textos de epidemiologia. Ainda de acordo com o padrão da coleção a que pertence, este livro não contém referências ou notas de rodapé comuns em textos científicos. Todas essas características visam a tornar a leitura mais agradável. Ao final do texto os leitores poderão encontrar uma breve lista de textos e também um conjunto de leituras recomendadas para aqueles que pretenderem aprofundar seus conhecimentos no tema.

Como e Por Que as Desigualdades Sociais Fazem Mal à Saúde está assim constituído. O primeiro capítulo apresenta de forma breve algumas considerações teóricas sobre o tema das desigualdades sociais em saúde, apontando as correntes e tendências existentes na pesquisa epidemiológica sobre o tema. O segundo trata da questão das classes sociais, ou seja, como a posição social de cada indivíduo repercute sobre sua saúde. O terceiro enfoca o tema da renda, isto é, as relações entre riqueza e estado de saúde. O quarto introduz a discussão sobre etnia e discriminação, como categorias importantes de análise no estudo de desigualdades sociais em saúde. No quinto capítulo o destaque é dado às relações 
de gênero e à produção da saúde e da doença. O sexto capítulo comenta as políticas públicas no enfrentamento das desigualdades sociais. Por último, apresentam-se algumas considerações e conclusões.

Boa leitura! 



\section{Que Queremos Dizer com Desigualdades Sociais em Saúde?}

Embora a resposta pareça óbvia, na verdade, não é bem assim... Muitos tentam esvaziar o conteúdo político e as conotações de injustiça social e desrespeito aos direitos humanos expressos nessas desigualdades, reduzindo-os simplesmente a diferenças entre indivíduos ou grupos de indivíduos definidos segundo características biológicas.

É importante então que comecemos esclarecendo o sentido que as desigualdades sociais em saúde têm para aqueles que procuram compreender o processo de produção da saúde e da doença nas populações, sem reduzir essa compreensão apenas aos aspectos biológicos.

Podemos começar dizendo que as desigualdades sociais que nos interessam são diferenças no estado de saúde entre grupos definidos por características sociais, tais como riqueza, educação, ocupação, raça e etnia, gênero e condições do local de moradia ou trabalho.

Quando falamos em igualdade ou desigualdade, estamos comparando situações, sem necessariamente, atribuirmos um juízo de valor àquilo que é igual ou desigual. Felizmente, os indivíduos e os grupos sociais reúnem grandes diferenças e variabilidade com relação a muitas características, fato que torna a vida tão interessante. 
Mas, quando falamos em desigualdade social geralmente estamos nos referindo a situações que implicam algum grau de injustiça, isto é, diferenças que são injustas porque estão associadas a características sociais que sistematicamente colocam alguns grupos em desvantagem com relação à oportunidade de ser e se manter sadio.

A discussão em torno das desigualdades sociais em saúde colocou a questão do direito à saúde na pauta política em todo o mundo. Diferentes populações atribuem maior ou menor importância ao direito à saúde como um direito humano fundamental. Como posições polares, podemos apontar, de um lado, o comportamento político da maioria dos dirigentes de países europeus, que cada vez mais concedem importância à redução das desigualdades sociais em saúde, considerando que os sistemas nacionais de saúde e outras políticas sociais devem ter como principal objetivo o alcance da equidade. De outro lado, os governos norte-americanos não consideram que esta seja uma questão relevante para o Estado. Na perspectiva deles, o direito à saúde é algo intrinsecamente relacionado com as capacidades individuais, estilos de comportamento e possibilidade de pagar pelos serviços apropriados.

Aqui no Brasil, ao aprovar o capítulo sobre a saúde na Constituição Federal de 1988, a população, por meio de seus representantes no Congresso, decidiu que a saúde é um direito de todos e que deve ser garantido mediante ações de política pública. Fez ainda mais do que isso, definiu a saúde através de um conceito amplo, que inclui os seus principais determinantes e apontou em linhas gerais os princípios que o sistema nacional de saúde deveria ter: universalidade, integralidade e equidade. 
As desigualdades sociais em saúde não são nenhuma novidade. Elas vêm sendo documentadas há muito tempo, principalmente a partir do século XIX. As condições políticas e sociais que surgiram com o capitalismo, em sua fase de produção industrial, foram favoráveis ao tema, seja pelas péssimas condições de vida da classe trabalhadora, seja pelo ideário político associado às revoluções burguesas. A contradição entre os valores de igualdade, fraternidade e liberdade, e a dura realidade de vida da maioria da população nos países industrializados possibilitou, aos chamados reformadores sociais, socialistas utópicos e comunistas, farto material para denunciar as injustiças sociais em vários campos inclusive no da saúde.

Em todas as sociedades, as situações de risco, os comportamentos relacionados à saúde e o estado de saúde físico e mental tendem a variar entre os grupos sociais. Observa-se um gradiente entre as posições sociais e os efeitos sobre a saúde. Não há um limiar a partir do qual as diferenças desaparecem.

Hoje em dia, praticamente não há quem questione a existência das desigualdades sociais em saúde, entretanto, como já assinalamos, as divergências aparecem no momento de elaborar explicações para as diferenças encontradas.

\section{QUAIS SÃO AS EXPLICAÇÕES MAIS FREQUENTES}

\section{PARA AS DESIGUALDADES SOCIAIS EM SAÚDE?}

$\mathrm{Na}$ falta de uma teoria sobre a produção da saúde e da doença, em âmbito populacional, tenta-se explicar as desigualdades sociais em saúde de maneira relativamente simplista. A primeira ideia que costuma ocorrer, quando os diferenciais em mortalidade geral ou específica são apresentados, é que o acesso aos 
serviços de saúde é diferenciado para os vários grupos e, portanto, os efeitos são decorrentes de problemas na utilização dos recursos disponíveis, seja por incapacidade do indivíduo, seja por características de organização dos próprios serviços. Esta explicação é rapidamente derrubada pela constatação de que as desigualdades não desaparecem naqueles países em que existem sistemas nacionais de saúde com garantia de acesso universal para todos os grupos sociais, como ocorre em diversos países da Europa, no Canadá, na Austrália, dentre outros.

Nas comparações entre países, as desigualdades tendem a ser atribuídas a diferentes graus de desenvolvimento da assistência médica. Entretanto, essa explicação, ainda que possa responder por parte do perfil de mortalidade observado, não é capaz de justificar por que as desigualdades vêm aumentando ao invés de diminuírem com o passar do tempo.

A difusão de tecnologias médicas, mesmo nos países menos desenvolvidos, é considerável e com o passar do tempo deveria provocar a redução das desigualdades, e não o seu aumento. Portanto, por mais importante que o desenvolvimento técnicocientífico possa ser para a recuperação da saúde, esta não parece ser a explicação mais plausível para essas desigualdades.

Para explicar as diferenças entre países e entre grupos sociais no interior dos países, há também os que utilizam a velha ideia do ciclo vicioso. Para eles, a doença é o principal determinante da posição social, e não ao contrário, isto é, as pessoas doentes não conseguem ter um desempenho social satisfatório e por isso encontram-se em posições desfavorecidas. Bastam alguns estudos longitudinais para derrubar essa justificativa. 
Entre aqueles que admitem a influência do contexto, ou seja, das condições de vida sobre o estado de saúde, a maioria acredita que é o estilo de vida dos indivíduos o principal responsável pelas desigualdades sociais. Esta perspectiva liberal de compreensão do processo saúde-doença acaba por esvaziar o conteúdo social do processo, atribuindo a preferências individuais a causa das diferenças observadas. As posições da saúde pública tradicional e da educação sanitária são amplamente baseadas nessa crença de que os indivíduos na sociedade atual são livres para escolher a qualidade de sua moradia, suas condições de trabalho, seus comportamentos e as situações de maior ou menor risco para a saúde.

Tal crença é mais difícil de ser contestada com evidências empíricas ou argumentos teóricos, pois implica uma visão de mundo particular. Entretanto, os estudos epidemiológicos têm mostrado que os fatores de risco não conseguem explicar mais do que $25 \%$ da ocorrência dos problemas crônicos de saúde. Portanto, mesmo que o estilo de vida seja importante individualmente, dificilmente seria capaz de explicar as desigualdades sociais.

Mais recentemente, com os avanços científicos no campo da genética, voltaram à moda as explicações baseadas em fatores genéticos. Toda e qualquer variação na ocorrência de doenças tende a ser relacionada com um gene ou conjunto de genes que acabam de ser 'descobertos'. Como essa explicação corresponde a 'má genética', isto é, a uma interpretação mecanicista da própria atuação dos determinantes genéticos, não cremos que seja necessário perder muito tempo para refutá-la. 
Assim, fica clara a necessidade de possuir teorias ao invés de simples explicações para compreender as desigualdades sociais em saúde. Teorias que possibilitem compreender não apenas a distribuição da doença, mas principalmente seu processo de produção em diferentes contextos sociais.

\section{QUAIS SÃO AS TEORIAS DISPONÍVEIS PARA}

\section{ENTENDERMOS AS DESIGUALDADES SOCIAIS EM SAÚDE?}

Podemos identificar quatro teorias principais que pretendem fornecer elementos para a compreensão do processo de produção da saúde e da doença e seus reflexos sobre a distribuição do estado de saúde na população.

A teoria mais antiga e mais facilmente aceita é a estruturalista ou materialista, que confere maior importância à estrutura econômica da sociedade. De acordo com este modelo, o montante de renda ou riqueza dos países, grupos sociais ou indivíduos é o principal determinante do estado de saúde A falta ou insuficiência dos recursos materiais para enfrentar de modo adequado os estressores ao longo da vida acaba por produzir a doença e diminuir a saúde.

A teoria estruturalista é capaz de explicar grande parte das desigualdades, mas tropeça diante do paradoxo de que nem sempre a riqueza de um país vem acompanhada de melhor nível de saúde, principalmente nos países cujas populações têm as suas necessidades básicas atendidas.

Uma outra teoria desenvolvida para enfrentar o paradoxo entre riqueza e nível de saúde é a psicossocial. Ela dá mais importância à percepção da desvantagem social como fonte de 
estresse e desencadeador de doenças. Nos países e grupos sociais em que as necessidades básicas estão atendidas, as diferenças relativas na posse de bens e nas posições de prestígio e poder passam a ser mais relevantes para a produção e distribuição das doenças do que simplesmente o nível de riqueza material.

Não há contradição insolúvel entre essas duas teorias, o que as diferencia fundamentalmente é o enfoque baseado na ideia de privação absoluta ou relativa. No primeiro caso, a falta total de condições para fazer face às necessidades básicas apresenta-se como principal determinante do estado de saúde. Esta situação pode ser exemplificada pela comparação entre a esperança de vida ao nascer e o Produto Interno Bruto (PIB) per capita dos países. As duas variáveis são diretamente correlacionadas e esta relação é forte. Por exemplo, a esperança de vida na Suécia, país que têm um PIB per capita de 42 mil dólares, é de 80 anos, enquanto em Angola, cujo PIB per capita é de 2.800 dólares, a esperança de vida ao nascer é de 40 anos.

No segundo caso, predomina a privação relativa, ou seja, uma vez ultrapassado o limiar de atendimento das necessidades básicas, as diferenças relativas entre os grupos sociais no interior de cada população passam a ser um determinante fundamental, com os países mais igualitários desfrutando de melhores níveis de saúde do que aqueles onde existe maior desigualdade. Como exemplo, podemos citar a comparação entre Cuba e os Estados Unidos. Cuba tem PIB per capita dez vezes menor que os Estados Unidos (4.650 e 43.562 dólares respectivamente) e apresenta a mesma esperança de vida: 77 anos.

Esses dados poderiam nos fazer pensar que a partir de um certo limiar de PIB per capita a esperança de vida tenderia a ser 
alta e semelhante entre os países, mas não é o que ocorre. A África do Sul, por exemplo, tem PIB per capita maior do que Cuba (5.133 dólares) e esperança de vida muito menor (49 anos), refletindo as profundas desigualdades sociais que marcaram a história desse país e que ainda não deixaram de agir sobre o nível de saúde da população.

$\mathrm{Na}$ América Latina a discussão sobre as desigualdades sociais vem sendo feita principalmente à luz da teoria da determinação social do processo saúde-doença. Essa teoria analisa a constituição do próprio sistema capitalista de produção e suas formas particulares de expressão nas diferentes sociedades, dando maior ênfase aos mecanismos de acumulação do capital e à distribuição de poder, prestígio e bens materiais deles decorrentes. A posição de classe e a reprodução social passam a ser vistas como os principais determinantes do perfil da saúde e doença.

Nessa abordagem o problema deixa de ser tratado como uma questão de pobreza absoluta ou relativa e passa a ser visto da perspectiva da inclusão ou exclusão social. Os impactos da estrutura social sobre a saúde são pensados nos processos de participação ou exclusão, associados às diferentes posições sociais e sujeitos a transformações em função do próprio processo histórico.

A versão brasileira da teoria da determinação social do processo saúde-doença dá maior ênfase explicativa ao modo de vida, considerando que nele estão englobados tanto os aspectos materiais quanto os aspectos simbólicos que refletem as características sociais de produção, distribuição e consumo, às quais cada grupo social está relacionado através do modo de vida. Ao mesmo tempo que busca articular as diferentes esferas da organização 
social, o conceito de modo de vida reúne em um mesmo marco teórico as condições coletivas dos grupos e os comportamentos dos indivíduos que compõem esses grupos.

Finalmente a teoria ecossocial chama a atenção para processos de incorporação, no sentido forte do termo, pelos organismos humanos, dos aspectos sociais e psíquicos predominantes no contexto nos quais os indivíduos vivem e trabalham. Nessa teoria, procura-se romper com uma visão linear que articula processos distais, intermediários e proximais, substituindo-a por uma concepção complexa de que cada um dos aspectos se manifesta e se reproduz em cada um dos níveis de organização dos seres vivos, caracterizando, assim, a incorporação das diferentes instâncias pelos organismos. Em outras palavras, a teoria ecossocial considera impossível a separação entre o biológico, o social e o psíquico.

As quatro teorias apresentadas compreendem o processo saúde-doença como intrinsecamente histórico, isto é, determinado pelas condições estruturais e conjunturais em que vivem as populações humanas. Do mesmo modo como os homens constroem sua vida material e não material, eles também produzem as doenças das quais irão padecer, bem como os instrumentos e as organizações sociais para combatê-las.

A teoria ecossocial e a teoria do modo de vida representam o esforço de articular as três anteriores - estruturalista, psicossocial e determinação social - considerando os padrões de saúde e doença como as consequências biológicas dos modos de vida e trabalho próprios de cada grupo social, determinados pela organização econômica e pelas prioridades políticas da sociedade. As relações econômicas, sociais e políticas afetam a forma como 
as pessoas vivem e seu contexto ecológico e, desse modo, acabam por moldar os padrões de distribuição das doenças.

Compreender as desigualdades sociais, portanto, vai muito além da simplificação habitual presente nas dicotomias 'doenças de pobre' vs 'doenças de rico' ou 'doenças sociais' vs 'doenças biológicas’. Toda e qualquer doença e sua distribuição populacional são produtos da organização social, não tendo sentido falar, portanto, em doenças sociais e doenças não sociais.

As desigualdades sociais em saúde podem manifestar-se de maneira diversa no que diz respeito ao processo saúde-doença em si, bem como ao acesso e utilização de serviços de saúde. As desigualdades no estado de saúde estão de modo geral fortemente atreladas à organização social e tendem a refletir o grau de iniquidade existente em cada sociedade. $\mathrm{O}$ acesso e a utilização dos serviços refletem também essas diferenças, mas podem assumir feições diversas, dependendo da forma de organização dos sistemas de saúde. Há sistemas que potencializam as desigualdades existentes na organização social e outros que procuram compensar, pelo menos em parte, os resultados danosos da organização social sobre os grupos socialmente mais vulneráveis. Voltaremos a tratar desse tema ao final, quando abordarmos as políticas de enfrentamento das desigualdades sociais.

A equidade na oferta de serviços de saúde implica a ausência de diferenças para necessidades de saúde iguais (equidade horizontal) e a provisão de serviços prioritariamente para grupos com maiores necessidades (equidade vertical). Trocando em miúdos, isso significa que todos devem ter acesso e utilizar os serviços indispensáveis para resolver as suas demandas de saúde, independentemente do grupo social ao qual pertençam, e aqueles que 
apresentam maior vulnerabilidade em decorrência da sua posição social devem ser tratados de maneira diferente para que a desvantagem inicial possa ser reduzida ou anulada.

Há diferentes eixos de análise possíveis no estudo das desigualdades sociais em ambas as dimensões assinaladas. Neste livro daremos maior destaque à análise e discussão das desigualdades em saúde relacionadas com a posição de classe social, a renda, o gênero e a etnia. 



\section{I A Posição Social e seus Reflexos SObRe a Saúde}

As explicações sócio-históricas das desigualdades em saúde baseiam-se na idéia de que saúde é um produto social e algumas formas de organização social são mais sadias do que outras. Assim, os mesmos processos que determinam a estruturação da sociedade são aqueles que geram as desigualdades sociais e produzem os perfis epidemiológicos de saúde e doença.

O conceito-chave nessas abordagens é o processo reprodução social, que, por sua vez, implica a reprodução de diferentes domínios da vida. No nível mais elementar está a reprodução biológica do indivíduo, que garante suas características como espécie biológica marcada principalmente pela interação entre genotipo e fenotipo, isto é, entre a herança genética e a modulação das potencialidades herdadas pelas condições concretas de existência, que irão resultar nas manifestações exteriores do genótipo.

Como os homens vivem em comunidade, compartilhando um espaço e um tempo particulares, a reprodução social implica também a reprodução de um segundo domínio: o das relações ecológicas dos grupos, ou seja, de suas relações com os ambientes, senso lato, em que tais comunidades se constituem. Estas comunidades partilham formas de consciência e de conduta resultantes das interações intersubjetivas que também participam dos processos de reprodução, configurando o terceiro domínio: o da cultura. Finalmente, os grupos sociais se 
reproduzem, reproduzindo as formas econômicas que lhes garantem o domínio sobre a natureza.

O sistema de reprodução social dos diferentes grupos inclui os padrões de trabalho e consumo, as atividades práticas da vida cotidiana, as formas organizativas ou de participação social, a política e a cultura. Esse sistema contraditório de relações, do qual participam processos benéficos mantenedores da saúde e processos deletérios produtores da doença, acoplam-se aos padrões de saúde-doença das frações de classes sociais, constituindo assim os perfis epidemiológicos de classe.

Todos esses processos produzem impactos sobre a saúde e a doença dos indivíduos, representando, cada um deles, um conjunto de determinações e mediações cujo resultado final será a preservação da saúde ou a ocorrência da doença ou agravos à saúde. As desigualdades nas condições de vida, decorrentes de diferenças substantivas nesse processo de reprodução social, terão reflexos nas situações de saúde que serão então identificadas como iniquidades.

As explicações históricas representam ruptura com a teoria da multicausalidade e com o paradigma do risco, adotando o conceito de determinação social, ou seja, processos de determinação histórica e social regidos pelas leis da dialética que estabelecem os limites dentro dos quais os fenômenos de menor nível de complexidade podem ocorrer. Porém, a determinação social implica aceitar que cada domínio da realidade apresenta processos mediadores que interferem com a emergência de novas características nos níveis de complexidade crescente, de modo que a consequência, em termos de saúde e doença, será sempre a resultante de um processo complexo de determinação-mediação. 
Adotar este tipo de explicação teórica significa romper com a concepção linear de causalidade e abandonar qualquer pretensão de identificar cadeias de causa-efeito entre características ou indicadores sociais e problemas de saúde, bem como entre indicadores de desigualdades sociais e saúde.

\section{Conceito marxista de Classe social}

Na década de 1980 foram feitas várias tentativas de operacionalização do conceito marxista de classe social para uso em investigações empíricas em diferentes campos do conhecimento, incluindo a saúde.

Na concepção marxista, as classes sociais são definidas como grandes grupos de indivíduos que se diferenciam entre si pela posição que ocupam no sistema de produção historicamente determinado, pelas relações que estabelecem com os meios de produção, pelo papel que desempenham na organização social do trabalho e pelo modo como se apropriam de parte da riqueza social. O conceito engloba as dimensões econômicas, sociais, jurídicas, políticas e ideológicas.

Embora difícil de operacionalizar, pois a decomposição das dimensões do conceito em variáveis e sua reagregação para compor as classes empíricas exijam um conjunto amplo de questões, o conceito de classe é visto como capaz de apresentar um grande potencial explicativo exatamente por condensar em si tantas dimensões.

Para efeito das investigações epidemiológicas, o que se pede ao conceito de classe social é que através dele possam ser identificados grupos definidos a partir de seus vínculos sociais 
estruturais, que são os determinantes mais imediatos das condições de vida das famílias e, portanto, da situação de saúde dos indivíduos.

Durante a década de 1980 surgiram diferentes modelos visando à operacionalização do conceito de classes sociais com base, sobretudo, na produção teórica de Poulantzas e outros autores marxistas. A maioria das propostas de operacionalização baseiase na definição leninista de classe social, levando em consideração principal ou exclusivamente o componente econômico do conceito, ou o que se convencionou chamar a "classe em si".

$\mathrm{Na}$ América Latina, destacam-se dois esquemas de operacionalização do conceito de classe social: o modelo de Bronfman e Tuirán e o de Singer. Ambos os modelos constroem classificações hierarquizadas iniciando pela posição na ocupação, ou seja, pela posse ou não dos instrumentos e meios de produção. Esses esquemas já foram utilizados para estudar diferentes problemas de saúde, bem como para avaliar o consumo de bens e serviços em saúde.

Um exemplo empírico pode facilitar a compreensão desses conceitos e de sua utilização nas pesquisas epidemiológicas de desigualdades sociais em saúde. Usaremos dados de estudo realizado por pesquisadores do Departamento de Medicina Social da Faculdade de Medicina, da Universidade de São Paulo (USP) de Ribeirão Preto, para demonstrar a potencialidade do conceito de classe social. O objetivo da investigação era identificar fatores de risco para baixo peso ao nascer.

A incidência de baixo peso foi 1,8 vezes maior em filhos de mães fumantes e 2,4 vezes maior em filhos de mães pobres. A incidência também variou por classe social da mãe. Na burguesia 
a incidência de baixo peso foi de 3,1 casos por 100 nascidos vivos; entre o proletariado, 10,7 e no subproletariado, 13,9, mostrando um gradiente de agravamento do problema conforme piora a situação de classe.

Portanto, classe social e hábito de fumar podem ser considerados fatores de risco para o baixo peso ao nascer. Entretanto, não constituem variáveis da mesma dimensão de análise. $\mathrm{Na}$ Tabela 1, observa-se o resultado da incidência de baixo peso quando ambas as variáveis são consideradas.

Tabela 1 - Incidência de baixo peso ao nascer segundo a classe social e o hábito de fumar materno. Ribeirão Preto (SP) - 1978-1979

\begin{tabular}{l|cc}
\hline Classe social & Fumantes & Não fumantes \\
\hline Burguesia & 4,4 & 2,7 \\
\hline Proletariado & 9,5 & 5,9 \\
\hline Subproletariado & 12,8 & 6,3 \\
\hline
\end{tabular}

Fonte: Adaptado de Silva et al., 1992.

Os dados mostram que em cada classe social o risco de baixo peso é sempre maior para os filhos de mães fumantes. Mas, o mais interessante é notar que o risco para os filhos de mães fumantes que pertencem à burguesia é menor do que o risco para os filhos das mães não fumantes que pertencem ao proletariado ou ao subproletariado. Conclui-se, então, que a determinação de classe social é mais forte e modula o risco representado pelo hábito de fumar.

A distribuição das crianças menores de 5 anos em São Paulo, segundo decis de altura/idade (indicador de estado nutricional) definidos pelo National Center for Health Statistics (NCHS) na 
década de 1980, também revela clara influência da posição de classe. Considerando o primeiro decil, isto é, aquele que define $10 \%$ dos valores mais baixos para a razão altura/idade, a distribuição das crianças residentes em São Paulo aponta significativa desigualdade (Tabela 2).

Se a distribuição fosse equilibrada, isto é, independente da classe social, cada uma deveria ter aproximadamente 10\% das crianças. O excesso relativo de crianças nesse decil entre as famílias da pequena burguesia tradicional, do proletariado e do subproletariado e a ausência de crianças da burguesia mostra a concentração do problema nas classes sociais com inserção mais precária.

Tabela 2 - Proporção de crianças pertencentes ao primeiro decil da distribuição NCHS para a razão altura/idade segundo classe social. São Paulo - 1984

\begin{tabular}{l|c}
\hline Classe social & Proporção \\
\hline Burguesia & 0,0 \\
\hline Nova pequena burguesia & 8,8 \\
\hline Pequena burguesia tradicional & 21,2 \\
\hline Proletariado setor serviço & 20,2 \\
\hline Proletariado setor industrial & 29,0 \\
\hline Subproletariado & 35,8 \\
\hline
\end{tabular}

Fonte: Monteiro, Freitas \& Baratho, 1989.

\section{Conceito Weberiano de Classe Social}

Na concepção weberiana a posição social dos indivíduos decorre da classificação segundo três dimensões: classe econômica, 
prestígio e poder político. Os estratos sociais são compostos por indivíduos que compartilham determinadas características de inserção econômica (ocupação), prestígio social (escolaridade) e poder ou riqueza (renda), características essas utilizadas para alocá-los em uma escala ou gradiente de valores crescentes ou decrescentes.

As teorias de estratificação social tratam as desigualdades de um ponto de vista predominantemente quantitativo, visto que os estratos são categorias eminentemente descritivas, construídas mediante a definição de determinados pontos de corte que repartem séries contínuas. As variáveis utilizadas na definição dos estratos referem-se a características individuais tomadas como indicadoras de condições sociais. Tais variáveis podem incluir a renda, a escolaridade, a ocupação, escalas de prestígio e outras. Eventualmente os estratos podem ser construídos utilizando indicadores compostos nos quais as variáveis são arranjadas por agregação, ponderação ou hierarquização.

As evidências empíricas produzidas pelas investigações das relações entre desigualdades sociais e saúde sugerem que a situação de saúde é afetada pela posição social dos indivíduos e também pelas diferenças socioeconômicas da estratificação social.

Embora os indivíduos façam escolhas que possam implicar comportamentos sadios ou nocivos à sua saúde, estas escolhas estão situadas em contextos familiares, econômicos, culturais, políticos e históricos. Os estilos de vida ou os comportamentos individuais são apenas as evidências mais imediatas de todo o processo de determinação-mediação.

As escalas de estratificação social podem ser úteis na investigação de diferenciais intraclasses ou entre diferentes famílias, 
auxiliando na especificação de relações particulares que possam explicar por meio de que características ou de que mecanismos as desigualdades sociais produzem efeitos sobre a saúde.

A ocupação é uma das variáveis mais utilizadas em pesquisas conduzidas nos países europeus como medida de classe social. A classificação baseada em ocupações, elaborada pelo sistema de estatística vital do Reino Unido, em 1911, vem sendo amplamente utilizada. Esta classificação foi baseada no grau de habilidade e no prestígio social correspondente a cada ocupação, de modo que pudesse servir como indicadora de posição social, o que, no entanto, não garante a correspondência exata entre classe social e ocupação.

A classificação inglesa divide as ocupações em cinco classes: profissionais (formação universitária), técnicos (formação técnica), trabalhadores qualificados manuais ou não manuais, trabalhadores semiqualificados e trabalhadores não qualificados.

Controlando a influência da idade, da classe social na idade adulta, o hábito de fumar e o índice de massa corporal, o risco de morrer por câncer de estômago foi 5,4 vezes maior nos trabalhadores manuais qualificados, e 5,8 vezes maior nos trabalhadores semi e não qualificados quando comparados aos profissionais e técnicos.

Crianças brasileiras prematuras também apresentam distribuição diferenciada por classe ocupacional. O risco de prematuridade é 1, 6 vezes maior entre trabalhadores manuais qualificados e semiqualificados, e 1,8 vezes maior entre trabalhadores manuais não qualificados quando comparados a trabalhadores não manuais.

Mesmo dentro de grupos ocupacionais mais homogêneos, é possível encontrar diferenças entre trabalhadores segundo a 
posição na hierarquia de trabalho, ou seja, segundo a ocupação de postos de trabalho com maior ou menor controle e autonomia. O estudo Whitehall II realizado entre os trabalhadores administrativos do governo britânico mostrou aumento do risco de ausências prolongadas no trabalho ( $>8$ dias) por motivo de doença conforme se descende na escala da hierarquia burocrática. Os funcionários com menor autonomia e submetidos a controle mais rígido por supervisores têm risco três vezes maior de se ausentar do trabalho por períodos longos em decorrência de problemas de saúde. A mesma relação foi observada entre trabalhadores franceses.

Nos exemplos apresentados, os problemas de saúde não estão diretamente relacionados com exposições a agentes nocivos no ambiente de trabalho. A ocupação foi tomada como um marcador da posição social dos indivíduos.

No estudo das desigualdades sociais em saúde, outra variável bastante usada é o nível de escolaridade, isoladamente, ou combinada à ocupação. Para a maioria dos problemas de saúde infantil, a escolaridade materna é um dos determinantes mais importantes, tanto como marcador de posição social quanto como indicador do nível de instrução e da possibilidade de compreender e aplicar corretamente as informações técnicas.

O risco de ter um bebê pequeno para a idade gestacional está inversamente relacionado com o número de anos de escolaridade da mãe. Tomando como referência a incidência para mães com 12 anos ou mais de escolaridade, o risco aumenta 1,5 vezes para mulheres com cinco a oito anos de escolaridade e 1,7 vezes para mulheres com zero a quatro anos de escolaridade. 


\section{Desigualdades nO estado de saúde E NO USO DE SERVIÇOS}

As desigualdades sociais em saúde podem se manifestar em relação ao estado de saúde e ao acesso e uso de serviços de saúde para ações preventivas ou assistenciais. Na população brasileira, segundo dados da Pesquisa Mundial de Saúde, a autoavaliação do estado de saúde varia marcadamente com o nível de escolaridade. Entre os adultos com menos de oito anos de escolaridade, ou seja, com ensino fundamental incompleto, apenas $41 \%$ classificam sua saúde como boa ou muito boa. Este valor sobe para $62,2 \%$ para os adultos que completaram o ensino fundamental e iniciaram o ensino médio, e chega a 72,1\% dos indivíduos com ensino médio completo.

A prevalência de doenças crônicas também varia com os anos de escolaridade após ajuste por idade. Entre os adultos com até três anos de escolaridade, a prevalência referida de doenças crônicas chega a 55,9\%, representando um risco 1,28 vezes maior do que aquele dos indivíduos com 11 anos ou mais de escolaridade. A prevalência diminui gradualmente entre os extremos da distribuição de anos de escolaridade.

O uso de serviço de saúde também é influenciado pelo grau de escolaridade, mas as diferenças são muito menores. A criação do Sistema Único de Saúde (SUS) possibilitou o acesso aos serviços para a grande maioria da população brasileira. A probabilidade de uso é 1,2 vezes maior entre os brasileiros com nove ou mais anos de escolaridade, quando comparados aos que têm entre zero e quatro anos. As taxas de internações hospitalares não mostram diferenças segundo a escolaridade 
e a renda, variando em função do estado de saúde e da presença de problemas crônicos de saúde.

A utilização de serviços preventivos mostra diferenciais mais acentuados segundo a escolaridade e a ocupação. Estas diferenças sugerem que, na procura por serviços preventivos, atuam fatores diferentes daqueles envolvidos na utilização dos serviços assistenciais. É provável que características culturais e o nível de acesso à informação desempenhem um papel mais ativo nesses casos.

Apenas 75\% das mulheres com 25 anos ou mais de idade, na população brasileira, em 2003, fizeram o exame Papanicolau para prevenção do câncer de colo uterino. Esta proporção varia com a escolaridade no sentido esperado, ou seja, as mulheres com maior escolaridade apresentam maior cobertura (Tabela 3).

Tabela 3 - Prevalência de realização do exame Papanicolau nos últimos cinco anos

\begin{tabular}{l|cc}
\hline Escolaridade & Prevalência & $\begin{array}{c}\text { Razão de } \\
\text { prevalência (RP) }\end{array}$ \\
\hline $\begin{array}{l}\text { Analfabeto/ensino } \\
\text { fundamental incompleto }\end{array}$ & 67,5 & $4,4(4,1-4,8)$ \\
\hline $\begin{array}{l}\text { Ensino fundamental } \\
\text { completo/ensino médio } \\
\text { incompleto }\end{array}$ & 83,8 & $1,6(1,5-1,7)$ \\
\hline $\begin{array}{l}\text { Ensino médio completo/ } \\
\text { superior incompleto }\end{array}$ & 86,0 & $1,5(1,4-1,6)$ \\
\hline $\begin{array}{l}\text { Superior completo/ } \\
\text { pós-graduação }\end{array}$ & 91,4 & 1,0 \\
\hline
\end{tabular}

Fonte: Novaes, Braga \& Schout, 2003. 
Enquanto o uso de serviços de saúde em geral, por pessoas com nove anos ou mais de escolaridade, no mesmo inquérito, foi 1,2 vezes mais frequente do que para os indivíduos analfabetos ou com ensino fundamental incompleto, para a realização do exame de Papanicolau a probabilidade de não ter feito o exame foi 4,4 vezes maior entre as mulheres com menor escolaridade. Portanto, parte dessa diferença não deve ser atribuída a dificuldades de acesso.

Apenas 36\% das mulheres com 25 anos ou mais de idade realizaram mamografia nos últimos dois anos. O mesmo perfil de distribuição pode ser observado entre os níveis de escolaridade. Neste caso é possível fazer o mesmo tipo de inferência quanto ao acesso, uma vez que a distribuição dos mamógrafos na rede de serviços é bem menor do que a dos recursos necessários para a realização do exame de Papanicolau.

Em pacientes diabéticos, classificados por ocupação e escolaridade, os comportamentos preventivos diminuíram e a exposição ao fumo aumentou conforme piorou a inserção social. Os pacientes em pior posição foram menos à consulta médica de rotina, tiveram menor probabilidade de realizar um exame de fundo de olho e menor probabilidade de ter o pé examinado e apresentaram, ainda, maior frequência do hábito de fumar.

\section{DESIGUALDADES RELACIONADAS AOS LOCAIS DE MORADIA}

O estudo das desigualdades sociais em saúde deveria, idealmente, ter como variável explicativa a classe social construída com base nas relações fundamentais estabelecidas a partir da 
posição dos indivíduos na estrutura produtiva da sociedade. Entretanto, as dificuldades que cercam a operacionalização desse conceito, bem como a necessidade de contar com muitas informações, raramente disponíveis nos sistemas regulares de registros de dados em saúde, levaram os pesquisadores a buscar outras alternativas.

A estratificação social através de variáveis indicadoras da posição social, tais como ocupação, escolaridade e renda, aparece como uma dessas alternativas. Embora, com menor dificuldade de operacionalização, nem sempre a análise de cada uma das estratificações atende de maneira adequada às necessidades de compreensão de fenômenos complexos, como a produção e a distribuição das doenças e eventos relacionados com a saúde.

Outra alternativa cada vez mais utilizada é a análise dos eventos de saúde em relação ao local de moradia, tomando o espaço geográfico como indicativo das condições de vida da população que nele reside. A vantagem de utilizar espaços geográficos como indicadores de condições de vida está em tomar a complexidade da organização social em seu todo, em vez de fragmentá-la em diferentes variáveis.

As análises que utilizam as características sociopolíticas de diferentes espaços geográficos permitem abordar as desigualdades sociais em saúde no plano de agregados, isto é, tanto as condições de vida quanto os impactos sobre a saúde são avaliados através de valores médios.

Um primeiro nível de comparações pode ser estabelecido entre países (Tabela 4). Apesar de serem consideravelmente heterogêneos em seu interior, as comparações entre eles permitem 
ressaltar a relação entre variáveis macroeconômicas ou macrossociais e seus impactos sobre a saúde populacional.

Tabela 4 - Indicadores socioeconômicos e impactos sobre a saúde em países selecionados - 2006

\begin{tabular}{l|cccccc}
\hline Indicador & Canadá & Espanha & $\begin{array}{c}\text { Nova } \\
\text { Zelândia }\end{array}$ & Brasil & Egito & Índia \\
\hline IDH* & 0,95 & 0,94 & 0,94 & 0,79 & 0,70 & 0,61 \\
\hline $\begin{array}{l}\text { PIB per capita } \\
\text { (US\$) }\end{array}$ & 39.004 & 27.913 & 25.603 & 5.640 & 1.484 & 784 \\
\hline Acesso Internet & $68 \%$ & $40 \%$ & $68 \%$ & $21 \%$ & $7 \%$ & $5 \%$ \\
\hline $\begin{array}{l}\text { Gasto em saúde } \\
\text { (\% PIB) }\end{array}$ & $7 \%$ & $5 \%$ & $6 \%$ & $3 \%$ & $2 \%$ & $1 \%$ \\
\hline $\begin{array}{l}\text { Gasto per capita } \\
\text { (US\$) }\end{array}$ & 2.666 & 1.522 & 1.598 & 189 & 320 & 9 \\
\hline Natalidade & 10,7 & 10,2 & 14,2 & 20,6 & 25,5 & 25,1 \\
\hline EV** ao nascer & 79,9 & 79,4 & 79,0 & 70,3 & 69,6 & 63,1 \\
\hline
\end{tabular}

*IDH - Índice de Desenvolvimento Humano

** EV - Esperança de vida ao nascer

Fonte: IBGE.

Os dados mostram que há correspondência entre os indicadores sociais (IDH e acesso à Internet) e econômicos (PIB per capita e gasto em saúde) e o nível de saúde da população (natalidade e esperança de vida ao nascer - EV). Chama a atenção a grande desigualdade entre a riqueza dos países e os gastos públicos em saúde. Essa desigualdade se reflete tanto no padrão de natalidade com diferença de 15 crianças por mil habitantes entre o Canadá e a Índia, quanto na EV, com diferença de 16,8 anos entre a Índia e o Canadá. As desigualdades sociais em saúde repetem-se também no interior dos países, entre suas regiões e cidades (Tabela 5). 
Tabela 5 - PIB per capita e mortalidade infantil para cinco capitais brasileiras -2005

\begin{tabular}{l|cc}
\hline Capital & PIB per capita & Mortalidade infantil \\
\hline São Paulo & 24.175 & 12,82 \\
\hline Porto Alegre & 20.563 & 12,67 \\
\hline Manaus & 16.528 & 19,64 \\
\hline Campo Grande & 9.528 & 15,14 \\
\hline Salvador & 7.656 & 21,63 \\
\hline
\end{tabular}

Fonte: IBGE.

Há um nítido gradiente na mortalidade infantil que acompanha o PIB per capita em cada capital, mostrando que quanto maior a riqueza, menor a taxa de mortalidade infantil. O PIB per capita de Salvador é três vezes menor do que o de São Paulo, e sua mortalidade infantil é 1,7 vezes maior, indicando, assim, que a correlação não é perfeita, pois na determinação da mortalidade atuam as condições concretas de vida e a oferta de serviços de saúde. A existência do SUS garante maior extensão de cobertura à população mesmo nas áreas mais pobres do país, compensando em certa medida as desigualdades decorrentes da organização social.

A desigualdade em saúde ocorre também no interior das cidades. Quanto mais homogêneo o espaço social considerado, mais evidentes tornam-se as desigualdades entre elas. As diferenças nas condições de vida e seu impacto nas desigualdades sociais em saúde podem ser aquilatadas pela análise de alguns dados referentes a áreas de subprefeituras no município de São Paulo (Tabela 6). 
Tabela 6 - Indicadores socioeconômicos e impactos sobre a saúde em subprefeituras selecionadas. Município de São Paulo - 2005

\begin{tabular}{|c|c|c|c|c|c|}
\hline Indicador & Pinheiros & Butantã & $\begin{array}{l}\text { Casa } \\
\text { Verde }\end{array}$ & $\begin{array}{l}\text { Campo } \\
\text { Limpo }\end{array}$ & Parelheiros \\
\hline $\begin{array}{l}\text { Renda per capita } \\
<0,5 \mathrm{SM}^{*}\end{array}$ & 1,6 & 8,6 & 11,2 & 15,2 & 27,0 \\
\hline $\begin{array}{l}\text { Aglomeração } \\
\text { (> } 3 \text { pessoas/ } \\
\text { dormitório) }\end{array}$ & 2,7 & 14,9 & 19,7 & 22,7 & 30,8 \\
\hline $\begin{array}{l}\text { Responsáveis } \\
\text { com }<4 \text { anos } \\
\text { de escolaridade }\end{array}$ & 9,0 & 30,9 & 37,5 & 42,0 & 54,2 \\
\hline $\begin{array}{l}\text { Moradores em } \\
\text { favela }\end{array}$ & 0,2 & 13,2 & 11,2 & 24,4 & 13,4 \\
\hline $\begin{array}{l}\text { Mortalidade } \\
\text { infantil }\end{array}$ & 8,3 & 9,9 & 15,1 & 13,5 & 15,9 \\
\hline $\begin{array}{l}\text { Taxa de } \\
\text { homicídios }\end{array}$ & 16,9 & 52,2 & 52,9 & 74,6 & 117,2 \\
\hline $\begin{array}{l}\text { Homicídios } \\
15-29 \text { a }\end{array}$ & 23,2 & 92,4 & 177,1 & 199,2 & 260,8 \\
\hline $\begin{array}{l}\text { Menos de sete } \\
\text { consultas de } \\
\text { pré-natal }\end{array}$ & 9,7 & 33,9 & 20,3 & 34,6 & 50,5 \\
\hline
\end{tabular}

* SM - salário mínimo

Fonte: CE-INFO Secretaria Municipal de Saúde de São Paulo, 2005.

A Tabela 6 mostra diferenças muito significativas entre as subprefeituras, tanto nos indicadores socioeconômicos quanto nos indicadores de saúde. Essas desigualdades são mais acentuadas do que aquelas observadas entre os países ou entre as capitais brasileiras. Novamente chama a atenção que as desigualdades na mortalidade infantil e na proporção de gestantes com núme- 
ro insatisfatório de consultas de pré-natal é muito menor - duas e cinco vezes respectivamente - do que as diferenças nos indicadores sociais. A subprefeitura que apresenta as piores condições de vida tem 17 vezes mais pessoas pobres, 11 vezes mais aglomeração intradomiciliar, seis vezes mais responsáveis com baixa escolaridade e 67 vezes mais moradores em favelas. Para os homicídios em geral e os homicídios entre jovens, as diferenças são também bastante acentuadas, visto que o sistema de saúde tem influência muito menor sobre esse tipo de agravo.

A posição social dos indivíduos e grupos sociais, medida por indicadores de classe social, variáveis isoladas como escolaridade e classes ocupacionais, ou a partir das condições de vida em determinados espaços geográficos, é um poderoso determinante do estado de saúde das populações, atuando sobre o perfil de morbidade e mortalidade e também sobre o acesso e utilização dos serviços de saúde.

Há inúmeras investigações científicas demonstrando a existência das desigualdades sociais em saúde e buscando modelos de interpretação para as mesmas, procurando entender os processos sociais e os processos mediadores entre as condições concretas de vida e a saúde no âmbito populacional. 



\section{I Ser Rico faz bem à Saúde?}

A maioria das pessoas responderia afirmativamente à pergunta, baseadas na observação de que indivíduos e países mais ricos conseguem garantir o atendimento das necessidades básicas, essenciais para a manutenção da saúde: moradia adequada, alimentação saudável, trabalho em condições satisfatórias, acesso a bens e serviços relacionados com a educação, a cultura e a saúde.

Tradicionalmente o nível de riqueza tem sido associado à garantia de melhor qualidade de vida e consequentemente a melhores níveis de saúde, refletidos em maior esperança de vida desde o nascimento até as idades mais avançadas, em menor mortalidade por qualquer causa e em qualquer idade, e na ausência de determinadas causas de morbidade associadas com a pobreza, tais como desnutrição e doenças infecciosas relacionadas a precárias condições de higiene e saneamento básico.

Entretanto, a relação entre a riqueza dos países medida pelo PIB ou pelo PIB per capita e os diversos indicadores de saúde não é linear. Não se observa uma relação simples do tipo quanto mais rico um país mais saudável sua população. Desde a década de 1970 pesquisas têm demonstrado que a relação entre PIB per capita e esperança de vida se assemelha a uma parábola, ou seja, a partir de certo limiar os aumentos na riqueza não se traduzem em mais saúde. 
Há vários aspectos a considerar no chamado paradoxo entre riqueza e saúde: a comparação entre os países, a comparação entre regiões de um mesmo país e a comparação entre ricos e pobres em uma mesma região. Além disso, é importante prestar atenção a dois aspectos relacionados à renda e à riqueza: os valores absolutos e a distribuição ou valores relativos.

\section{QUAIS SÃO OS IMPACTOS DO NÍVEL ABSOLUTO DE RIQUEZA SOBRE OS INDICADORES DE SAÚDE?}

Em estudo recente, comparando as tendências temporais de redução da mortalidade na infância e entre adultos, em todos os países membros da Organização das Nações Unidas (ONU), no período de quarenta anos, entre 1960 e 2000, observou-se comportamento distinto entre três grupos constituídos segundo a taxa de mortalidade em 2000.

Foram constituídos três grupos para a mortalidade na infância, correspondendo aos países com mortalidade de menores de cinco anos: baixa (3,9 a 60,0 óbitos por 100 mil habitantes), média (66,0 a 156,0 óbitos por 100 mil habitantes) ou alta (160,0 a 316,0 óbitos por 100 mil habitantes). No primeiro grupo foram classificados 117 países com PIB per capita médio de US\$12.086,00; 8\% da população vivendo na miséria com renda inferior a um dólar por dia; $14 \%$ de população feminina analfabeta e gasto público médio em saúde de US\$650,00 por pessoa/ano.

No segundo grupo foram classificados 45 países com PIB per capita de US\$2.660,00; 26\% da população vivendo na miséria; $38 \%$ da população feminina analfabeta e gasto médio em saúde de US $\$ 56,00$. No terceiro grupo foram classificados 23 países 
extremamente pobres com PIB per capita de US\$1.011,00; 53\% da população vivendo na miséria; $63 \%$ da população feminina analfabeta e gasto médio em saúde de apenas US\$10,00.

A taxa média de mortalidade na infância foi de 20 óbitos por 100 mil no primeiro grupo, 106 óbitos por 100 mil no segundo e 207 óbitos por 100 mil no terceiro, mostrando relação inversa entre a riqueza dos países e a mortalidade na infância. A análise de tendência da mortalidade no período de 1960 a 2000 revelou declínio das taxas nos três grupos, porém com menor aceleração no grupo dos países mais pobres, embora se considere mais fácil, através de medidas de saúde pública, reduzir taxas de mortalidade na infância partindo de patamares mais altos.

As mesmas comparações feitas para a mortalidade de homens adultos mostraram que houve declínio da mortalidade durante todo o período para os países dos grupos um e dois. Nos países do grupo três, a mortalidade aumentou na década de 1990, revertendo a tendência anterior de declínio, atingindo, em 2000, valores mais altos do que os observados em 1960.

As desigualdades na riqueza dos países aumentaram acentuadamente desde o início do século XIX até o final do século XX. Por volta de 1820 o país mais rico era a Grã-Bretanha, com PIB per capita de US $\$ 1.756,00$ (valores ajustados ao dólar de 1990) e o mais pobre era a China, com PIB per capita de US\$523,00. Portanto, a diferença entre os extremos era de cerca de três vezes. Em 1900, essa diferença alcançou dez vezes. Em 2000, chegou a 75 vezes e, em 2006, a 660 vezes. O PIB per capita dos países mais pobres, que, em 1820 , era de US $\$ 523,00$ para a China, em 2006 era de apenas US\$133,00 para o Zimbábue. 
Ainda que se leve em conta o fato de que os dados não eram disponíveis para os países mais pobres nos primeiros anos analisados, é notória a deterioração da situação econômica dos países africanos no final do século XX e início do XXI. De maneira ainda mais espetacular observa-se o crescimento da riqueza dos países mais ricos, cujo PIB per capita passou de US\$1.756,00 para o Reino Unido em 1820, e a US\$ 87.829,00 para Luxemburgo em 2006. Resumo da ópera: os países pobres ficaram cada vez mais pobres e os países ricos cada vez mais ricos durante os últimos dois séculos. A diferença de esperança de vida ao nascer entre a população do Zimbábue e a de Luxemburgo é de 41,2 anos, ou seja, um recém-nascido em Luxemburgo pode esperar viver cerca de quarenta anos a mais do que outro no Zimbábue.

No interior dos países também ocorre grande desigualdade no nível de riqueza, com repercussões sobre a saúde. Por exemplo, no Brasil, em 2005, as diferenças entre os estados do Maranhão - com um dos menores PIB per capita do país $(\mathrm{R} \$ 4.138,90)$ - e o de São Paulo $(\mathrm{R} \$ 18.255,00)$ podem ser observadas na esperança de vida ao nascer, esperança de vida aos 60 anos, mortalidade infantil e mortalidade infantil pós-neonatal, entre outros indicadores de saúde. $\mathrm{Na}$ esperança de vida ao nascer, a diferença é de 6,8 anos; aos 60 anos uma pessoa vivendo em São Paulo pode esperar viver em média mais 21 anos, enquanto outra, vivendo no Maranhão, pode esperar viver em média mais 19 anos. A mortalidade infantil e a mortalidade pós-neonatal são três vezes maiores no Maranhão.

Além dos diferenciais assinalados entre as unidades da federação também são importantes as diferenças entre as cidades e no interior das cidades. A Fundação Sistema Estadual de Análise 
de Dados (Seade), responsável pelos sistemas de informação estatística do governo do estado de São Paulo, desenvolveu o Índice Paulista de Responsabilidade Social para classificar os municípios segundo três eixos: riqueza, longevidade e escolaridade. No grupo I foram incluídos os municípios com elevado nível de riqueza e que apresentavam bons indicadores sociais em educação e saúde; no grupo II, os municípios com bons níveis de riqueza e indicadores sociais ruins. Os municípios do grupo III eram pobres, mas apresentavam bons indicadores sociais; os do grupo IV eram pobres e apresentavam indicadores sociais intermediários e no grupo $\mathrm{V}$ os municípios eram pobres e apresentavam indicadores sociais ruins. O próprio indicador, portanto, permite separar o desempenho nos indicadores sociais do nível de riqueza municipal.

Utilizando esse indicador, observa-se que, embora a proporção de mães adolescentes apresente um gradiente que aumenta conforme diminui a riqueza dos municípios considerados, a proporção de mulheres com sete ou mais consultas de pré-natal é mais alta no município do grupo III: pobre com bons indicadores sociais. A pior situação é observada nos municípios pobres com indicadores sociais ruins ou intermediários. E a situação intermediária ocorre nos municípios ricos. Chama a atenção o fato do IDH ser relativamente próximo entre os municípios dos vários grupos, exceto para o primeiro, em que ele é significativamente mais alto. Estes dados já começam a indicar que a relação entre riqueza e condições de saúde ou uso de serviços de saúde não é simples.

O Centro de Informação em Saúde, da Secretaria Municipal de Saúde de São Paulo, criou um índice de saúde baseado na 
mortalidade infantil, mortalidade proporcional precoce (antes dos 60 anos) por doenças crônicas, incidência de tuberculose e mortalidade por causas externas para estratificar as subprefeituras da capital. Os valores do índice permitem a distribuição das 31 subprefeituras em seis estratos. No grupo I, com índice de saúde acima de 0,80, foram classificadas quatro subprefeituras que apresentavam, em 2005, mortalidade infantil variando entre 6,1 e 10,9 óbitos por mil nascidos vivos; 7,4 a 17,9\% de mortalidade proporcional precoce; 32,5 a 51,6 casos por 100 mil habitantes de incidência de tuberculose e 33,1 a 38,3 óbitos por causas externas para 100 mil habitantes. Para todos os indicadores utilizados os valores são os mais baixos observados.

No grupo II, com índice da saúde entre 0,70 e 0,79, foram classificadas duas subprefeituras com mortalidade infantil de 8,0 e 9,5 óbitos por mil nascidos vivo; 15,3 e 19,8\% de mortalidade proporcional precoce; 49,0 casos de tuberculose por 100 mil habitantes e 44,8 e 48,8 óbitos por causas externas para cada 100 mil habitantes. Comparativamente ao grupo anterior, este apresenta maior mortalidade proporcional precoce e maior mortalidade por causas externas.

No grupo III, havia quatro subprefeituras com índice de saúde entre 0,60 e 0,69. Nessas áreas a mortalidade infantil foi de 12,0 a 14,0 óbitos por mil nascidos vivos; a mortalidade proporcional precoce variou entre 16,4 e $23,7 \%$; a incidência de tuberculose, entre 52,4 e 58,9 casos por 100 mil e a mortalidade por causas externas, entre 43,7 e 57,9 óbitos por 100 mil. Os indicadores são todos mais altos do que aqueles observados nos grupos I e II. 
Três subprefeituras classificaram-se no grupo IV com índices de saúde entre 0,50 e 0,59. A mortalidade infantil variou de 11,7 a 12,9 óbitos por mil nascidos vivos; a mortalidade proporcional precoce, entre 14,8 e $26,2 \%$; a mortalidade por causas externas, de 56,6 a 81,7 óbitos por 100 mil e a incidência de tuberculose, de 59,4 a 72,5 casos por 100 mil. Este grupo apresenta pior situação do que o anterior em relação à incidência de tuberculose e mortalidade por causas externas.

O grupo V reuniu 14 subprefeituras, com índices de saúde entre 0,40 e 0,49 . A mortalidade por causas externas foi muito alta, variando entre 55,1 e 121,6 óbitos por 100 mil habitantes; a incidência de tuberculose também foi muito alta, entre 47,8 e 81,0 casos por 100 mil habitantes; a mortalidade proporcional precoce atingiu 20,1 a 42,1\% dos óbitos e a mortalidade infantil chegou ao valor mais alto: 16,7 óbitos por mil nascidos vivos.

Finalmente o grupo VI reuniu quatro subprefeituras com índices de saúde muito baixos $(<0,40)$. Embora a mortalidade infantil e a mortalidade por causas externas sejam comparáveis àquelas observadas nos demais grupos (11,5 a 15,2 óbitos por mil nascidos vivos e 42,5 a 53,1 óbitos por 100 mil habitantes respectivamente), a mortalidade proporcional precoce chegou a $44 \%$ dos óbitos, e a incidência de tuberculose foi maior do que 70 casos por 100 mil em todas as subprefeituras. Há forte correspondência entre os índices de saúde e a renda média dos responsáveis pelos domićlios, que variou entre 17,67 salários mínimos no grupo I e 3,95 salários mínimos no grupo VI.

Em resumo, as desigualdades no nível de saúde e no uso de serviços de saúde parecem estar relacionadas com o nível absoluto de renda ou de riqueza dos países, estados, municípios e 
divisões intramunicipais. O paradoxo da dissociação entre nível de renda ou riqueza e o estado de saúde começa a ser notado quando as comparações se restringem aos países ricos, ou seja, quando são feitas entre populações de países desenvolvidos, onde as necessidades básicas estão adequadamente supridas para a maioria da população, e mesmo as pessoas mais pobres ultrapassaram os limiares das carências materiais básicas.

\section{A CONCENTRAÇÃO NA DistRiBUiÇÃO RELATIVA DA RIQUEZA}

Ainda na década de 1970 começa a chamar a atenção o fato de que, a partir de certo limiar de renda, os ganhos adicionais na esperança de vida deixam de estar associados aos níveis médios de renda.

Na década de 1980, Richard Wilkinson, estudando nove países desenvolvidos, mostrou que a esperança de vida ao nascer estava associada mais fortemente a indicadores de distribuição de renda do que ao PIB per capita. Na década seguinte, diversos estudos reforçaram as demonstrações empíricas da relação entre nível de saúde e distribuição de renda.

A partir de 1969 observa-se enorme crescimento das desigualdades na distribuição da renda, tanto entre os países como entre diferentes grupos sociais no interior de cada país. Em 2000, cerca de três quintos da população mundial viviam em sessenta países extremamente pobres, apropriando-se apenas de $6 \%$ da riqueza produzida no mundo, recebendo menos de dois dólares por pessoa por dia. Em vinte anos, entre 1977 e 1999, nos Estados Unidos, os $20 \%$ mais pobres da população tiveram redução 
de $9 \%$ em sua renda, enquanto os $20 \%$ mais ricos tiveram um acréscimo de $43 \%$. No topo da pirâmide, o 1\% dos mais ricos teve um aumento de $115 \%$ em sua riqueza. Os quatrocentos cidadãos norte-americanos mais ricos possuem riqueza superior ao PIB da China.

Estudos que buscam explorar a relação entre nível de riqueza, distribuição de renda e satisfação com a vida, ou bem-estar mostram que, embora o nível geral de satisfação e bem-estar aumente com o crescimento do nível de riqueza do país, para o mesmo nível de riqueza, a satisfação e o bem-estar são maiores nos países que apresentam menor desigualdade na distribuição da renda.

\section{PARADOXO DA DISSOCIAÇÃO ENTRE RIQUEZA E NÍVEL DE SAÚDE}

As análises das relações entre PIB per capita e esperança de vida ao nascer mostram que de maneira geral os países mais pobres também apresentam menores esperanças de vida. Entretanto, algumas exceções chamam a atenção e não são fáceis de serem explicadas no marco das teorias materialistas apresentadas no primeiro capítulo. Por exemplo, o Sri Lanka e o Vietnã, países muito pobres com PIB per capita inferior a US\$ 1.500,00, apresentam esperança de vida acima de 70 anos; o Gabão com PIB per capita mais alto que o do Brasil e com esperança de vida cerca de 15 anos mais baixa; a Costa Rica com PIB per capita oito vezes menor do que o dos Estados Unidos e a mesma esperança de vida.

Entre os países pertencentes à Organização para a Cooperação Econômica e o Desenvolvimento (OCED), a correlação 
entre o PIB per capita e a esperança de vida é mediana ( $\mathrm{r}=0,5824)$. Até o PIB per capita de 20 mil dólares, a relação é mais linear. A partir desse limiar, os acréscimos no PIB per capita não estão necessariamente associados a iguais aumentos na esperança de vida. Os países com maior longevidade de suas populações não são os mais ricos.

Cerca de três quartos da diferença na esperança de vida entre os países ricos pode ser explicada pela maior ou menor igualdade na distribuição da renda. As sociedades mais igualitárias compartilham uma característica comum, que é a maior coesão social. A saúde é produzida socialmente e algumas formas de organização social são mais saudáveis do que outras.

A esperança de vida se correlaciona com qualquer uma das medidas de concentração de renda: o coeficiente de Gini, a proporção da riqueza apropriada pelo percentil 70 da distribuição populacional, a proporção da população vivendo em pobreza relativa e outros. O mesmo pode ser observado para outros desfechos de saúde, como taxas de mortalidade infantil, mortalidade geral e específica por causas dentre as quais se destacam as mortes violentas.

Os impactos das desigualdades na qualidade de vida são diretos sobre os mais pobres, mas afetam as demais camadas da sociedade porque provocam deterioração da vida pública, perda do senso de comunidade, bem como aumento da criminalidade e da violência. A vida em sociedades com grandes desigualdades sociais parece menos civilizada, como afirma Wilkinson, importante estudioso do tema.

Wilkinson demonstra que os períodos em que houve maior aumento na esperança de vida na Inglaterra foram os que 
coincidiram com a primeira e a segunda guerras mundiais. Ao contrário do que seria esperado, a escassez a que a população civil foi submetida nessas épocas não foi acompanhada de redução na esperança de vida. No primeiro período, observou-se ganho de 6,6 anos na esperança de vida e, no segundo, 6,5 anos.

Durante as guerras houve piora no padrão de vida e deterioração dos serviços de saúde que foram prioritariamente direcionados para o atendimento aos soldados feridos. No entanto, a esperança de vida cresceu. Em ambos os períodos houve pleno emprego para fazer frente ao esforço de guerra e dramática redução na desigualdade de renda. O salário real da classe trabalhadora cresceu $9 \%$ enquanto na classe média caiu $7 \%$. A coesão social aumentou em decorrência da união frente ao inimigo comum, das mudanças no mercado de trabalho e da política de cooperação para o esforço de guerra.

Além da maior coesão social e dos laços cooperativos que caracterizam o chamado capital social, outras explicações para melhor nível de saúde em situações de menor desigualdade apontam as políticas públicas universalistas como responsáveis por parcela dos resultados.

Os países mais igualitários gastam mais em bens e serviços públicos. Serviços universais de saúde podem reduzir as desigualdades basicamente de duas maneiras: diminuindo as diferenças nas condições de vida, representando um salário indireto para os trabalhadores e oferecendo serviços similares para toda a população. Em contrapartida, a segregação urbana reforça os efeitos negativos da desigualdade de renda, concentrando a pobreza, produzindo isolamento social e diminuição de oportunidades, 
reduzindo a aplicação de recursos públicos nas áreas pobres e provocando o declínio da coesão social.

A menor esperança de vida nos países pobres pode ser o resultado da fome, do consumo de água contaminada e das más condições sanitárias, mas não é possível explicar por esses mesmos motivos a menor esperança de vida das pessoas que vivem nas áreas mais pobres dentro de países ricos. A pobreza é potencialmente fatal para os mais pobres, porém eles representam pequena parcela da população nas nações ricas. A desigualdade, entretanto, afeta todos os grupos sociais e tem maior impacto sobre a mortalidade mesmo entre os mais bem situados socialmente.

O melhor nível de saúde observado nas situações de menor desigualdade pode ser explicado através de comportamentos saudáveis que seriam mais frequentes nessas populações. Entretanto, conforme demonstrado pelo estudo dos funcionários públicos na Inglaterra, os tradicionais fatores de risco explicam menos de metade do excesso da mortalidade por doença isquêmica do coração entre os trabalhadores em diferentes posições ocupacionais.

Tomando como referência a taxa de mortalidade nos funcionários administrativos, os executivos apresentam risco de morrer por doença isquêmica do coração (DIC) 2,1 vezes maior. Desse excesso de risco, apenas 0,3 é explicado pelos fatores de risco tradicionais. Entre os gerentes, o excesso de risco é de 3,2 vezes com apenas 0,9 sendo explicado por exposições aos fatores de risco comportamentais. Para os trabalhadores manuais, o excesso é de quatro vezes e 1,4 é explicado por comportamentos não saudáveis. 
Marmot, um dos autores do estudo, dá mais importância às condições e às relações no trabalho, como determinantes dos riscos observados, do que ao chamado "estilo de vida". Postulase assim um conjunto amplo de determinantes psicossociais, relacionados com o maior ou menor controle sobre a vida, como elementos mediadores entre a posição social e o nível de saúde.

As desigualdades sociais em saúde são manifestações de determinantes sociais do processo saúde-doença. Os desfechos de saúde não são específicos a nenhuma causa em particular, mas o resultado de processos sociais nos quais interferem inúmeras mediações. Portanto, nenhuma resposta médica resolverá o problema, nem intervenções que enfatizem o estilo de vida concebido como fruto de escolhas individuais. O enfrentamento das desigualdades sociais em saúde depende de políticas públicas capazes de modificar os determinantes sociais, melhorar a distribuição dos benefícios ou minorar os efeitos da distribuição desigual de poder e propriedade nas sociedades modernas. 



\section{$4 \mid$ As Desigualdades Étnicas
Necessariamente Significam Racismo?}

A igualdade e a desigualdade são conceitos dimensionais relativos a quantidades mensuráveis, ou seja, referem-se a quantidades equivalentes ou distintas de atributos estudados. Equidade e iniquidade são conceitos políticos que expressam, além da igualdade ou desigualdade quantitativa, uma avaliação moral relacionada com a noção de justiça social.

As iniquidades são desigualdades injustas ou decorrentes de alguma forma de injustiça. A maioria das desigualdades sociais em saúde é injusta porque reflete a distribuição dos determinantes sociais da saúde na sociedade, remetendo, portanto, à distribuição desigual de poder e propriedade. Na perspectiva liberal, as desigualdades sociais em saúde são vistas como reflexo das escolhas pessoais que levam alguns a alcançar posições sociais de prestígio, que lhes conferem poder e posses na sociedade, enquanto outros permanecem em posições desvantajosas sem poder usufruir a riqueza social, sem desfrutar de prestígio ou poder político.

Na perspectiva do materialismo histórico, a posição dos indivíduos na estrutura de classes sociais representa um conjunto de constrangimentos e circunstâncias que acabam por moldar as escolhas individuais, de modo que o pertencimento de classe leva os diferentes indivíduos a compartilharem modos de vida semelhantes. 
Essas visões de mundo que competem na explicação das desigualdades e iniquidades sociais, entretanto, não dão conta das iniquidades relacionadas com o pertencimento a determinados grupos étnicos, uma vez que os indivíduos não são livres para escolher a qual grupo pertencer, nem esta determinação está relacionada diretamente com a posição de classe.

Qualquer consideração das desigualdades sociais em relação a grupos étnicos carrega a dupla determinação: a posição social que tais grupos ocupam na sociedade e a aceitação/rechaço que possam ter frente aos grupos majoritários.

Segundo a teoria ecossocial, apresentada no primeiro capítulo, nossas características biológicas, decorrentes da história evolutiva da espécie, do contexto ecológico em que vivemos e da trajetória de vida de cada indivíduo concreto, somam-se aos arranjos societais de distribuição de poder e propriedade, definindo padrões de produção e consumo próprios de cada classe social. Este conjunto de determinações estrutura exposições e vulnerabilidades distintas, além de definir as opções de resistência e enfrentamento das agressões e vicissitudes ao longo da vida.

Nesse contexto teórico, a discriminação praticada contra determinados grupos étnicos é um meio de expressar e institucionalizar relações sociais de dominação e repressão. É um fenômeno sancionado socialmente, justificado pela ideologia e expresso em relações pessoais e institucionais, visando ao privilégio dos grupos dominantes às custas da exclusão e dominação dos outros. 


\section{Mas afinal 0 que é raça?}

Nas ciências biológicas raça é sinônimo de uma divisão dentro de uma mesma espécie. Entre os humanos, a noção de raça aparece como uma construção ideológica relacionada com a crença dominante na inferioridade inata de certos grupos, como os judeus, os ciganos, os indígenas, os negros e os imigrantes.

Durante o século XIX e o princípio do século XX, com a expansão econômica e política do modo de produção capitalista e a formulação das teorias evolutivas, esta visão relativa a certos grupos sociais foi bastante reforçada como expressão da lei natural da "sobrevivência dos mais adaptados". Evidentemente os povos dominantes eram os considerados mais adaptados e capazes de exercer não apenas seu domínio sobre a natureza como também sobre os povos considerados inferiores.

Esta perspectiva considerada científica na época ainda persiste entre muitos teóricos, embora o desenvolvimento da genética tenha demonstrado que todos os seres humanos são idênticos em mais de $75 \%$ do seu material genético, sendo totalmente impossível identificar, através da análise das características genéticas da espécie, qualquer indicador seguro da existência de raças ou subespécies humanas.

Nos últimos tempos os avanços da genética permitiram demonstrar que mais de 95\% das variações genéticas humanas são observadas no interior dos grupos 'raciais', de modo que há mais variação genética dentro da mesma raça do que entre elas.

Os traços físicos externos, que em todos os tempos permitiram a identificação de grupos com particularidades em relação aos outros, representam o resultado das interações entre o 
genótipo e o ambiente e a trajetória histórica de cada grupo. Está bastante demonstrado que a expressão fenotípica de qualquer gene, ou conjunto de genes, é extremamente variável segundo o ambiente no qual o organismo vive e se desenvolve.

Assim, não há, do ponto de vista estritamente biológico, nenhuma sustentação científica para a noção de raça. Embora esta noção não seja útil como marcador de diferenças biológicas, ela pode ser um importante marcador de iniquidades e injustiças sociais. Oficialmente, portanto, a noção de raça/ etnia é um construto sociopolítico, e não uma categoria baseada cientificamente em diferenças biológicas intrínsecas.

Com o avanço científico, a noção de raça passa a ser vista como equivalente ao conceito de grupo étnico, definido, principalmente, com base em características socioculturais próprias de certos grupos sociais, que, por diferentes motivos, mantém um isolamento relativo a outros grupos e populações, conservando seus hábitos e costumes mesmo quando deslocados em relação a seu país ou região de origem.

Raça ou etnia é uma importante dimensão da estratificação social que se relaciona de maneira complexa com a classe social, refletindo principalmente a distribuição de poder entre os grupos sociais no interior de uma dada sociedade. Frequentemente as diferenças entre os grupos raciais estão fortemente associadas às condições socioeconômicas e tendem a desaparecer quando essas são controladas para efeito de análise. Entretanto, na maioria dos estudos de desigualdades sociais aparece um efeito independente da raça sobre a saúde após controlar para variáveis socioeconômicas. 
Alguns autores consideram que raça é um poderoso construto social com profundas implicações sobre a saúde e que é fundamental utilizar a categoria etnia como variável social para melhor compreender o modo como as relações raciais produzem desigualdades sociais em saúde.

Nos Estados Unidos a raça tem sido usada como variável de classificação no lugar da classe social desde o censo de 1790. Ela é definida com base na ancestralidade, isto é, na origem africana de qualquer um dos progenitores ou antepassados dos indivíduos, independentemente das características fenotípicas atuais.

Quanto mais miscigenada uma população, mais difícil é a aplicação dessa concepção. Nestes casos o mais comum é a substituição do critério de ancestralidade pela classificação baseada na cor da pele, admitindo-se diferentes gradações entre os tipos não miscigenados e os demais. No Brasil a classificação sempre esteve baseada no critério de cor e traços fisionômicos.

O significado concreto da raça como variável social preditora de estados de saúde é modelado pelo contexto histórico, socioeconômico, cultural e epidemiológico, sendo praticamente impossível estabelecer regras universais sobre as relações entre raça e saúde. Dito de outra maneira, não é possível afirmar, sem levar em conta o contexto, que determinados grupos étnicos apresentarão inexoravelmente determinados problemas de saúde.

Os determinantes sociais de saúde são mais bem compreendidos em contextos particulares do que como variáveis independentes com vida própria. Ser homem ou mulher, jovem ou idoso, pobre ou rico, sérvio ou croata, tem diferentes significados e diferentes consequências para a saúde em diferentes contextos 
históricos e sociais. Ou seja, as relações entre essas categorias intermediárias e a posição social de classe são sempre complexas e subordinadas.

De qualquer modo, a raça ou etnia, como dimensão particular da estratificação social, é um importante determinante dos processos de reprodução social, condicionando as possibilidades de acesso aos bens e serviços, modelando a dimensão dos processos sociais e estabelecendo os limites para a repartição do poder.

\section{Relações entre etnia e saúde}

Embora as raças não tenham expressão biológica, como construto social elas têm importante impacto sobre as condições de saúde e o acesso e utilização de serviços de saúde.

Nas pesquisas em desigualdades sociais em saúde, as desigualdades raciais ou étnicas são geralmente atribuídas a diferentes condições socioeconômicas ou valores culturais resultantes da pior inserção social desses grupos na sociedade. Entretanto, mesmo após controlar o efeito dessas variáveis, as diferenças permanecem demonstrando o efeito independente que o pertencimento a determinado grupo étnico ou racial pode ter sobre o estado de saúde.

Há pelo menos três aspectos dessa relação que são normalmente subavaliados nas pesquisas epidemiológicas: o efeito da acumulação de desvantagens ao longo da trajetória de vida, os efeitos contextuais decorrentes da concentração de grupos étnicos minoritários em áreas residenciais pobres e deterioradas do ponto de vista urbano e os efeitos deletérios de viver em uma sociedade percebida como racista. 
No Brasil, embora nunca tenha havido um sistema consolidado de segregação racial, a população negra sofre sistematicamente maior desvantagem social. A concentração desta população é maior nas regiões mais pobres do país, seu nível de desenvolvimento humano é inferior ao da população em geral, o acesso a saneamento básico, educação e postos de trabalho também é significantemente menor.

O efeito das desigualdades étnicas sobre a saúde pode ser modificado pela inserção ocupacional, conforme demonstrado em investigação sobre tabagismo em diferentes grupos étnicos e ocupacionais na população norte-americana. Os pesquisadores verificaram que as maiores prevalências de tabagismo ocorreram em quatro grupos sociais: trabalhadores manuais ou do setor de serviços; brancos com escolaridade secundária ou inferior; trabalhadores agrícolas negros com escolaridade secundária ou inferior; indígenas e esquimós em todos os grupos exceto aqueles com formação universitária e em hispânicos trabalhando no setor de serviços.

Entre funcionários de uma universidade pública brasileira, o ganho excessivo de peso mostrou associação com a cor apenas para mulheres, para os homens não existem diferentes por cor. A associação se reduziu após o controle das variáveis socioeconômicas, mas permaneceu significante.

No estado de Nova York, no período de 1988 a 1992, praticamente não se observaram diferenças raciais na mortalidade por doenças coronarianas em homens, entre trabalhadores não manuais, independentemente das características dos municípios de residência. Entre os trabalhadores manuais, o risco era sempre maior para trabalhadores negros e diretamente proporcional à 
desigualdade de renda existente no município de residência. Assim, para os municípios com maior desigualdade, a diferença na mortalidade entre negros e brancos chegou a 1,8 vezes, caindo para 1,3 nos municípios com menor desigualdade. Esses dados demonstram os efeitos complexos da interação entre distintas variáveis sociais, reforçando a concepção de raça como construto social.

$\mathrm{O}$ risco de mortalidade prematura, ou seja, anterior ao indivíduo completar 65 anos, é sempre maior em negros e menor em hispânicos, em comparação às taxas observadas para os brancos, nos mesmos grupos de setores censitários, agrupados segundo proporção de pobres, concentração de renda e percentual de riqueza.

Os índios Maoris na Nova Zelândia morrem em média dez anos mais cedo do que os descendentes de europeus, provavelmente em decorrência da pobreza e das menores oportunidades socioeconômicas, além das dificuldades de acesso e utilização dos serviços de saúde. A demora na busca de tratamento possivelmente contribui para a maior mortalidade por doenças cerebrovasculares, câncer, doenças cardíacas, diabetes e enfermidades mentais.

No Brasil a probabilidade de ter um recém-nascido de baixo peso, pequeno para a idade ou prematuro, é significantemente maior entre mães pretas ou mulatas quando comparadas a mães brancas, mesmo após anular o efeito da renda e da escolaridade, ou seja, tornando esses grupos de mães comparáveis com relação a essas variáveis.

Há muitas evidências empíricas das relações entre etnia e saúde, entretanto, a maioria dos estudos não consegue separar 
adequadamente os efeitos decorrentes da posição social, do nível socioeconômico, das características culturais, de aspectos que poderiam ser decorrentes da discriminação e do racismo. Há uma tendência a considerar qualquer desigualdade como reflexo das condições de discriminação, porém não é tão simples assim. Como todos esses aspectos são socialmente determinados e todos eles têm implicações uns sobre os outros, as questões de etnia e saúde carregam um conjunto complexo de determinações nem sempre passíveis de tratamento estatístico, ou mesmo qualitativo, adequado nas pesquisas populacionais.

\section{Diferenças nO ACESSO A SERVIÇOS DE SAÚdE}

As diferenças no acesso a serviços de saúde têm outro tipo de determinantes. Além das condições socioeconômicas já assinaladas em relação ao estado de saúde, nas desigualdades no acesso a serviços importa também a configuração da política nacional de saúde, isto é, quais são os princípios que a constituem, a forma de organização dos serviços e as formas de relação que se estabelecem entre clientela e profissionais de saúde.

No âmbito da política de saúde, os princípios de universalidade, integralidade e equidade que orientam a constituição do sistema de saúde brasileiro podem garantir acesso mais igualitário aos diferentes grupos sociais. Como evidência, podemos comparar a situação observada em dois momentos distintos: um anterior à criação do SUS e outro posterior à sua existência.

Em relação ao primeiro momento, podemos comparar a probabilidade de acompanhamento pré-natal em mulheres brancas, mulatas e pretas, em Ribeirão Preto (SP), no final da década de 1970. É interessante utilizar nesse exemplo dados do estado 
de São Paulo, onde a rede de atenção básica sempre foi bastante extensa, não constituindo um obstáculo ao acesso. Tomando como referência as mulheres brancas, a probabilidade de não ter tido acompanhamento pré-natal para as mulheres mulatas era 1,82 vezes maior e para mulheres pretas, 3,47 vezes maior.

Após a criação do SUS, dados de internações hospitalares, de uma amostra significativa da população brasileira em 1998, mostram que não há diferença nas taxas entre brancos e negros. A probabilidade de ter sido internado no último ano é diretamente proporcional à idade, maior entre os indivíduos mais pobres e com menor escolaridade e com pior estado de saúde, independentemente da cor.

Isto não significa que não existam mais diferenças por grupos étnicos no acesso e utilização dos serviços de saúde nem a inexistência de discriminação, mas demonstra que uma política pública de acesso universal pelo menos pode possibilitar acesso ampliado para todas as camadas da população. Certamente continua havendo diferenciais na qualidade da assistência e na possibilidade de utilização de determinados bens e serviços.

Com relação à organização dos serviços, estudo realizado no Rio de Janeiro, sobre a qualidade da assistência pré-natal e ao parto, mostrou probabilidades distintas de obter um cuidado pré-natal adequado para mulheres brancas, mulatas ou pretas. A proporção de mulheres sem assistência pré-natal, embora baixa em todos os grupos, foi significativamente mais alta em pardas $(4,7 \%)$ e pretas $(6,7 \%)$ quando comparadas às gestantes brancas $(2,5 \%)$.

Nessa mesma pesquisa, as autoras encontraram diferenças significativas na probabilidade de receber anestesia durante o 
parto para as gestantes brancas $(86,5 \%)$ quando comparadas a gestantes negras $(78,2 \%)$. Menor proporção de mulheres brancas $(18,5 \%)$ teve de procurar mais de uma maternidade até ser atendida quando comparadas a mulheres pardas $(28,8 \%)$ ou pretas $(31,8 \%)$.

Parte dessas diferenças pode ser atribuída a diferentes condições socioeconômicas, porém, mesmo após levar em conta o nível de escolaridade como indicativo da posição social, as diferenças permanecem.

\section{RACISMO E DISCRIMINAÇÃO}

O termo racismo refere-se a uma ideologia social de inferioridade, que é usada para justificar o tratamento diferencial concedido a membros de grupos raciais ou étnicos, por indivíduos e instituições, usualmente acompanhados por atitudes negativas de depreciação com relação a esses grupos. As manifestações de racismo variam consideravelmente segundo tempo e lugar, sendo geralmente produzidas por sociedades nas quais a distribuição desigual do poder está baseada não apenas na posição de classe, mas são atravessadas também pela noção de raça ou etnia.

A discriminação racial ou étnica é um fenômeno estruturado e sancionado socialmente, justificado pela ideologia e expresso através de interações entre indivíduos e instituições; baseada na dominação, visa a manter privilégios para os grupos dominantes à custa de privação e exclusão dos demais.

Uma sociedade racista acaba por reproduzir a discriminação em toda a estrutura social, limitando e restringindo o desenvolvimento econômico e social não apenas dos grupos discriminados, mas da sociedade como um todo. Os integrantes dos grupos 
étnicos ou raciais discriminados sofrem vários tipos de desvantagens, acumulando-se os efeitos da discriminação econômica, segregação espacial, exclusão social, destituição do poder político e desvalorização cultural.

A segregação significa restrição das possibilidades de acesso a oportunidades de educação e emprego, resultando em inserção social desvantajosa e ausência de mobilidade social. As diferenças em relação à riqueza são particularmente marcantes no caso da segregação racial contra os negros norte-americanos. A riqueza mediana das famílias brancas, em 1994, era de aproximadamente 44 mil dólares enquanto para as famílias negras era de apenas quatro mil dólares, portanto 11 vezes menor.

O racismo significa também maior probabilidade de exposição a experiências pessoais de discriminação. A percepção de discriminação varia com o nível socioeconômico dos indivíduos, sendo maior entre aqueles mais bem posicionados na escala social. Com relação ao gênero, a discriminação é proporcionalmente mais percebida pelos homens, enquanto a relação com a idade é bastante variável nas diferentes sociedades.

Alguns problemas e comportamentos de saúde apresentam maior associação com a exposição a situações de discriminação e racismo: transtornos mentais, hipertensão arterial, baixo peso e prematuridade, doenças cardíacas, diabetes e obesidade, abuso de álcool e drogas e tabagismo. Os efeitos do racismo e da discriminação sobre a saúde podem ser agudos ou crônicos, agindo provavelmente através dos mecanismos fisiopatológicos do estresse. A experiência de exposição a atos racistas e discriminatórios pode funcionar como um estressor agudo, enquanto viver em uma sociedade racista pode funcionar como um estressor 
crônico. Os efeitos podem ser modificados pelos estilos pessoais de adaptação a situações de estresse (coping), bem como pelas expectativas dos indivíduos, estrutura comunitária, fatores históricos e políticos de resposta e enfrentamento ao racismo.

No Mississipi, após a abertura dos hospitais públicos aos negros, entre 1965 e 1971, a mortalidade pós=neonatal caiu 50\%, demonstrando o impacto da aprovação da lei dos direitos civis sobre a saúde populacional. De forma geral, entre 1950 e 2004, houve acentuada redução da mortalidade infantil entre os negros, como resultado de distintos processos sociais: migrações do sul para o norte e consequente urbanização, crescimento econômico sustentado no país e movimento pelos direitos civis garantindo acesso à educação e saúde.

Os efeitos da discriminação sobre a saúde decorrem de diferentes mecanismos que envolvem a segregação residencial e ocupacional, com aumento da probabilidade de viver em bairros sem acesso a condições mínimas de vida saudável; aumento do risco de exposições a contaminantes ambientais; acumulação das sensações de medo e raiva; aumento de comportamentos insalubres como o consumo de álcool, drogas e tabaco; diagnósticos e tratamentos tardios ocasionados pela menor possibilidade de acesso aos serviços, agravada pela discriminação institucional.

Mesmo em sociedades em que o racismo não é institucionalizado, ou seja, não está legalmente sancionado, a prevalência da experiência de exposição a agressões motivadas pelo racismo pode ser impressionantemente alta. Em pesquisa realizada no Reino Unido no final dos anos 90, com grupos étnicos minoritários, foram relatadas agressões físicas motivadas pelo racismo por 3\% dos entrevistados, $12 \%$ de agressões verbais, e $64 \%$ deles 
acreditavam que os empregadores exerciam algum tipo de discriminação nas contratações de trabalho.

Um aspecto que tem sido observado nas pesquisas empíricas sobre racismo e discriminação é a chamada dissociação pessoa/ grupo. Os entrevistados tendem a identificar e reconhecer maior discriminação contra o grupo ao qual pertencem do que contra si mesmos. Este aspecto é visto como um recurso adaptativo que leva à negação da discriminação, visando a limitar ou conter os efeitos nocivos dessa percepção sobre a saúde.

A proporção de recém-nascidos com menos de 1.500 gramas de peso ao nascer é três vezes maior entre mães negras de Chicago que referem experiências de discriminação racial. Este aumento de risco não é explicado pela idade, número de filhos anteriores, assistência pré-natal, tabagismo, consumo de álcool, uso de drogas ou pela inexistência de rede social de apoio. Pesquisa comparando a chance de ter um bebê com peso muito baixo mostra que ela varia com a composição racial do casal. Casais com pais e mães brancos têm menor chance de terem bebês com menos de 1.500 gramas. Em seguida, em ordem crescente de risco, vêm os casais formados por mães brancas e pais negros, mães negras e pais brancos e mães e pais negros.

A discriminação pode assumir muitas formas, embora o racismo seja uma das mais importantes. O direito a receber tratamento igual, isto é, não-discriminação, é um dos aspectos fundamentais dos direitos humanos. Ninguém deve ser tratado de maneira diferente e negativa com base nas diferenças de gênero, etnia, crença religiosa, orientação sexual ou incapacidade.

Em termos operacionais, a discriminação pode ser captada com a investigação de ocorrência de tratamento ofensivo. No 
inquérito nacional de saúde realizado na Suécia, em 2006, 6,7\% da população relatou ter sido vítima de tratamento ofensivo. Destes, $35 \%$ relacionaram o fato a alguma forma de discriminação. A maioria das mulheres atribuiu esse tratamento ofensivo a questões de gênero ou idade, ao passo que os homens referiram mais a questões étnicas.

As pessoas que relataram ter sofrido algum tipo de discriminação apresentaram maior prevalência de saúde mental ruim, ansiedade e depressão, estresse, problemas graves de sono, ideação suicida, tentativas de suicídio, baixa autoestima e doenças físicas.

A discriminação percebida também está relacionada com comportamentos de saúde e busca por assistência médica. O mesmo inquérito realizado na Suécia analisou a probabilidade de refrear a busca por serviço de saúde na presença de uma necessidade sentida entre indivíduos que referiram ou não discriminação. Após controlar por idade, escolaridade, presença de doenças crônicas e viver sozinho, os pesquisadores observaram que quanto maior a frequência de exposição a situações de discriminação, maior a probabilidade de refrear a busca a serviços de saúde, ainda que o comportamento ofensivo não estivesse relacionado com esses serviços.

Os autores do inquérito citado analisaram ainda o efeito da interação entre desvantagem econômica e percepção de discriminação, encontrando que homens que não apresentavam desvantagem econômica, sujeitos a tratamentos ofensivos atribuídos à discriminação, tiveram 5,6 vezes maior probabilidade de não procurar um serviço de saúde, do que os que não sofreram nenhum tipo de tratamento ofensivo. Para as mulheres em igual 
situação, a probabilidade de refrear a busca a serviços foi 4,2 vezes maior. Para os indivíduos com desvantagem econômica e percepção de tratamento discriminatório, a probabilidade de não procurar serviços de saúde foi 12,0 vezes maior entre os homens e 11,6 vezes maior entre as mulheres.

Um achado interessante desse inquérito é que se a pessoa que referia ter sofrido algum tipo de tratamento ofensivo não fosse capaz de identificar uma razão para o mesmo, não se observava maior probabilidade de não procurar serviços de saúde. Para os homens as razões de discriminação que estiveram mais associadas com a diminuição da procura destes serviços foram, em ordem decrescente de risco: religião, etnia ou raça, gênero e idade. Para as mulheres as razões foram: etnia ou raça, religião, gênero e idade.

Embora só recentemente as pesquisas em saúde tenham começado a se interessar pela questão da discriminação e de suas repercussões nas condições de vida e no perfil de morbimortalidade dos grupos sociais, já existem evidências importantes sobre esses aspectos.

Geralmente as pessoas que vivenciam situações de discriminação são mais vulneráveis também porque, com maior probabilidade, não podem contar com uma rede de suporte social, emocional, afetivo e prático, não confiam nas instituições nem nas pessoas com as quais convivem. Uma demonstração da importância da rede de suporte social é fornecida pela análise de uma situação limite de discriminação, como foi o extermínio dos judeus durante a ocupação nazista na Holanda. Estudo feito a partir das informações do censo da população judaica, realizado pelas autoridades nazistas, e das informações de mortalidade nos 
campos de extermínio permitiu verificar que a sobrevivência estava associada a ter familiares não judeus, pertencer a famílias não ortodoxas em questões religiosas, pertencer a famílias convertidas a outras religiões ou ter domínio da língua alemã.

Estudo conduzido em instituições andaluzas para menores infratores encontrou piores condições de saúde entre crianças e adolescentes de origem cigana nascidas na própria Espanha, quando comparadas com crianças imigrantes de outros países europeus e não europeus com situações socioeconômicas piores, sugerindo, assim, a existência de efeitos deletérios decorrentes da discriminação social contra esse grupo na sociedade espanhola.

Embora comecem a haver estudos de desigualdades sociais em saúde, enfocando especificamente os efeitos deletérios das situações em que a distribuição de poder é assimétrica entre diferentes grupos sociais, seja por questões relacionadas à idade, gênero, etnia, religião, seja por questões relacionadas à classe social ou às condições materiais de vida, ainda há um longo caminho a percorrer na compreensão de fenômenos com essa complexidade. 



\section{$5 \mid \begin{aligned} & \text { Relações de Gênero e Saúde: } \\ & \text { desigualdade OU discriminação? }\end{aligned}$}

\section{Afinal 0 que é 0 COnCeito de gênero?}

$\mathrm{Na}$ língua portuguesa a palavra 'gênero' apresenta inúmeros sentidos dependendo do campo do conhecimento em cujo discurso se insere. Entretanto, em termos gerais, gênero significa o conjunto de seres ou objetos que possuem mesma origem ou que se acham ligados pela similitude de uma ou mais particularidades. Em biologia, o termo se refere à categoria taxonômica que agrupa espécies relacionadas filogeneticamente, distinguíveis das outras por características marcantes que permitem assim a subdivisão das famílias. Na gramática, gênero se refere a classes de palavras que permitem estabelecer o contraste entre masculino e feminino, nem sempre referido a diferenças de sexo.

$\mathrm{Na}$ área de saúde o conceito de gênero retém algumas das características de sentido que a palavra tem tanto na biologia quanto na gramática. Assim, ele é utilizado para marcar características próprias aos comportamentos de grupos de sujeitos sociais e para estabelecer o contraste entre masculino e feminino, mas, principalmente, para enfocar as relações que se estabelecem entre masculino e feminino no âmbito social e que apresentam repercussões para o estado de saúde e para o acesso e utilização dos serviços de saúde.

Definitivamente, gênero não é sinônimo de sexo. Em biologia, e também na área médica, sexo é um marcador de diferenças 
biológicas entre indivíduos da espécie humana, relacionadas com aspectos anatômicos e fisiológicos do aparelho reprodutivo e eventualmente com características genéticas vinculadas aos cromossomos $x$ ou $y$. Entretanto, é muito comum atualmente os textos publicados em periódicos científicos utilizarem gênero como substituto para sexo mesmo em situações nas quais o termo correto seria sexo, pois se está fazendo referência a características biológicas de homens e mulheres. Nestes tempos do 'politicamente correto' parece que os médicos e pesquisadores em geral passaram a considerar de 'bom tom' não utilizar a palavra sexo.

Segundo a epidemiologista Nancy Krieger, o termo gênero foi introduzido nas pesquisas em saúde para ajudar a clarear o pensamento em face do ressurgimento do movimento feminista em meados no século XX. Uma das preocupações do movimento foi debater as diferenças observadas na inserção e nos papéis sociais de homens e mulheres nas sociedades capitalistas do Ocidente. Dentre os aspectos e as desigualdades enfocadas estavam, desde o início, as desigualdades em saúde. O centro do debate feminista nesta questão estava na indagação sobre os motivos ou as explicações para essa diferença: elas eram todas derivadas de diferenças inatas ligadas ao sexo ou poderiam ser atribuídas a convenções culturais construídas socialmente no processo de educação e aculturação dos homens e das mulheres, que acabavam por moldar não apenas as características masculinas e femininas, mas também determinavam os padrões de relação estabelecidos entre homens e mulheres? Para diferenciar este último aspecto foi proposto o conceito de gênero.

Como afirma Krieger, todos nós somos sexo e gênero, isto é, temos um sexo, biologicamente determinado, que influencia 
algumas das nossas condições de saúde, mas também somos gênero, isto é, produto do processo sociocultural que molda na sociedade os papéis femininos e masculinos e define as pautas de relação entre homens e mulheres. Há, assim, uma relação de mútua determinação entre sexo e gênero no qual este último adquire a maior hierarquia na produção dos estados de saúde. Portanto, as desigualdades em saúde observadas entre homens e mulheres devem ser analisadas a partir dessa dupla determinação: as relações de gênero e as peculiaridades do sexo biológico.

A confusão entre os termos sexo e gênero presente em parte da pesquisa epidemiológica e de saúde em geral é sinal de um grave erro conceitual. Além do problema já assinalado de utilizar gênero como sinônimo de sexo, outro aspecto desse uso inadequado é a utilização do conceito para denotar exclusivamente problemas relacionados com as mulheres, especialmente aqueles ligados à saúde reprodutiva.

Embora na pesquisa epidemiológica clássica, a variável sexo já fosse vista como indicadora de diferentes padrões de exposição relacionados aos comportamentos específicos de homens e mulheres e às distintas situações de vida de uns e outros, a complexidade e as múltiplas facetas das relações de gênero não estavam presentes. Esta ausência se faz sentir principalmente no âmbito das explicações teóricas para as diferenças encontradas, quando se analisa qualquer evento de saúde segundo o sexo dos indivíduos.

A variável sexo, entretanto, não dá conta das questões de gênero, pois um dos aspectos mais salientes dessas relações é a assimetria de poder que se estabelece entre homens e mulheres na maioria das sociedades e praticamente em todos os âmbitos da vida social. Por isso, a abordagem de gênero em seus aspectos 
mais complexos está presente principalmente em pesquisas com abordagens qualitativas. Porém, as diferenças observadas na distribuição do estado de saúde, das doenças e outros agravos à saúde e as desigualdades no acesso e uso de serviços de saúde podem indiretamente apontar as consequências dessas relações assimétricas de poder, permitindo o desvelamento das questões de gênero ainda que a variável de classificação utilizada seja sexo.

\section{RELAÇÃO ENTRE GÊNERO E OUTRAS CATEGORIAS NO ESTUDO DAS DESIGUALDADES}

Um aspecto muito discutido desde o surgimento do enfoque de gênero é a relação entre esta categoria de análise para a compreensão de problemas de saúde e sua distribuição social e categorias tradicionais, tais como classe social ou renda, escolaridade e ocupação, como variáveis de estratificação social.

A segunda metade do século XX assistiu à emergência de movimentos sociais diversos, centrados principalmente na defesa de interesses específicos de determinados grupos sociais definidos com base em questões de identidade cultural, diferentemente dos movimentos sociais anteriores, fortemente marcados por questões de classe, ou seja, vinculadas à posição dos sujeitos na estrutura produtiva. É nesse novo contexto que o movimento feminista ressurge e dele emerge a questão de gênero.

Parte da militância desses movimentos vai considerar que as determinações de gênero são mais importantes do que aquelas decorrentes da posição dos indivíduos na estrutura social, conferindo às relações de gênero o maior grau de determinação nos processos de saúde-doença e em outros processos sociais. 
O principal argumento dessa corrente é que ao nascer o indivíduo já passa a ter toda sua existência determinada pelas relações de gênero e, portanto, elas serão as mais importantes na hierarquia de determinações e mediações que acabam por moldar o perfil epidemiológico. Outros, entretanto, dão maior peso aos determinantes de inserção social dos indivíduos, vale dizer, à classe social, tendo nas relações de gênero um dos mediadores importantes da relação entre a posição social e o perfil epidemiológico dos grupos sociais.

$\mathrm{Na}$ realidade é muito difícil desembaraçar as diferentes dimensões de determinação e mediação presentes nos processos sociais. As relações sociais que se expressam na divisão sexual do trabalho, a divisão sexual do poder na sociedade, assim como a própria construção social do feminino e do masculino são diversas modalidades de manifestação da organização social e do papel dos homens e das mulheres nessa organização, seja na dimensão predominantemente econômica, seja nas dimensões sociais, culturais ou políticas propriamente ditas.

As relações de gênero atravessam todas as dimensões da vida social, possuem dinâmica própria independente de outros processos sociais e são marcadas pelo antagonismo na relação de dominação das mulheres pelos homens. A idealização do papel do trabalho remunerado, como elemento de fortalecimento da identidade e da liberdade feminina, desaparece face à constatação da pouca ou nenhuma qualificação da maioria dos postos de trabalho ocupados pelas mulheres, dos salários inferiores para as mesmas funções e da dupla jornada, representada pelo trabalho doméstico ou pelas tarefas de cuidado destinado a membros da família das quais invariavelmente são as mulheres que se ocupam. 
Ignorar a importância da estrutura social em todos os seus aspectos acarreta o enfraquecimento do poder explicativo da categoria gênero e impede a compreensão de diferentes fenômenos, nos quais cada um dos múltiplos aspectos das relações de gênero pode assumir proeminência temporária. Por exemplo, o fenômeno da violência doméstica contra as mulheres não pode ser entendido em toda sua extensão com base apenas na perspectiva de classe social, uma vez que ele extrapola amplamente as divisões de classe. Entretanto, as formas de manifestação dessa violência podem estar fortemente marcadas por aspectos relativos às classes sociais.

Portanto, não há como estabelecer de maneira unívoca e permanente uma hierarquia rígida entre as diferentes categorias de determinação do processo saúde-doença. Em cada tipo de problema analisado, haverá a necessidade de elaborar modelos explicativos específicos nos quais a categoria gênero pode tanto ocupar a posição de determinação, quanto a posição de mediação entre diferentes aspectos da organização social.

Do mesmo modo que se compreende raça como construto social, é possível pensar nas questões de gênero como construções sociais baseadas nas diferenças de sexo, mas cujo alcance ultrapassa largamente os aspectos exclusivamente biológicos.

\section{Gênero e estado de saúde}

Para a maioria das populações, a mortalidade é maior entre os homens em todas as faixas etárias a partir do nascimento. Apenas em culturas que praticam o infanticídio feminino, ou em sociedades onde a assistência à gestação e ao parto é muito precária, a mortalidade pode ser maior entre as mulheres em certos 
grupos etários. Este fato é geralmente atribuído à diferença na exposição a fatores e situações de risco ao longo da vida, que costuma ser maior entre os homens, seja na exposição a situações insalubres de trabalho, seja em relação a comportamentos nocivos para a saúde, tais como o consumo exagerado de álcool, cigarros e outras drogas, e a exposição mais frequente a situações de risco para acidentes e violências (Gráfico 1).

Gráfico 1 - Razão de mortalidade geral por sexo e idade. São Paulo - 2005

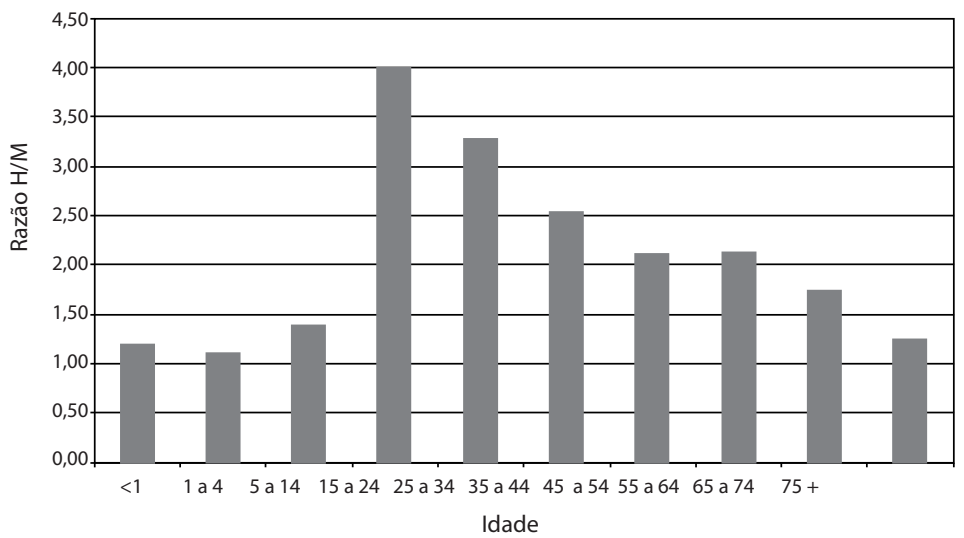

Fonte: Datasus.

O Gráfico 1 mostra que para todas as idades a mortalidade geral foi maior para os homens do que para as mulheres no estado de São Paulo, em 2005. Para os menores de cinco anos a diferença é pequena e a razão é ligeiramente maior do que 1. A partir dos cinco anos a diferença começa a se acentuar, atingindo valor máximo no grupo de 15 a 24 anos, em que a razão chega a 4. A partir dos 25 anos a diferença torna-se progressivamente menor, porém mantendo-se sempre acima de 1 . 
O excesso de mortalidade masculina entre jovens e adultos jovens reflete o impacto não só das mortes violentas, mais frequentes nessas faixas etárias e entre os homens, mas também dos óbitos por Aids.

Com a maior mortalidade masculina em todas as idades, a esperança de vida das mulheres cresce mais aceleradamente do que a esperança de vida dos homens. No Brasil, entre 1960 e 2006 a esperança de vida foi maior para as mulheres, e a diferença entre as curvas masculina e feminina tende a aumentar a cada ano. Em 1960 a diferença era de três anos e em 2006 ela chega a 7,6 anos.

Esses dados, embora classificados por sexo dos indivíduos afetados, podem indicar diferenças de gênero, pois não há razões estritamente biológicas para que os homens apresentem maior mortalidade geral em todas as idades e, consequentemente, menor esperança de vida ao nascer, nem para que os homens jovens apresentem risco de morrer tão acentuado em comparação com o risco das mulheres. As diferenças mencionadas certamente refletem diferenças de gênero, isto é, decorrentes da divisão sexual do trabalho, da construção social e cultural do masculino e do feminino em nossa sociedade, bem como dos distintos modos de vida determinados pela inserção social dos indivíduos, mas modulados pela posição e pelas relações de gênero.

$\mathrm{O}$ excesso de mortalidade masculino também se manifesta em relação aos grupos de causas, conforme pode ser observado no Gráfico 2. 
Gráfico 2 - Razão de mortalidade hospitalar segundo sexo. São Paulo - 2007

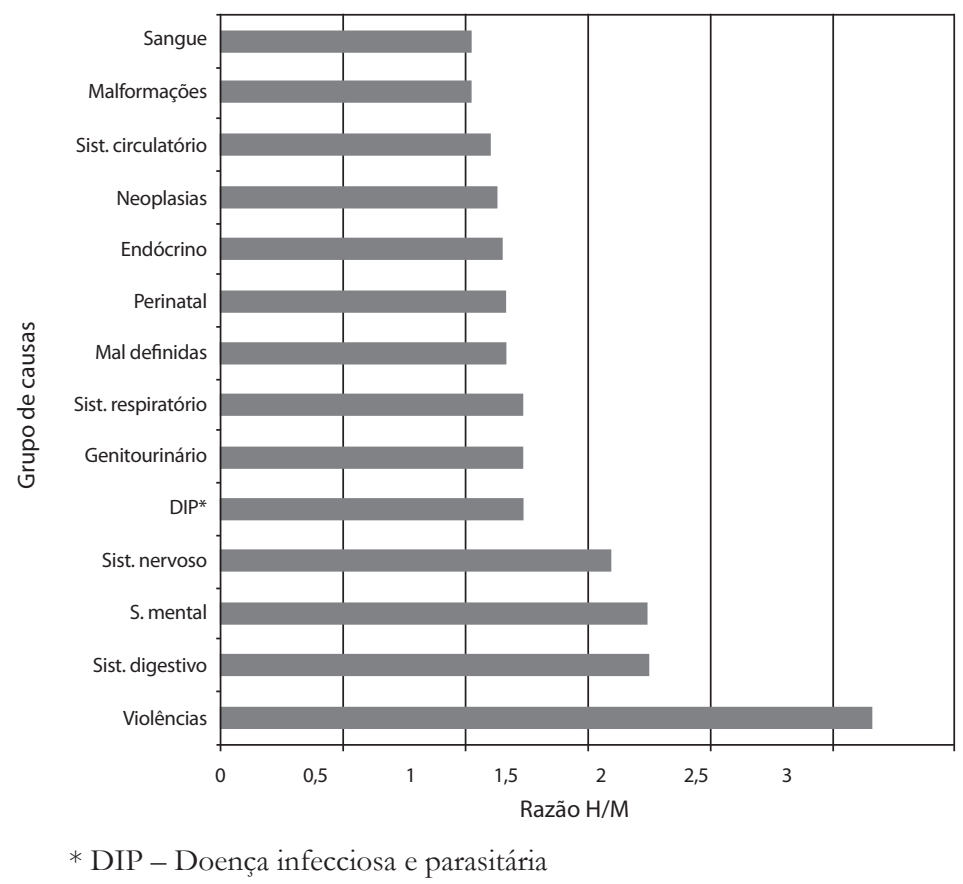

Fonte: Datasus.

Para todos os grupos há um excesso de mortes masculinas, entretanto, a diferença é muito pequena para os óbitos por malformações congênitas e problemas do sangue e dos órgãos hematopoiéticos. O excesso é significativo para doenças do sistema nervoso, problemas mentais e sistema digestivo. A maior diferença é observada para as mortes violentas. Novamente não existem razões biológicas capazes de explicar essas constatações. 
Paradoxalmente, as mulheres, em praticamente todas as populações estudadas, referem pior avaliação do próprio estado de saúde e maior frequência de morbidade do que os homens. Algumas explicações para a morbidade mais acentuada nas mulheres baseiam-se nas diferenças hormonais e genéticas entre os sexos, considerando estritamente o ponto de vista biológico. $\mathrm{O}$ enfoque nas relações de gênero, entretanto, assinala os diferentes papéis sociais dos homens e mulheres que acabam por determinar diferentes percepções sobre o processo saúde doença, assim como comportamentos distintos em relação à doença.

O papel universal e histórico conferido às mulheres como responsáveis pelos cuidados dos filhos e de outros membros da família provavelmente determina a maior atenção para as questões de saúde e doença e, portanto, percepção mais aguçada para os próprios problemas.

Inquéritos populacionais mostram diferenças na morbidade referida pelas mulheres que permaneceram significantes mesmo após controlar o efeito da idade, renda, educação, classe social, estado civil, desemprego e raça. As mulheres com maior frequência referiram sintomas em geral, sintomas graves, problemas crônicos, estado de saúde regular ou ruim, distúrbios psiquiátricos maiores e presença de três ou mais sintomas simultaneamente. A constatação da maior morbidade entre as mulheres, mesmo após a anulação do efeito da idade e de variáveis socioeconômicas, sugere, assim, o efeito independente da condição de gênero sobre o estado de saúde.

Certamente, parte do excesso de morbidade apresentado pelas mulheres pode estar relacionado com as características do trabalho feminino, uma vez que as condições de trabalho são 
determinantes muito relevantes do estado de saúde. O trabalho feminino geralmente está concentrado em certos setores de atividade e em certas profissões predominantemente mal remuneradas. Em algumas sociedades como a brasileira, para empregos semelhantes com o mesmo grau de exigência em termos de qualificação, é comum as mulheres receberem salários menores em comparação com os homens.

No estado de São Paulo, em 2006, 55,4\% das mulheres entre 15 e 59 anos estavam no mercado de trabalho. A renda média feminina era $R \$ 869,00$, enquanto a masculina era $R \$ 1.291,00$. Entretanto, a jornada média de trabalho era menor para as mulheres - em torno de 39 horas - ao passo que para os homens a jornada média era de 45 horas. Assim, a comparação mais adequada é através do valor da hora trabalhada. Novamente o valor é menor para as trabalhadoras: $R$ \$ 5,21 contra $R \$ 6,70$ dos trabalhadores.

$\mathrm{O}$ valor da hora é sempre menor para as mulheres, qualquer que seja a inserção no trabalho. Em 2005, para a posição de empregador, as mulheres ganharam $\mathrm{R} \$ 9,01$ por hora, enquanto os homens ganharam $\mathrm{R} \$ 13,14$. Entre os trabalhadores autônomos, a diferença foi de $\mathrm{R} \$ 3,94$ a hora feminina para $\mathrm{R} \$ 5,77$ a hora masculina. $\mathrm{O}$ trabalho assalariado no setor privado remunerou a hora feminina em $\mathrm{R} \$ 5,24$ e a masculina em $\mathrm{R} \$ 6,10$. Finalmente, o trabalho assalariado no setor público pagou $\mathrm{R} \$ 9,52$ a hora de trabalho das mulheres e R $\$ 11,09$ a dos homens. No caso do setor público, em função das características do emprego, em que para mesma função a remuneração é obrigatoriamente a mesma, a diferença na remuneração média só pode ser atribuída ao fato das mulheres ocuparem predominantemente postos pior remunerados. 
O censo britânico de 2001 também mostrou maior proporção de percepção de saúde regular ou ruim entre as mulheres nas diferentes condições de classe ocupacional. As condições no estado de saúde são piores para mulheres em praticamente todas as classes, exceto para as ocupações intermediárias na hierarquia gerencial, pequenos empregadores e autônomos com negócio e ocupações semiqualificadas. Nas demais, o estado de saúde referido foi pior entre as mulheres. A diferença na proporção de indivíduos com saúde regular ou ruim, entre os extremos do espectro de posições na ocupação, foi mais acentuada entre os homens, com razão de prevalências de 2,7 vezes entre os trabalhadores em ocupações não qualificadas e os profissionais e altos executivos. Para as mulheres essa diferença foi de 2,2 vezes, principalmente pelo excesso de risco apresentado pelas profissionais e ocupantes de postos executivos de alta hierarquia, sugerindo maior pressão sobre as mulheres em posições de status social mais elevado.

Os empregos femininos, além dos salários menores, geralmente são mais monótonos, com pequeno ou nenhum grau de autonomia na execução das tarefas, menores perspectivas de progressão, vínculos trabalhistas mais precários, movimentos repetitivos, contato com o público e outras características de desgaste psicológico e emocional. Eventualmente as trabalhadoras ainda estão sujeitas a assédio psicológico ou sexual, agravando as condições de precariedade e desgaste.

Às condições muitas vezes nocivas no trabalho remunerado acrescem-se às demandas do trabalho doméstico não pago. Karen Giffin chama a atenção para o fato de que para grande parte das mulheres a dupla jornada, representada pela somatória entre trabalho doméstico e trabalho remunerado desqualificado e mal 
pago, acaba por anular os potenciais benefícios que eventualmente o trabalho fora das atividades domésticas poderia representar.

Distúrbios psiquiátricos menores estão associados com a dupla jornada das mulheres pobres e também com jornadas de trabalho de mais de dez horas diárias. A maioria delas tinha o trabalho doméstico fora de casa como ocupação principal. A associação entre ter dupla jornada, ser casada e ter filhos em idade pré-escolar dobrou o risco de apresentarem sintomas psiquiátricos. Esta relação desaparece para mulheres sem a dupla jornada. Os dados reforçam a hipótese de que o trabalho remunerado pode representar uma sobrecarga para a saúde das mulheres quando a qualidade do emprego é baixa e se associa com o trabalho doméstico para a própria família.

Há maior risco para transtornos mentais comuns em mulheres desempregadas ou trabalhadoras do setor informal, donas de casa ou inativas, em comparação a mulheres empregadas no setor formal. Entre os homens, a prevalência também é maior para os desempregados e inativos, mas não há diferença entre trabalho formal e informal. Comparando a prevalência de transtornos mentais entre homens e mulheres, com a mesma posição no mercado de trabalho, observa-se prevalência sempre maior para as mulheres.

A inserção da mulher no mercado formal desempenhou papel protetor em relação à saúde mental, entretanto, comparativamente com os homens inseridos no mercado formal ou informal, a situação de saúde mental das mulheres se mostrou pior, refletindo provavelmente o efeito da dupla jornada de trabalho.

Como para a maioria dos processos sociais, a inserção feminina no mundo do trabalho é contraditória. Por um lado, pode representar a oportunidade de construção da autoestima, 
independência financeira, confiança na capacidade decisória e de liderança, rede de suporte social extrafamiliar, realização profissional, maior poder nas relações de gênero; por outro, pode significar exposição a situações de desgaste biopsíquico e acúmulo de desvantagens. Esse jogo contraditório entre aspectos positivos e negativos para a saúde acaba por definir e modelar o perfil epidemiológico no qual as mulheres geralmente apresentam maior frequência de doenças e agravos à saúde e menor mortalidade, em comparação com os homens.

As desigualdades na autopercepção do estado de saúde indicam que as mulheres tendem a considerar sua saúde pior em comparação com a percepção que os homens têm de sua própria saúde. Os dados empíricos reforçam o conceito de gênero com construto social que determina como homens e mulheres experimentam os eventos vitais de modo particular.

Inquérito realizado em amostra representativa da população brasileira, exceto para a população rural da região Norte do país, mostrou diferença significativa na autopercepção do estado de saúde entre homens e mulheres. As mulheres apresentam maior proporção de saúde regular ou ruim, em todos os grupos de idade, estratos de renda e níveis de escolaridade.

As diferenças entre o estado de saúde de homens e mulheres se tornam ainda mais acentuadas após o ajuste por variáveis socioeconômicas, como escolaridade e renda, sugerindo que os determinantes estruturais não são capazes de explicar a variação encontrada. Do mesmo modo, a cor da pele e a idade não modificam essa relação.

As quatro variáveis mencionadas explicam pouco mais de $10 \%$ da desigualdade observada no estado de saúde entre homens 
e mulheres. Portanto, outros aspectos, além das condições diretamente materiais e biológicas (expressas pela idade), interferem na determinação do estado de saúde de homens e mulheres, sendo necessário recorrer a outras dimensões da vida social para compreender as desigualdades de gênero.

Um problema de saúde com importância crescente e no qual a determinação das relações de gênero ocupa uma posição central é a violência. Por um lado, a violência urbana afeta de maneira desproporcional os homens; por outro, a violência doméstica afeta desproporcionalmente as mulheres. Além de vários determinantes socioeconômicos, políticos e culturais, as relações de gênero desempenham papel fundamental na produção desses agravos à saúde.

As mortes e traumatismos decorrentes da violência vêm aumentando de maneira alarmante a partir da década de 1980, convertendo-se em problema de saúde pública, seja por sua magnitude e transcendência social, seja pelo volume de gastos que o atendimento das vítimas representa para o setor saúde. A mortalidade por homicídios representa uma das facetas do crescimento da violência urbana, ocupando lugar de destaque entre as causas básicas de óbito, principalmente entre adolescentes e adultos jovens do sexo masculino, em muitos países da América, constituindo, ao lado dos acidentes de trânsito, os principais motivos das mortes por causas externas.

Na cidade de São Paulo, no período de 1996 a 2005, a taxa de mortalidade por homicídio para homens apresentou valores extremamente altos até 2003, quando então começou a declinar. Em 1999 a taxa atingiu seu valor mais alto: 129,07 óbitos por 100 mil habitantes. Em 2005 foi registrado o valor mais baixo: 49,85 
óbitos por 100 mil habitantes. Para as mulheres, no mesmo período, as taxas foram em média 14 vezes menores. $\mathrm{O}$ valor mais alto também foi registrado em 1999, chegando a 9,20 óbitos por 100 mil habitantes, e o valor mais baixo em 2005 foi de 3,95 óbitos por 100 mil. Durante esse período, a razão de mortalidade por homicídios variou entre 12,62 em 2005 e 15,66 em 2001.

Estudo que realizamos em amostra de homicídios ocorridos em 1998 mostrou que a razão entre os óbitos por homicídio de homens e mulheres varia segundo os estratos socioeconômicos das áreas de residência das vítimas. No estrato de melhores condições de vida, a relação observada foi de cinco óbitos masculinos para cada óbito feminino, enquanto no estrato de piores condições de vida a relação foi de 32 óbitos masculinos para cada óbito feminino.

Estas marcadas diferenças no risco para homens e mulheres não podem ser explicadas exclusivamente pelos processos macrossociais. Os fenômenos sociais e econômicos, que estão na gênese do crescimento da violência urbana e que se traduzem no aumento sem precedentes dos óbitos por homicídio, são mediados pelas relações de gênero, determinando riscos bastante diferenciados para homens e mulheres nas mesmas condições sociais.

Para as camadas da população vivendo em condições de exclusão social, os comportamentos violentos aparecem muitas vezes como reafirmadores de identidade. A frustração das expectativas, associada ao desemprego crônico e à falta de participação na vida social, acaba por produzir sentimentos de marginalização e diminuição da autoestima, potencializados pela vivência da extrema situação de desigualdade, concorrendo para maior exposição e vitimização dos moradores das áreas periféricas mais pobres. 
Nessas áreas os homicídios ocorrem majoritariamente no espaço público, geralmente na rua ou em bares ou salões de baile, e estão relacionados com brigas e desavenças e também com o tráfico de drogas. O consumo de álcool e outras drogas ilegais estão frequentemente associados com essas mortes, sendo comum que a vítima e o agressor estejam sob o efeito do álcool ou de outras drogas quando o homicídio é praticado.

No estrato mais pobre predominam, como circunstâncias em que os homicídios são cometidos, as brigas entre conhecidos ou amigos e em boa parte dos casos são utilizadas armas brancas. Nos três estratos intermediários no espectro socioeconômico são mais frequentes as execuções relacionadas com o tráfico de drogas na cobrança de dívidas, disputa por pontos de vendas e diversas situações relacionadas com vingança. $\mathrm{Na}$ quase totalidade dos casos, os homicídios foram cometidos com armas de fogo e as pessoas foram alvejadas na cabeça, havendo pouca ou nenhuma chance de sobrevida.

Nas camadas da população vivendo em melhores condições de vida, os homicídios estão mais relacionados a situações de assaltos seguidos de homicídio ou a crimes passionais. Parte significativa dos casos ocorre no domić́lio da vítima, explicando assim o aumento proporcional do risco para as mulheres.

Os homens se tornam vítimas de homicídio mais frequentemente do que as mulheres, tanto por apresentarem maior exposição a situações de risco, quanto pelo maior consumo de álcool e drogas ilícitas. Mas provavelmente há outros aspectos mais diretamente relacionados à construção do papel masculino na sociedade que acabam por favorecer a maior exposição dos homens. 
Do mesmo modo a vitimização das mulheres é mediada pela construção do papel feminino na sociedade. Exemplar desse tipo de situação é o homicídio praticado pelo companheiro, seja como vingança por abandono ou traição amorosa, seja como decorrência de situações de crescente violência na relação de casal.

Alguns estudos realizados no âmbito da psicologia social têm demonstrado que homens e mulheres apresentam diferentes atitudes em relação à igualdade nas relações de gênero e que estas atitudes podem influenciar a qualidade da relação entre casais. As mulheres tendem a endossar atitudes mais igualitárias nas relações de gênero, independentemente de terem ou não sido vítimas de agressões físicas ou psicológicas. Nos homens a ideologia do papel de gênero parece estar mais vinculada às próprias experiências. Homens que não foram vítimas de agressões tendem a aprovar atitudes mais igualitárias do que aqueles que foram vitimizados em algum momento da vida.

No Brasil, em dois inquéritos nacionais representativos da população urbana, os pesquisadores encontraram alta prevalência de violência sexual praticada por companheiro ou companheira $(8,6 \%)$. O risco para as mulheres foi duas vezes maior do que para os homens. A prevalência foi extremamente alta para indivíduos de ambos os sexos, com prática homo ou bissexual, correspondendo ao dobro da observada entre as mulheres heterossexuais e cinco vezes maior do que para os homens heterossexuais.

Os dados revelam que, além das relações de gênero, a preferência sexual dos indivíduos também atua como mediadora nas questões de violência doméstica por parceiro íntimo. A prevalência de violência sexual foi maior nos indivíduos mais velhos, 
com menor renda e menor grau de escolaridade, mostrando assim a influência da posição social nesse tipo de violência.

\section{AS QUESTÕES DE GÊNERO E 0 USO DE SERVIÇOS DE SAÚDE}

A utilização dos serviços de saúde apresenta um conjunto de determinantes, dentre os quais a necessidade de saúde ou a existência de um problema de saúde é aquele que impulsiona o indivíduo a buscá-los. Há uma série de fatores predisponentes que alteram a percepção das necessidades de saúde e, portanto, desempenham papel decisivo na concretização da demanda por serviços. Estes fatores incluem a idade, o gênero, a etnia e a condição socioeconômica. A partir da demanda, a utilização dos serviços irá se realizar na dependência da disponibilidade de serviços e recursos humanos, da facilidade de acesso, das formas de financiamento e remuneração aos prestadores.

A utilização de consulta médica, em todos os estratos de renda familiar, apresenta maior frequência entre as mulheres, tanto para os indivíduos com bom estado de saúde, quanto para aqueles com saúde regular ou ruim, segundo os dados das pesquisas nacionais por amostra de domicílios.

O uso de consulta médica aumenta proporcionalmente com a renda familiar, tanto para homens quanto para mulheres, havendo redução progressiva da desigualdade relativa entre eles à medida que se vai da faixa de menor para a de maior renda e com o aumento da idade. A maior desigualdade por gênero é observada entre os jovens com bom estado de saúde e com renda familiar de até dois salários mínimos. Observa-se maior desigualdade de gênero entre as pessoas com bom estado de saúde, em 
todos os grupos de idade, sugerindo utilização diferencial de consultas preventivas segundo gênero. Entre as pessoas com estado de saúde regular ou ruim, as desigualdades entre gêneros são menores, tendendo a desaparecer para os grupos com maior renda. Este comportamento sugere que, em face da necessidade sentida, essas diferenças tendem a exercer menor influência no comportamento de busca por serviços de saúde.

A taxa de utilização de consultas médicas no último ano também aumentou com a idade e com o nível de escolaridade, tanto para homens quanto para mulheres. As desigualdades entre homem e mulheres quanto a este dado apresentam-se mais altas entre os mais jovens e entre aqueles com menor escolaridade e bom estado de saúde. Para as pessoas com condições de saúde regulares ou ruins, as desigualdades não se alteram em função dos níveis de escolaridade, reproduzindo os achados relativos aos níveis de renda.

Para o estado de saúde, a desigualdade indica desvantagem relativa das mulheres que sempre apresentam pior estado de saúde autorreferido, enquanto para a utilização de serviços de saúde a desigualdade se mostra favorável às mulheres que sempre referem maior consumo, em consonância com a autopercepção do estado de saúde.

A desigualdade de gênero na prevalência de estado de saúde regular ou ruim foi observada também para a presença de doença crônica, restrição de atividades e procura por serviços de saúde nos últimos 15 dias, nesta mesma população.

Dados do inquérito nacional de saúde do Canadá mostram que parcela maior das variações no estado de saúde dos homens e mulheres é explicada por determinantes estruturais (19,23\% e 
$19,47 \%$ respectivamente) mais do que por determinantes comportamentais $(14,95 \%$ e $10,92 \%$ respectivamente), reforçando a concepção de gênero como uma construção social. Homens e mulheres têm suas experiências de vida diversificadas em um mesmo contexto, conforme indicado pela diferença entre determinantes estruturais bem menor do que a diferença entre os determinantes comportamentais, ainda que os primeiros sejam preditores mais importantes do estado de saúde.

Homens e mulheres diferenciam-se marcadamente nos papéis sociais dentro da família e na sociedade em geral. Diferentes sociedades também podem produzir diferentes graus de desigualdade entre homens e mulheres.

Tendo em vista que as necessidades de saúde constituem o principal determinante do uso de serviços de saúde, e que a autoavaliação do estado de saúde das mulheres tende a ser pior do que a dos homens, a frequência maior de utilização de consultas médicas pelas mulheres poderia ser explicada apenas por esta maior necessidade percebida. Entretanto, a diferença nas taxas de utilização de consultas entre homens e mulheres é mais acentuada para as pessoas com bom estado de saúde do que para aquelas com saúde regular ou ruim.

O número médio de consultas/ano também é maior para as mulheres, e elas utilizam proporcionalmente mais consultas para prevenção ou exames de rotina e menos consultas por motivo de doença do que os homens. O consumo de consultas médicas mostra padrão inverso à necessidade de saúde nos diferentes estratos socioeconômicos, e parte dessa utilização diferencial é decorrente do maior uso de consultas preventivas pelos estratos sociais privilegiados, denotando maior preocupação com a saúde, 
incorporação da ideia de risco não como fatalidade, mas como uma possibilidade de ocorrência evitável através de intervenções preventivas.

Para as internações hospitalares o sistema de saúde parece propiciar maior equidade, visto que as taxas de utilização têm distribuição coerente com a do estado de saúde, sugerindo que o maior determinante da utilização é a necessidade de saúde.

As desigualdades de gênero no estado de saúde e na utilização de serviços resultam da ação complexa de diversos determinantes que incluem desde a dimensão biológica, com a carga de problemas relacionados à função reprodutiva, até a dimensão política relacionada à divisão do poder na sociedade.

Gênero, como construção social, consiste em um sistema multinível, incluindo arranjos econômicos e políticos e crenças culturais na dimensão macrossocial, padrões de comportamento na dimensão intermediária e aspectos ligados à identidade individual na dimensão microssocial. Esta estrutura multidimensional se traduz para os indivíduos em identidades de homens e mulheres que estão engajados em papéis familiares e sociais diversos.

A equidade de gênero não implica a igualdade entre homens e mulheres, seja no estado de saúde, seja no consumo de serviços de saúde, mas o atendimento equitativo das necessidades de homens e mulheres. Para a população brasileira não parece haver discriminação dos serviços de saúde quanto ao gênero, visto que a maior utilização pelas mulheres parece acompanhar o estado de saúde e a maior atenção que elas costumam dar à sua saúde. Entretanto, caberia investigar até que ponto a existência de políticas de saúde voltadas principalmente para a saúde reprodutiva das mulheres pode estar influenciando essa maior utilização. 


\section{$6 \mid$ Políticas para o Enfrentamento
Das Desigualdades}

A abordagem coletiva ou populacional do processo saúdedoença na perspectiva da epidemiologia social implica fazer algumas perguntas básicas sobre como são produzidas as doenças na população, que forças determinam sua distribuição, por que alguns indivíduos adoecem e outros não, e quais são as maneiras pelas quais as políticas públicas podem interferir nesses processos.

Para compreender o processo de determinação das doenças e ter elementos para a intervenção através de políticas públicas desenhadas para alcançar a modificação das condições de produção e de distribuição dos problemas de saúde, é necessário inicialmente tratar dos modelos de causalidade em uso pela epidemiologia.

$\mathrm{Na}$ abordagem convencional dos modelos multicausais, cada variável ou fator de risco é analisado inicialmente em sua associação com o desfecho de interesse, ou seja, com a doença ou problema de saúde em estudo. Na pesquisa anteriormente citada da associação entre idade materna, hábito de fumar das mães e classe social como fatores de risco para baixo peso ao nascer, a abordagem multicausal - que não foi a adotada pelos autores, mas que podemos utilizar apenas a título de exemplificação indicaria ao final dos ajustes a importância de cada uma dessas variáveis (Tabela 7). 
Tabela 7 - Incidência de baixo peso e risco relativo segundo características maternas. Ribeirão Preto (SP) - 1978-1979

\begin{tabular}{l|cc}
\hline Fatores de risco & $\begin{array}{c}\text { Incidência } \\
\text { (casos por 100) }\end{array}$ & RR \\
\hline Idade materna & \multicolumn{2}{l}{} \\
\hline$<20$ anos & 9,38 & 1,52 \\
\hline$\geq 20$ anos & 6,15 & 1,00 \\
\hline Hábito de fumar da mãe & & 1,77 \\
\hline Fumante & 9,62 \\
\hline Não fumante & 5,43 \\
\hline Pobreza & & \\
\hline Pobres & & \\
\hline Não pobres & 7,35 & 2,35 \\
\hline
\end{tabular}

Fonte: Silva et al., 1992.

A análise dos dados permite afirmar que as mães adolescentes que fumam e são pobres apresentam maior risco de ter recémnascidos com baixo peso quando comparadas a mães com 20 anos ou mais de idade, não fumantes e não pobres. Consequentemente, se a idade materna é um fator de risco, as políticas para redução do baixo peso ao nascer devem incluir ações visando a diminuir a gravidez na adolescência. Do mesmo modo, se o hábito de fumar é um fator de risco, será necessário que as mães deixem de fumar para reduzir a incidência de baixo peso e, finalmente, se a pobreza também está relacionada, será preciso usar políticas compensatórias que possibilitem melhor alimentação durante a gestação para evitar o baixo peso. Teríamos assim um conjunto de intervenções educativas, de controle da gravidez na 
adolescência, redução do hábito de fumar e de suplementação alimentar para enfrentar o problema.

Sabemos que na realidade as mesmas mães podem apresentar as três características analisadas, e que tratá-las separadamente pode não ser a melhor estratégia para o enfrentamento do problema.

Segundo Leonard Syme, do Departamento de Epidemiologia Social de Berkeley (EUA), há três problemas principais na prática em saúde pública. Primeiro, gastamos muito tempo tentando identificar fatores de risco, mas todos somados explicam menos da metade da ocorrência das doenças. Além disso, mesmo quando as pessoas conhecem os fatores de risco, elas têm dificuldade em mudar seu comportamento e, ainda que algumas delas mudem o comportamento, haverá sempre outras pessoas entrando na população. Em segundo lugar não podemos imaginar que a promoção de saúde seja possível com enfoque exclusivo nos fatores de risco e nas doenças. O terceiro aspecto é que a tarefa mais importante é a identificação dos determinantes de saúde, e o principal determinante é a classe social.

No modelo de determinação social do processo saúde-doença, as variáveis seriam tratadas através de um modelo hierárquico, no qual o principal determinante é a classe social (em vez do nível de pobreza). A inserção de classe determina igualmente as chances de ocorrência de uma gravidez na adolescência (idade materna) e a de ser fumante, e ambas as variáveis intermediárias determinam a probabilidade de ter um recém-nascido de baixo peso. Deste modo, as variáveis são tratadas de maneira articulada (Tabela 8). 
Tabela 8 - Incidência de baixo peso ao nascer segundo a classe social e o hábito de fumar maternos. Ribeirão Preto (SP) - 1978-1979

\begin{tabular}{l|cc}
\hline Classe social & Mães fumantes & Mães não fumantes \\
\hline Burguesia & 4,36 & 2,67 \\
\hline Proletariado & 9,52 & 5,93 \\
\hline Subproletariado & 12,77 & 6,27 \\
\hline
\end{tabular}

Fonte: Silva et al., 1992.

Ambos os fatores são considerados determinantes, entretanto, se observarmos a combinação de ambas as variáveis, veremos que a determinação exercida pela classe social subordina a atuação do hábito de fumar como fator de risco. Assim, mesmo que todas as mães deixassem de fumar, continuaria havendo desigualdade no risco de ter recém-nascidos de baixo peso, na medida em que as diferenças de classe social continuariam a existir.

Comparando os resultados obtidos em cada uma das abordagens, verificamos que ambas apontam os fatores analisados como fatores de risco, mas o modelo multicausal não permite detectar a hierarquia entre eles e induz à adoção de medidas que não serão totalmente eficazes, exatamente por ignorar a complexidade das relações entre as variáveis.

Dentre os modelos de determinação social do processo saúde-doença, duas formulações atuais merecem destaque pela abordagem complexa dos distintos níveis de organização da vida social que representam: o modelo do modo de vida elaborado por Naomar de Almeida Filho e o proposto pela comissão de Determinantes Sociais em Saúde da Organização Mundial da Saúde (OMS). 
O primeiro modelo reúne as esferas de produção e da reprodução material e simbólica da sociedade, o modo de vida dos grupos sociais, o processo de trabalho, a estrutura de classes, as práticas cotidianas e a construção cultural como determinantes das configurações de risco que se acoplam ao perfil de saúdedoença-cuidado no âmbito populacional.

O segundo modelo destaca cada um dos aspectos mais relevantes das dimensões apontadas no modelo do modo de vida, visando a facilitar a identificação de possíveis áreas de intervenção para as políticas sociais que busquem a redução das desigualdades.

A Comissão de Determinantes Sociais em Saúde define estes determinantes como o conjunto das condições sociais nas quais as pessoas vivem e trabalham e que podem ser alteradas pela ação das políticas públicas. Uma sociedade justa é aquela que é capaz de prover a todos os cidadãos um alto grau de liberdade para escolher dentre as opções de vida aquelas que se ajustem à concepção de 'vida boa'. A meta de qualquer política equânime não deve ser simplesmente igualar o estado de saúde para os diferentes grupos sociais, mas sim buscar igualdade de oportunidades de saúde.

O contexto social determina a cada indivíduo sua posição e esta, por sua vez, determina as oportunidades de saúde segundo exposições a condições nocivas ou saudáveis e segundo situações distintas de vulnerabilidade.

Há pelo menos três níveis distintos de ação política para a redução das desigualdades, dependendo do contexto político e social em cada país. O enfrentamento das desigualdades sociais em saúde pode incluir políticas macrossociais, tais como políticas 
econômicas e sociais que modifiquem a estratificação social; políticas que modifiquem as condições de exposição e vulnerabilidade dos grupos sociais; ou políticas de saúde que atuem sobre as consequências negativas das desigualdades, buscando minimizar o impacto de seus efeitos.

Navarro e colaboradores demonstram que, dependendo da duração dos governos e das características dos partidos no governo, nos países europeus, entre 1950 e 2000, os gastos sociais e com saúde, bem como as consequências sobre o nível de saúde das populações foram bastante diversos (Tabela 9).

Tabela 9 - Concentração de renda, gasto social e gasto em saúde dos países europeus segundo partidos que permaneceram por mais tempo no governo. Europa - 1950-2000

\begin{tabular}{l|ccc}
\hline Governos & $\begin{array}{c}\text { Coeficiente } \\
\text { Gini }\end{array}$ & $\begin{array}{c}\text { Gasto social } \\
(\%)\end{array}$ & $\begin{array}{c}\text { Gasto em } \\
\text { saúde }(\%)\end{array}$ \\
\hline Social-democratas & 0,225 & 30,0 & 7,2 \\
\hline Democracia cristã & 0,306 & 28,0 & 6,4 \\
\hline $\begin{array}{l}\text { Liberal } \\
\text { conservadores }\end{array}$ & 0,320 & 24,0 & 5,8 \\
\hline Ditatoriais & 0,420 & 14,0 & 4,8 \\
\hline
\end{tabular}

Fonte: Navarro et al., 2006.

As políticas redistributivas, praticadas principalmente pelos governos social-democratas, estão positivamente associadas com menor mortalidade infantil e maior esperança de vida. A taxa de mortalidade infantil apresenta correlação negativa com a quantidade de anos de governo social-democrata e com o nível de distribuição da renda; a implementação de políticas sociais desenhadas para reduzir desigualdades está 
associada com baixas taxas de mortalidade infantil; e existe correlação negativa entre desigualdade de renda e esperança de vida para homens e mulheres.

Os princípios para a ação política devem ser o compromisso ético com a equidade; a abordagem baseada em evidências científicas; a preocupação com todo o gradiente de desigualdades, e não apenas com os extremos da distribuição ou com as diferenças individuais; a atuação na vida cotidiana, pois é nela que experimentamos o impacto da estrutura social; e a consciência de que as evidências são importantes, mas há outros ingredientes na tomada de decisão, dentre as quais talvez a mais relevante seja a vontade de transformar as evidências disponíveis em estratégias para a ação.

As experiências levadas a efeito para promover a equidade em saúde incluem políticas de redução da desigualdade de renda e de redução da pobreza, políticas fiscais progressivas, controle sobre o capital volátil, perdão da dívida e novas fórmulas de cálculo baseadas na atenção às necessidades básicas, políticas de redução da vulnerabilidade e investimentos em saúde.

A definição da saúde como bem público significa que o consumo dos serviços e práticas de saúde não é exclusivo de um indivíduo, nem seu uso por um indivíduo rivaliza com o consumo por outros. Há inúmeros exemplos de bens públicos nas ações de saúde, tais como os programas de controle das doenças transmissíveis, a produção de conhecimentos científicos em saúde, a regulação de produtos com impacto sobre a saúde, e a organização de sistemas universais de saúde.

No nível de atuação intermediário, estão as intervenções que têm como objetivo a modificação das condições de exposição e vulnerabilidade dos diferentes grupos sociais. Como exemplo de 
atuação setorial para reduzir a vulnerabilidade social dos grupos em piores condições socioeconômicas, podemos analisar o efeito dos investimentos realizados no Programa de Saúde MaternoInfantil, tanto na atenção primária quanto na assistência hospitalar, pela prefeitura de Belo Horizonte, visando a reduzir os diferenciais intraurbanos na mortalidade infantil (Tabela 10).

Tabela 10 - Gastos do orçamento participativo e administrativo, diferenciais de mortalidade infantil (MI) segundo distritos de saúde (DS) ordenados por condições de vida. Belo Horizonte 1994 e 1997

\begin{tabular}{|c|c|c|c|c|c|}
\hline \multirow[t]{2}{*}{ DS } & \multirow{2}{*}{$\begin{array}{c}\text { Gasto per } \\
\text { capita } \\
(\mathrm{R} \$)\end{array}$} & \multirow{2}{*}{$\begin{array}{c}\text { Orçamento } \\
\text { participativo } \\
\text { per capita } \\
\text { (R\$) }\end{array}$} & \multirow{2}{*}{$\begin{array}{c}\text { Orçamento } \\
\text { administrativo } \\
\text { per capita } \\
(\mathrm{R} \$)\end{array}$} & \multicolumn{2}{|c|}{$\begin{array}{c}\text { Diferenciais } \\
\text { de MI }\end{array}$} \\
\hline & & & & 1994 & 1997 \\
\hline Pampulha & 23,00 & 21,00 & 2,00 & 0,61 & \\
\hline & & & & & $0,00^{*}$ \\
\hline Nordeste & 33,00 & 17,00 & 16,00 & 0,74 & 0,64 \\
\hline Barreiro & 47,00 & 14,00 & 33,00 & 0,78 & 0,06 \\
\hline $\begin{array}{l}\text { Venda } \\
\text { nova }\end{array}$ & 34,00 & 21,00 & 14,00 & 0,90 & 0,09 \\
\hline
\end{tabular}

* Taxa de referência

Fonte: Junqueira et al., 2002.

Os dados apresentados na Tabela 10 referem-se exclusivamente a quatro dos distritos sanitários. Os diferenciais de mortalidade infantil foram calculados com relação à taxa de mortalidade infantil observada no distrito da Pampulha em 1997 (taxa de 17,7 óbitos por 1.000 nascidos vivos). Os diferenciais calculados para 1994 mostram gradiente nítido entre os distritos segundo as condições de vida. Com vistas a reduzir essas 
brechas, o governo municipal optou por realizar investimentos diferenciados, destinando mais recursos para os distritos com maiores necessidades (orçamento administrativo). Simultaneamente, a distribuição de recursos para as diferentes políticas sociais foi objeto de discussão e deliberação pelo orçamento participativo. Chama a atenção o fato de que no orçamento participativo foram destinados mais recursos para o Programa Materno-Infantil, tanto no distrito com piores condições de vida quanto naquele com as melhores condições de vida.

Após quatro anos, houve redução nas brechas de mortalidade para os dois distritos com piores condições de vida e também para o distrito com melhores condições de vida, enquanto o distrito em situação intermediária mostrou pequena redução. Este tipo de política setorial redistributiva logrou reduzir as desigualdades sociais em saúde, diminuindo a vulnerabilidade de grupos sociais que apresentavam inserção social mais precária.

O Programa Nacional de Imunizações (PNI) pode ser tomado como outro exemplo de política setorial voltada para esse fim. Ele associa uma atuação universal através do fornecimento de vacinas de forma continuada nos serviços de atenção primária com a realização de 'dias nacionais de vacinação', promovidos para abranger parcelas da população que, por diferentes motivos, não conseguem utilizar de maneira apropriada os serviços regulares de saúde.

O programa fornece gratuitamente vacinas contra dez doenças através de uma ampla rede de serviços distribuídos em todo o território nacional. Apesar do PNI ser bastante abrangente e totalmente gratuito, a cobertura vacinal apresenta diferença entre os estratos socioeconômicos da população. Ela é satisfatória para 
os estratos B, C e D, com valores médios acima de 95\%, mas é significativamente menor nos extremos da distribuição, ficando abaixo de $90 \%$ nos estratos A e E.

No estrato A, mais da metade das crianças é vacinada em serviços privados de saúde, sugerindo que a menor cobertura não é motivada por dificuldades de acesso. Nesse estrato os pais escolhem as vacinas que desejam aplicar nos filhos, ponderam entre o risco de adquirir a doença e o risco de efeitos colaterais após a aplicação da vacina. Além disso, têm acesso a informações pela Internet ou em revistas de vulgarização do conhecimento científico e geralmente valorizam negativamente as vacinas tradicionais, considerando-as desnecessárias em sua classe social.

No estrato E, as razões para a menor cobertura são muito diferentes. Parte das famílias é constituída por migrantes, recém-chegados à cidade, com inserção social precária, o que dificulta o uso dos equipamentos sociais existentes, sem documentação das crianças, sem conhecimento sobre os direitos sociais e a gratuidade dos serviços. Uma parte dessas famílias é chefiada por mulheres que necessitam trabalhar para o próprio sustento e o de seus filhos, não dispondo de tempo para frequentar os serviços de atenção primária e manter os filhos adequadamente vacinados.

Assim, mesmo um programa de ampla abrangência como o de imunizações não consegue em sua execução superar todas as desigualdades geradas na estrutura social. $\mathrm{O}$ fato de pertencer a uma determinada classe ou estrato social significa não apenas poder desfrutar de determinadas condições materiais, mas também acaba por moldar toda uma visão de mundo com complexas implicações para a saúde. 
Finalmente, é preciso considerar iniciativas que, não tendo abrangência suficiente para modificar a estratificação social, nem para modificar as condições de vulnerabilidade dos diferentes grupos, destinam-se a mitigar as desigualdades sociais através da oferta de serviços de saúde.

Há uma preocupação crescente não apenas em desenhar e implementar sistemas de saúde capazes de proteger as famílias dos efeitos catastróficos das doenças, mas também em que a atuação dos serviços e profissionais de saúde não aumentem ainda mais as desigualdades sociais, através de ações que estigmatizem ou discriminem grupos de indivíduos segundo idade, sexo, etnia, preferência sexual, religião, condição econômica ou outras características.

Na pesquisa mundial de saúde realizada no Brasil, a proporção de indivíduos que disse haver sido vítima de comportamentos discriminatórios nos serviços ambulatoriais de saúde foi relativamente pequena, exceto para discriminação de classe social ou econômica. Cerca de 11\% das pessoas atendidas em serviços do SUS e $5 \%$ das pessoas atendidas em serviços privados de saúde mencionaram ter sofrido discriminação por falta de dinheiro, enquanto $9 \%$ e $5 \%$, respectivamente, citaram discriminação de classe social.

A discriminação relacionada à cor da pele, idade, sexo ou tipo de doença foi referida por menos de $2 \%$ dos indivíduos nos dois grupos, não apresentando diferenças significantes entre eles. Apenas $0,3 \%$ dos entrevistados mencinou haver sido discriminado por sua nacionalidade.

A existência de um sistema nacional de saúde com acesso universal é uma precondição para buscar a redução das desigualdades 
sociais através do atendimento às necessidades de saúde de todos os grupos da população.

O Gráfico 2 mostra a proporção de mulheres que iniciaram o atendimento pré-natal no primeiro trimestre de gestação segundo a cor da pele, no Brasil e na África do Sul. Pode-se notar que, embora no Brasil existam diferenças nas proporções observadas para brancas, negras e mulatas, elas são bem menores do que aquelas observadas na África do Sul. Após o ajuste por variáveis sociodemográficas, disponibilidade de serviços e necessidades percebidas, as diferenças por cor deixam de ser significantes no Brasil.

Gráfico 2 - Início do pré-natal no primeiro trimestre segundo cor. Brasil e África do Sul - 1996

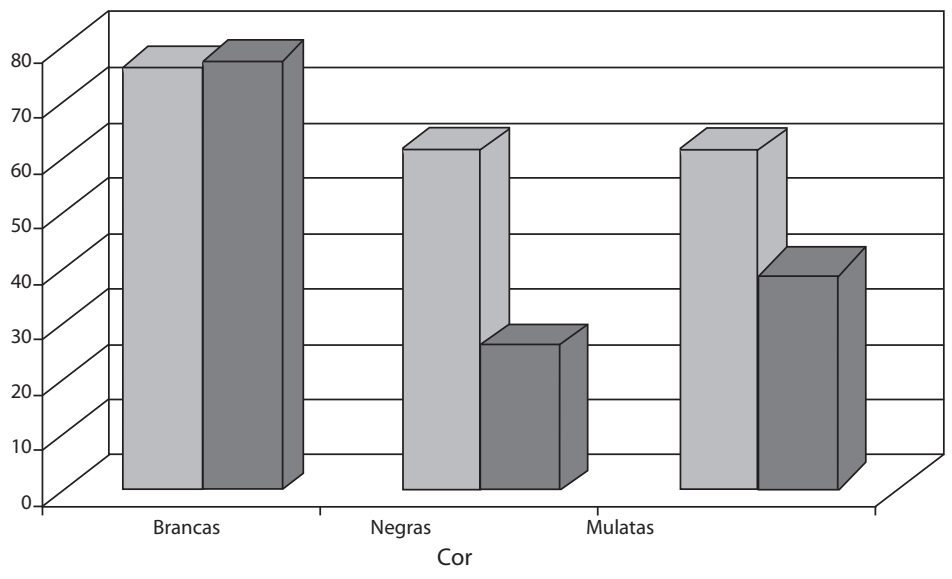

$\square$ Brasil $\square$ África do Sul

Fonte: Adaptado de Burgard, 2004. 
Além do sistema nacional de saúde com acesso universal, é preciso que exista distribuição adequada de serviços e de equipamentos no território, para que os mesmos possam ser utilizados pelos indivíduos que deles necessitam independentemente das condições socioeconômicas, gênero, etnia e outras particularidades.

Os profissionais de saúde precisam estar adequadamente habilitados para garantir a qualidade técnica e humana do atendimento, e os serviços precisam estar organizados para responder às necessidades de saúde. 



\section{CONSIDERAÇões Finais}

A redução das desigualdades sociais em saúde não é uma tarefa fácil, e nem sempre as boas intenções resultam em intervenções com o impacto esperado. Como afirma Fernando Lolas, diretor do programa de bioética da Organización Panamericana de la Salud (OPS) e professor da Universidade do Chile,

embora cada indivíduo separadamente não possa conseguir ou garantir a equidade, valor que se realiza e aperfeiçoa no coletivo, pode não obstante reconhecer e estimular sua manifestação (...) e assim encontrará um sentido para ser feliz, de ordem superior e distinto daquele que nos dá a satisfação de nossas próprias necessidades.

Reconhecer as desigualdades sociais em saúde, buscar compreender os processos que as produzem e identificar os diferentes aspectos que estabelecem a mediação entre os processos macrossociais e o perfil epidemiológico dos diferentes grupos sociais é uma condição indispensável para que seja possível buscar formas de enfrentamento, sejam elas no âmbito das políticas públicas, sejam elas no âmbito da vida cotidiana.

A epidemiologia é apenas uma das disciplinas do campo da saúde coletiva a se preocupar com a temática das desigualdades sociais. Há diversas abordagens dessa mesma temática no âmbito das ciências sociais em saúde e também relativas ao financiamento e à organização dos serviços de saúde. 
A confluência desses saberes de distintas fontes, aliada ao imperativo ético de buscar a construção de uma sociedade mais justa, na qual os indivíduos não sejam inferiorizados em função de qualquer diferença que apresentem em relação à norma, pode resultar em maior comprometimento dos profissionais da saúde coletiva com a formulação e implementação de políticas de saúde mais equânimes.

Há inúmeros desafios relacionados com a questão das desigualdades sociais em saúde. Em primeiro lugar, podemos assinalar o desafio, no plano teórico, de formular explicações consistentes para os dados empíricos obtidos em nossas pesquisas. Em segundo lugar, podemos mencionar o desafio metodológico. Todas as categorias de análise utilizadas no estudo das desigualdades sociais em saúde - classe social, estratificação ocupacional, educacional ou de renda, etnia, gênero - necessitam permanente desenvolvimento conceitual e aprimoramento em sua operacionalização para utilização em pesquisas empíricas.

Ainda enfocando desafios relacionados com a produção de conhecimentos, constata-se a necessidade de desenvolver indicadores apropriados, seja para mensurar os fenômenos sociais, seja para mensurar os resultados deles sobre a saúde, bem como de elaborar técnicas de análise estatística capazes de refletir a complexidade e a estrutura hierárquica desses processos.

No âmbito das práticas, os desafios são ainda maiores em decorrência da natural limitação do campo de atuação do setor saúde. Evidentemente, a superação das desigualdades sociais em saúde requer um conjunto de políticas e processos de transformação social que vão muito além do escopo de atuação do setor. No entanto, é possível iniciar pela própria política de saúde, a 
transformação necessária visando pelo menos a minorar os efeitos danosos da desigualdade gerada na organização social.

A implementação e o aprimoramento contínuo do SUS, com o fim de tornar realidade os princípios da universalidade, integralidade e equidade, fazem parte deste esforço para minorar as desigualdades sociais em saúde

Como cidadãos, entretanto, outras frentes de luta podem-se abrir com o objetivo de repudiar todas as formas de preconceito e discriminação. A atuação política - desde o plano cotidiano até o exercício do direito do voto, na escolha de dirigentes comprometidos com princípios verdadeiramente democráticos e de respeito às diferenças, e que considerem inaceitável o perpetuar das enormes desigualdades sociais na população brasileira também é uma forma de tentar realizar o ideal expresso na citação de Fernando Lolas com a qual iniciamos estas considerações finais. 



\section{Bibliografia}

ALMEIDA-FILHO, N. Modelos de determinação social das doenças crônicas não-transmissíveis. Ciência \& Saúde Coletiva, 9 (4): 865-884, 2004.

BRAVEMAN, P. Health disparities and health equity: concepts and measurement. Annual Review of Public Health, 27(18): 1-28, 2006.

BURGARD, S. Race and pregnancy-related care in Brazil and South Africa. Social Science \& Medicine, 59: 1127-1146, 2004.

COOPER, H. Investigating socio-economic explanations for gender and ethnic inequalities in health. Social Science \& Medicine, 54: 693706, 2002.

JUNQUEIRA, V. et al. Equidad en la salud: evaluación de políticas públicas en Belo Horizonte, Minas Gerais, Brasil, 1993-1997. Cadernos de Saúde Pública, 18(4): 1087-1101, 2002.

KAWACHI, I.; SUBRAMANIAN, S. V. \& ALMEIDA-FILHO, N. A glossary for health inequalities. Journal of Epidemiol. Community Health, 56: 647-652, 2002.

KRIEGER, N. Theories for social epidemiology in the $21^{\text {st }}$ century: an ecosocial perspective. International Journal of Epidemiology, 30: 668-677, 2001.

KRIEGER, N. \& DAVEY-SMITH, G. Bodies count and body counts: social epidemiology and embodying inequality. Epidemiol. Rev., 26:92-103, 2004.

LEAL, M. C.; GAMA, S. G. N. \& CUNHA, C. B. Desigualdades raciais, sociodemográficas e na assistência ao pré-natal e ao parto, 19992001. Revista de Saúde Pública, 39(1): 100-107, 2005. 
MECHANIC, D. Population health: challenges for science and society. The Milbank Quarterly, 85(3):533-559, 2007.

MONTEIRO, C. A.; FREITAS, I. C. M. \& BARATHO, R. M. Saúde, nutrição e classes sociais: o nexo empírico evidenciado em um grande centro urbano, Brasil. Revista de Saúde Pública, 23(5): 422-428, 1989.

NAVARRO, V. \& SHI, L. The political context of social inequalities and health. International Journal of Health Services 31(1): 1-21, 2001.

NAVARRO V. et al. Politics and health outcomes. The Lancet, 368: 1033-1037, 2006.

NOVAES, H. M. D.; BRAGA, P. E. \& SCHOUT, D. Fatores associados à realização de exames preventivos para câncer nas mulheres brasileiras, Pnad 2003. Ciência \& Saúde Coletiva, 11(4): 1023-1035, 2006.

ROHLFS, I. et al. The incorporation of gender perspective into Spanish health surveys. Journal of Epidemiol. Community Health, 61(suppl. II): 20-25, 2007.

SCHRAIBER, L. B. et al. Prevalência da violência contra a mulher por parceiro íntimo em regiões do Brasil. Revista de Saúde Pública, 41(5): 797-807, 2007.

SILVA, A. A. M. et al. Associação entre idade, classe social e hábito de fumar maternos com peso ao nascer. Revista de Saúde Pública, 26(3): 150-154, 1992.

STARFIELD, B. Pathways of influence on equity in health. Social Science \& Medicine, 64: 1355-1362, 2007.

STEPKE, F. L. \& DRUMMOND, J. G. F. Fundamentos de uma Antropologia Bioética. São Paulo: Edições Loyola, 2007.

SYME, S. L. Social determinants of health: the community as an empowered partner. Preventing Chronic Disease, 1(1): 1-5, 2004.

WILLIANS, D. R. Patterns and causes of disparities in health. In: MECHANIC, D.; LYNN, B. R. \& COLBY, D. C. (Eds.) Policy Challenges in Modern Health Care. New Jersey: Rutgers University Press, 2005. 


\section{Sugestões de Leituras}

BARATA, R. B. Desigualdades sociais em saúde. In: CAMPOS, G. W. S. et al. (Orgs.) Tratado de Saúde Coletiva. São Paulo, Rio de Janeiro: Hucitec, Editora Fiocruz, 2006.

Apresenta de forma didática as principais questões relativas às desigualdades sociais em saúde. Cada tópico é ilustrado com exemplos, e o caráter didático do texto facilita a compreensão de questões teóricas e metodológicas para aqueles que estão fazendo uma primeira aproximação com o tema.

BREILH, J. La Inequidady la Perspectiva de los Sin Poder: construcción de lo social y del género-cuerpos, diferencias y desigualdades. Bogotá: Utópica Ediciones, 1998.

Aborda a questão da determinação social do processo saúdedoença, destacando principalmente os desequilíbrios de poder entre as distintas classes sociais e entre gêneros.

CASTELLANOS, P. L. Epidemiologia, saúde pública, situação de saúde e condições de vida: considerações conceituais. In: BARATA, R. B. (Org.) Condições de Vida e Situação de Saúde. Rio de Janeiro: Abrasco, 1997.

Discute aspectos conceituais centrais para questão das desigualdades em saúde, não apenas em sua dimensão descritiva, mas, principalmente, na dimensão interpretativa. $\mathrm{O}$ autor apresenta claramente a diferença entre uma abordagem populacional e a 
abordagem individuada, que tem predominado nas pesquisas epidemiológicas

HOFRICHTER, R. (Ed.) Health and Social Justice. San Francisco: John Wiley \& Sons, 2003.

Pode ser visto como um tratado de epidemiologia social em que as várias dimensões das desigualdades são abordadas por diferentes autores. É um balanço da produção nos países desenvolvidos selecionando pesquisadores mais críticos. Num certo sentido pode ser considerado como um contraponto ao livro organizado por Kawachi e Berkman.

KAWACHI, I. \& KENNEDY, B. P. The Health of Nations: why inequality is harmful to your health. New York: New Press, 2002.

Escrito numa linguagem acessível e agradável, apresenta dados muito interessantes sobre o processo acelerado de crescimento das desigualdades entre países a partir da década de 1990.

MARMOT, M. \& WILKINSON, R. G. Social Determinants of Health. London: Oxford Press, 1999.

É um clássico do tema dos determinantes sociais em saúde, embora haja algum desequilíbrio entre seus capítulos. De todo modo, tenta abarcar, com uma visão pragmática, as várias dimensões da determinação da saúde e da doença.

PAIM, J. S. Abordagens teórico-conceituais em estudos de condições de vida e saúde: notas para reflexão e ação. In: BARATA, R. B. (Org.) Condições de Vida e Situação de Saúde. Rio de Janeiro: Abrasco, 1997.

Escrito para um seminário da Comissão de Epidemiologia da Abrasco, este capítulo é um excelente material sobre questões conceituais no campo dos determinantes sociais em saúde. A leitura é densa, mas bastante clara. 
POULANTZAS, N. As Classes Sociais no Capitalismo de Hoje. São Paulo: Zahar Editores, 1978.

Embora relativamente antigo, é um clássico da discussão das classes sociais nas sociedades ocidentais. Este texto tem iluminado a produção no campo da sociologia e também foi muito utilizado por autores da epidemiologia social latino-americana, nas diversas tentativas de operacionalização do conceito para uso em estudos epidemiológicos

SAMAJA, J. A Reprodução Social e a Saúde: elementos teóricos e metodológicos sobre a questão das relações entre saúde e condições de vida. Salvador: Casa da Saúde, 2000.

Estimulado por uma reunião realizada na cidade de Salvador com o objetivo de aprofundar aspectos teóricos e metodológicos dos estudos de desigualdades sociais em saúde, Juan Samaja escreveu esta pequena jóia para compreender o conceito de reprodução social. Além de um filósofo muito culto e inspirado, era também um excelente metodólogo. A leitura é densa mas vale a pena.

WILKINSON, R. G. Unhealtby Societies: the afflictions of inequality. London: Routledge, 1996.

Outro clássico dos estudos de determinação social, este livro traz uma série de evidências que ajudam a compreender por que as desvantagens relativas são tão importantes para a saúde quanto o nível de privação econômica e social.

WHO (World Health Organization). Commission on Social Determinants of Health. A Conceptual Framework for Action on the Social Determinants of Health. Discussion Paper, 2007.

Este documento da Comissão de Determinantes Sociais em Saúde da WHO/OMS, embora não constitua uma publicação 
formal, é acessível no site da organização e apresenta a discussão mais conceitual que orientou os trabalhos da mesma. Além disso, traz a discussão das alternativas de políticas públicas possíveis no enfrentamento das desigualdades. 
Formato: $12,5 \times 18 \mathrm{~cm}$

Tipologia: Letter Gothic e Garamond

Papel: Off Set $75 \mathrm{~g} / \mathrm{m} 2$ (miolo)

Cartão Supremo $250 \mathrm{~g} / \mathrm{m} 2$ (capa)

CTP, impressão e acabamento: Imo's Gráfica e Editora Ltda.

Rio de Janeiro, maio de 2012

Não encontrando nossos títulos em livrarias, contactar a Editora Fiocruz:

Av. Brasil, 4036 - térreo - sala 112 - Manguinhos

21040-361 - Rio de Janeiro - RJ

Tel.: (21) 3882-9039 e 3882-9041

Telefax: (21) 3882-9006

http://www.fiocruz.br/editora

e-mail: editora@fiocruz.br 



\section{Como e Por Que as \\ Desigualdades Sociais Fazem Mal à Saúde}




\section{FUNDAÇÃO OSWALDO CRUZ}

Presidente

Paulo Ernani Gadelha Vieira

Vice-Presidente de Ensino, Informação e Comunicação

Nísia Trindade Lima

\section{EDITORA FIOCRUZ}

\section{Diretora}

Nísia Trindade Lima

Editor Executivo

$$
\text { João Carlos Canossa Mendes }
$$

Editores Científicos

Gilberto Hochman

Ricardo Ventura Santos

Conselho Editorial

Ana Lúcia Teles Rabello

Armando de Oliveira Schubach

Carlos E. A. Coimbra Jr.

Gerson Oliveira Penna

Joseli Lannes Vieira

Ligia Vieira da Silva

Maria Cecília de Souza Minayo

Coleção Temas em Saúde

Editores Responsáveis

Maria do Carmo Leal

Nísia Trindade Lima

Ricardo Ventura Santos 
RITA BARRADAS BARATA

\section{Como e Por Que as Desigualdades Sociais Fazem Mal à Saúde}

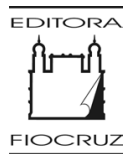


Copyright (C) 2009 da autora

Todos os direitos desta edição reservados à

FUNDAÇÃO OSWALDO CRUZ / EDITORA

ISBN: 978-85-7541-184-1

$1^{a}$ edição: 2009

$1^{\text {a }}$ reimpressão: 2012

Capa e projeto gráfico

Carlota Rios

Editoração

Robson Lima

Revisão

Cláudia Dias Sampaio

Catalogação na fonte

Instituto de Comunicação e Informação Científica e Tecnológica em Saúde/Fiocruz Biblioteca de Saúde Pública

N318s Barata, Rita Barradas

Como e Por Que as Desigualdades Sociais

Fazem Mal à Saúde. / Rita Barradas Barata. Rio de

Janeiro: Editora Fiocruz, 2009.

120 p. (Coleção Temas em Saúde)

1. Saúde Bucal. 2. Boca Edentada. 3. Atenção à Saúde. 4.

Direito à Saúde. 5. Sistema Único de Saúde.

I. Frazão, Paulo. II. Título. III. Série.

$$
\text { CDD - 21.ed. - } 617.601
$$

2012

EDITORA FIOCRUZ

Av. Brasil, 4036 - Térreo - sala 112 - Manguinhos

21040-361 - Rio de Janeiro - RJ

Tels.: (21) 3882-9039 / 3882-9041

Telefax: (21) 3882-9006

e-mail: editora@fiocruz.br

http://www.fiocruz.br 


\section{SUMÁRIO}

Apresentação

1. O que queremos dizer com desigualdades sociais em saúde?

2. A posição social e seus reflexos sobre a saúde

3. Ser rico faz bem à saúde?

4. As desigualdades étnicas necessariamente significam racismo?

5. Relações de gênero e saúde: desigualdade ou discriminação?

6. Políticas para o enfrentamento das desigualdades

Consideracões finais

Bibliografia 



\section{Apresentação}

Meu interesse pela temática das desigualdades sociais em saúde é relativamente antigo. Desde os tempos da faculdade, o interesse pelas ciências sociais e pela epidemiologia me fez buscar articular esses saberes para melhor compreender o processo saúde-doença em sua dimensão coletiva.

A temática das desigualdades sociais em saúde esteve sempre presente na minha trajetória como investigadora do campo da epidemiologia social. Ainda na etapa de elaboração da dissertação de mestrado, sob a influência da professora Cecília Donnangelo e do meu orientador, professor José da Silva Guedes, decidi estudar o comportamento de uma epidemia de doença meningocóccica, analisando o surgimento e a disseminação do processo segundo distritos da cidade de São Paulo classificados por diferentes condições de vida. O trabalho acabou virando livro ainda na década de 1980.

Na década seguinte, organizei em São Paulo um seminário ibero-americano sobre a temática das condições de vida e a situação de saúde, que resultou em uma publicação pela Abrasco dos trabalhos ali apresentados. Esta publicação teve enorme repercussão e circulação no âmbito da saúde coletiva em vários países da América Latina.

Mais recentemente, escrevi o capítulo sobre desigualdades sociais em saúde para o tratado de saúde coletiva organizado por 
Gastão Campos, Maria Cecília Minayo, Marco Akerman, Marcos Drumond e Yara Carvalho, publicado em parceria pela Abrasco e Hucitec.

Assim, pareceu-me perfeitamente natural preparar este volume para a coleção Temas em Saúde da Editora Fiocruz. Vocês verão que este texto apresenta algumas particularidades decorrentes do caráter da coleção. O livro está apresentado em um estilo mais leve, que facilite a leitura e permita, mesmo para leitores não especializados, uma visão panorâmica sobre o assunto. Também para respeitar o formato adotado tentei reduzir ao máximo as tabelas e os gráficos, normalmente mais freqüentes em textos de epidemiologia. Ainda de acordo com o padrão da coleção a que pertence, este livro não contém referências ou notas de rodapé comuns em textos científicos. Todas essas características visam a tornar a leitura mais agradável. Ao final do texto os leitores poderão encontrar uma breve lista de textos e também um conjunto de leituras recomendadas para aqueles que pretenderem aprofundar seus conhecimentos no tema.

Como e Por Que as Desigualdades Sociais Fazem Mal à Saúde está assim constituído. O primeiro capítulo apresenta de forma breve algumas considerações teóricas sobre o tema das desigualdades sociais em saúde, apontando as correntes e tendências existentes na pesquisa epidemiológica sobre o tema. O segundo trata da questão das classes sociais, ou seja, como a posição social de cada indivíduo repercute sobre sua saúde. O terceiro enfoca o tema da renda, isto é, as relações entre riqueza e estado de saúde. O quarto introduz a discussão sobre etnia e discriminação, como categorias importantes de análise no estudo de desigualdades sociais em saúde. No quinto capítulo o destaque é dado às relações 
de gênero e à produção da saúde e da doença. O sexto capítulo comenta as políticas públicas no enfrentamento das desigualdades sociais. Por último, apresentam-se algumas considerações e conclusões.

Boa leitura! 



\section{Que Queremos Dizer com Desigualdades Sociais em Saúde?}

Embora a resposta pareça óbvia, na verdade, não é bem assim... Muitos tentam esvaziar o conteúdo político e as conotações de injustiça social e desrespeito aos direitos humanos expressos nessas desigualdades, reduzindo-os simplesmente a diferenças entre indivíduos ou grupos de indivíduos definidos segundo características biológicas.

É importante então que comecemos esclarecendo o sentido que as desigualdades sociais em saúde têm para aqueles que procuram compreender o processo de produção da saúde e da doença nas populações, sem reduzir essa compreensão apenas aos aspectos biológicos.

Podemos começar dizendo que as desigualdades sociais que nos interessam são diferenças no estado de saúde entre grupos definidos por características sociais, tais como riqueza, educação, ocupação, raça e etnia, gênero e condições do local de moradia ou trabalho.

Quando falamos em igualdade ou desigualdade, estamos comparando situações, sem necessariamente, atribuirmos um juízo de valor àquilo que é igual ou desigual. Felizmente, os indivíduos e os grupos sociais reúnem grandes diferenças e variabilidade com relação a muitas características, fato que torna a vida tão interessante. 
Mas, quando falamos em desigualdade social geralmente estamos nos referindo a situações que implicam algum grau de injustiça, isto é, diferenças que são injustas porque estão associadas a características sociais que sistematicamente colocam alguns grupos em desvantagem com relação à oportunidade de ser e se manter sadio.

A discussão em torno das desigualdades sociais em saúde colocou a questão do direito à saúde na pauta política em todo o mundo. Diferentes populações atribuem maior ou menor importância ao direito à saúde como um direito humano fundamental. Como posições polares, podemos apontar, de um lado, o comportamento político da maioria dos dirigentes de países europeus, que cada vez mais concedem importância à redução das desigualdades sociais em saúde, considerando que os sistemas nacionais de saúde e outras políticas sociais devem ter como principal objetivo o alcance da equidade. De outro lado, os governos norte-americanos não consideram que esta seja uma questão relevante para o Estado. Na perspectiva deles, o direito à saúde é algo intrinsecamente relacionado com as capacidades individuais, estilos de comportamento e possibilidade de pagar pelos serviços apropriados.

Aqui no Brasil, ao aprovar o capítulo sobre a saúde na Constituição Federal de 1988, a população, por meio de seus representantes no Congresso, decidiu que a saúde é um direito de todos e que deve ser garantido mediante ações de política pública. Fez ainda mais do que isso, definiu a saúde através de um conceito amplo, que inclui os seus principais determinantes e apontou em linhas gerais os princípios que o sistema nacional de saúde deveria ter: universalidade, integralidade e equidade. 
As desigualdades sociais em saúde não são nenhuma novidade. Elas vêm sendo documentadas há muito tempo, principalmente a partir do século XIX. As condições políticas e sociais que surgiram com o capitalismo, em sua fase de produção industrial, foram favoráveis ao tema, seja pelas péssimas condições de vida da classe trabalhadora, seja pelo ideário político associado às revoluções burguesas. A contradição entre os valores de igualdade, fraternidade e liberdade, e a dura realidade de vida da maioria da população nos países industrializados possibilitou, aos chamados reformadores sociais, socialistas utópicos e comunistas, farto material para denunciar as injustiças sociais em vários campos inclusive no da saúde.

Em todas as sociedades, as situações de risco, os comportamentos relacionados à saúde e o estado de saúde físico e mental tendem a variar entre os grupos sociais. Observa-se um gradiente entre as posições sociais e os efeitos sobre a saúde. Não há um limiar a partir do qual as diferenças desaparecem.

Hoje em dia, praticamente não há quem questione a existência das desigualdades sociais em saúde, entretanto, como já assinalamos, as divergências aparecem no momento de elaborar explicações para as diferenças encontradas.

\section{QUAIS SÃO AS EXPLICAÇÕES MAIS FREQUENTES}

\section{PARA AS DESIGUALDADES SOCIAIS EM SAÚDE?}

$\mathrm{Na}$ falta de uma teoria sobre a produção da saúde e da doença, em âmbito populacional, tenta-se explicar as desigualdades sociais em saúde de maneira relativamente simplista. A primeira ideia que costuma ocorrer, quando os diferenciais em mortalidade geral ou específica são apresentados, é que o acesso aos 
serviços de saúde é diferenciado para os vários grupos e, portanto, os efeitos são decorrentes de problemas na utilização dos recursos disponíveis, seja por incapacidade do indivíduo, seja por características de organização dos próprios serviços. Esta explicação é rapidamente derrubada pela constatação de que as desigualdades não desaparecem naqueles países em que existem sistemas nacionais de saúde com garantia de acesso universal para todos os grupos sociais, como ocorre em diversos países da Europa, no Canadá, na Austrália, dentre outros.

Nas comparações entre países, as desigualdades tendem a ser atribuídas a diferentes graus de desenvolvimento da assistência médica. Entretanto, essa explicação, ainda que possa responder por parte do perfil de mortalidade observado, não é capaz de justificar por que as desigualdades vêm aumentando ao invés de diminuírem com o passar do tempo.

A difusão de tecnologias médicas, mesmo nos países menos desenvolvidos, é considerável e com o passar do tempo deveria provocar a redução das desigualdades, e não o seu aumento. Portanto, por mais importante que o desenvolvimento técnicocientífico possa ser para a recuperação da saúde, esta não parece ser a explicação mais plausível para essas desigualdades.

Para explicar as diferenças entre países e entre grupos sociais no interior dos países, há também os que utilizam a velha ideia do ciclo vicioso. Para eles, a doença é o principal determinante da posição social, e não ao contrário, isto é, as pessoas doentes não conseguem ter um desempenho social satisfatório e por isso encontram-se em posições desfavorecidas. Bastam alguns estudos longitudinais para derrubar essa justificativa. 
Entre aqueles que admitem a influência do contexto, ou seja, das condições de vida sobre o estado de saúde, a maioria acredita que é o estilo de vida dos indivíduos o principal responsável pelas desigualdades sociais. Esta perspectiva liberal de compreensão do processo saúde-doença acaba por esvaziar o conteúdo social do processo, atribuindo a preferências individuais a causa das diferenças observadas. As posições da saúde pública tradicional e da educação sanitária são amplamente baseadas nessa crença de que os indivíduos na sociedade atual são livres para escolher a qualidade de sua moradia, suas condições de trabalho, seus comportamentos e as situações de maior ou menor risco para a saúde.

Tal crença é mais difícil de ser contestada com evidências empíricas ou argumentos teóricos, pois implica uma visão de mundo particular. Entretanto, os estudos epidemiológicos têm mostrado que os fatores de risco não conseguem explicar mais do que $25 \%$ da ocorrência dos problemas crônicos de saúde. Portanto, mesmo que o estilo de vida seja importante individualmente, dificilmente seria capaz de explicar as desigualdades sociais.

Mais recentemente, com os avanços científicos no campo da genética, voltaram à moda as explicações baseadas em fatores genéticos. Toda e qualquer variação na ocorrência de doenças tende a ser relacionada com um gene ou conjunto de genes que acabam de ser 'descobertos'. Como essa explicação corresponde a 'má genética', isto é, a uma interpretação mecanicista da própria atuação dos determinantes genéticos, não cremos que seja necessário perder muito tempo para refutá-la. 
Assim, fica clara a necessidade de possuir teorias ao invés de simples explicações para compreender as desigualdades sociais em saúde. Teorias que possibilitem compreender não apenas a distribuição da doença, mas principalmente seu processo de produção em diferentes contextos sociais.

\section{QUAIS SÃO AS TEORIAS DISPONÍVEIS PARA}

\section{ENTENDERMOS AS DESIGUALDADES SOCIAIS EM SAÚDE?}

Podemos identificar quatro teorias principais que pretendem fornecer elementos para a compreensão do processo de produção da saúde e da doença e seus reflexos sobre a distribuição do estado de saúde na população.

A teoria mais antiga e mais facilmente aceita é a estruturalista ou materialista, que confere maior importância à estrutura econômica da sociedade. De acordo com este modelo, o montante de renda ou riqueza dos países, grupos sociais ou indivíduos é o principal determinante do estado de saúde A falta ou insuficiência dos recursos materiais para enfrentar de modo adequado os estressores ao longo da vida acaba por produzir a doença e diminuir a saúde.

A teoria estruturalista é capaz de explicar grande parte das desigualdades, mas tropeça diante do paradoxo de que nem sempre a riqueza de um país vem acompanhada de melhor nível de saúde, principalmente nos países cujas populações têm as suas necessidades básicas atendidas.

Uma outra teoria desenvolvida para enfrentar o paradoxo entre riqueza e nível de saúde é a psicossocial. Ela dá mais importância à percepção da desvantagem social como fonte de 
estresse e desencadeador de doenças. Nos países e grupos sociais em que as necessidades básicas estão atendidas, as diferenças relativas na posse de bens e nas posições de prestígio e poder passam a ser mais relevantes para a produção e distribuição das doenças do que simplesmente o nível de riqueza material.

Não há contradição insolúvel entre essas duas teorias, o que as diferencia fundamentalmente é o enfoque baseado na ideia de privação absoluta ou relativa. No primeiro caso, a falta total de condições para fazer face às necessidades básicas apresenta-se como principal determinante do estado de saúde. Esta situação pode ser exemplificada pela comparação entre a esperança de vida ao nascer e o Produto Interno Bruto (PIB) per capita dos países. As duas variáveis são diretamente correlacionadas e esta relação é forte. Por exemplo, a esperança de vida na Suécia, país que têm um PIB per capita de 42 mil dólares, é de 80 anos, enquanto em Angola, cujo PIB per capita é de 2.800 dólares, a esperança de vida ao nascer é de 40 anos.

No segundo caso, predomina a privação relativa, ou seja, uma vez ultrapassado o limiar de atendimento das necessidades básicas, as diferenças relativas entre os grupos sociais no interior de cada população passam a ser um determinante fundamental, com os países mais igualitários desfrutando de melhores níveis de saúde do que aqueles onde existe maior desigualdade. Como exemplo, podemos citar a comparação entre Cuba e os Estados Unidos. Cuba tem PIB per capita dez vezes menor que os Estados Unidos (4.650 e 43.562 dólares respectivamente) e apresenta a mesma esperança de vida: 77 anos.

Esses dados poderiam nos fazer pensar que a partir de um certo limiar de PIB per capita a esperança de vida tenderia a ser 
alta e semelhante entre os países, mas não é o que ocorre. A África do Sul, por exemplo, tem PIB per capita maior do que Cuba (5.133 dólares) e esperança de vida muito menor (49 anos), refletindo as profundas desigualdades sociais que marcaram a história desse país e que ainda não deixaram de agir sobre o nível de saúde da população.

$\mathrm{Na}$ América Latina a discussão sobre as desigualdades sociais vem sendo feita principalmente à luz da teoria da determinação social do processo saúde-doença. Essa teoria analisa a constituição do próprio sistema capitalista de produção e suas formas particulares de expressão nas diferentes sociedades, dando maior ênfase aos mecanismos de acumulação do capital e à distribuição de poder, prestígio e bens materiais deles decorrentes. A posição de classe e a reprodução social passam a ser vistas como os principais determinantes do perfil da saúde e doença.

Nessa abordagem o problema deixa de ser tratado como uma questão de pobreza absoluta ou relativa e passa a ser visto da perspectiva da inclusão ou exclusão social. Os impactos da estrutura social sobre a saúde são pensados nos processos de participação ou exclusão, associados às diferentes posições sociais e sujeitos a transformações em função do próprio processo histórico.

A versão brasileira da teoria da determinação social do processo saúde-doença dá maior ênfase explicativa ao modo de vida, considerando que nele estão englobados tanto os aspectos materiais quanto os aspectos simbólicos que refletem as características sociais de produção, distribuição e consumo, às quais cada grupo social está relacionado através do modo de vida. Ao mesmo tempo que busca articular as diferentes esferas da organização 
social, o conceito de modo de vida reúne em um mesmo marco teórico as condições coletivas dos grupos e os comportamentos dos indivíduos que compõem esses grupos.

Finalmente a teoria ecossocial chama a atenção para processos de incorporação, no sentido forte do termo, pelos organismos humanos, dos aspectos sociais e psíquicos predominantes no contexto nos quais os indivíduos vivem e trabalham. Nessa teoria, procura-se romper com uma visão linear que articula processos distais, intermediários e proximais, substituindo-a por uma concepção complexa de que cada um dos aspectos se manifesta e se reproduz em cada um dos níveis de organização dos seres vivos, caracterizando, assim, a incorporação das diferentes instâncias pelos organismos. Em outras palavras, a teoria ecossocial considera impossível a separação entre o biológico, o social e o psíquico.

As quatro teorias apresentadas compreendem o processo saúde-doença como intrinsecamente histórico, isto é, determinado pelas condições estruturais e conjunturais em que vivem as populações humanas. Do mesmo modo como os homens constroem sua vida material e não material, eles também produzem as doenças das quais irão padecer, bem como os instrumentos e as organizações sociais para combatê-las.

A teoria ecossocial e a teoria do modo de vida representam o esforço de articular as três anteriores - estruturalista, psicossocial e determinação social - considerando os padrões de saúde e doença como as consequências biológicas dos modos de vida e trabalho próprios de cada grupo social, determinados pela organização econômica e pelas prioridades políticas da sociedade. As relações econômicas, sociais e políticas afetam a forma como 
as pessoas vivem e seu contexto ecológico e, desse modo, acabam por moldar os padrões de distribuição das doenças.

Compreender as desigualdades sociais, portanto, vai muito além da simplificação habitual presente nas dicotomias 'doenças de pobre' vs 'doenças de rico' ou 'doenças sociais' vs 'doenças biológicas’. Toda e qualquer doença e sua distribuição populacional são produtos da organização social, não tendo sentido falar, portanto, em doenças sociais e doenças não sociais.

As desigualdades sociais em saúde podem manifestar-se de maneira diversa no que diz respeito ao processo saúde-doença em si, bem como ao acesso e utilização de serviços de saúde. As desigualdades no estado de saúde estão de modo geral fortemente atreladas à organização social e tendem a refletir o grau de iniquidade existente em cada sociedade. $\mathrm{O}$ acesso e a utilização dos serviços refletem também essas diferenças, mas podem assumir feições diversas, dependendo da forma de organização dos sistemas de saúde. Há sistemas que potencializam as desigualdades existentes na organização social e outros que procuram compensar, pelo menos em parte, os resultados danosos da organização social sobre os grupos socialmente mais vulneráveis. Voltaremos a tratar desse tema ao final, quando abordarmos as políticas de enfrentamento das desigualdades sociais.

A equidade na oferta de serviços de saúde implica a ausência de diferenças para necessidades de saúde iguais (equidade horizontal) e a provisão de serviços prioritariamente para grupos com maiores necessidades (equidade vertical). Trocando em miúdos, isso significa que todos devem ter acesso e utilizar os serviços indispensáveis para resolver as suas demandas de saúde, independentemente do grupo social ao qual pertençam, e aqueles que 
apresentam maior vulnerabilidade em decorrência da sua posição social devem ser tratados de maneira diferente para que a desvantagem inicial possa ser reduzida ou anulada.

Há diferentes eixos de análise possíveis no estudo das desigualdades sociais em ambas as dimensões assinaladas. Neste livro daremos maior destaque à análise e discussão das desigualdades em saúde relacionadas com a posição de classe social, a renda, o gênero e a etnia. 



\section{I A Posição Social e seus Reflexos SObRe a Saúde}

As explicações sócio-históricas das desigualdades em saúde baseiam-se na idéia de que saúde é um produto social e algumas formas de organização social são mais sadias do que outras. Assim, os mesmos processos que determinam a estruturação da sociedade são aqueles que geram as desigualdades sociais e produzem os perfis epidemiológicos de saúde e doença.

O conceito-chave nessas abordagens é o processo reprodução social, que, por sua vez, implica a reprodução de diferentes domínios da vida. No nível mais elementar está a reprodução biológica do indivíduo, que garante suas características como espécie biológica marcada principalmente pela interação entre genotipo e fenotipo, isto é, entre a herança genética e a modulação das potencialidades herdadas pelas condições concretas de existência, que irão resultar nas manifestações exteriores do genótipo.

Como os homens vivem em comunidade, compartilhando um espaço e um tempo particulares, a reprodução social implica também a reprodução de um segundo domínio: o das relações ecológicas dos grupos, ou seja, de suas relações com os ambientes, senso lato, em que tais comunidades se constituem. Estas comunidades partilham formas de consciência e de conduta resultantes das interações intersubjetivas que também participam dos processos de reprodução, configurando o terceiro domínio: o da cultura. Finalmente, os grupos sociais se 
reproduzem, reproduzindo as formas econômicas que lhes garantem o domínio sobre a natureza.

O sistema de reprodução social dos diferentes grupos inclui os padrões de trabalho e consumo, as atividades práticas da vida cotidiana, as formas organizativas ou de participação social, a política e a cultura. Esse sistema contraditório de relações, do qual participam processos benéficos mantenedores da saúde e processos deletérios produtores da doença, acoplam-se aos padrões de saúde-doença das frações de classes sociais, constituindo assim os perfis epidemiológicos de classe.

Todos esses processos produzem impactos sobre a saúde e a doença dos indivíduos, representando, cada um deles, um conjunto de determinações e mediações cujo resultado final será a preservação da saúde ou a ocorrência da doença ou agravos à saúde. As desigualdades nas condições de vida, decorrentes de diferenças substantivas nesse processo de reprodução social, terão reflexos nas situações de saúde que serão então identificadas como iniquidades.

As explicações históricas representam ruptura com a teoria da multicausalidade e com o paradigma do risco, adotando o conceito de determinação social, ou seja, processos de determinação histórica e social regidos pelas leis da dialética que estabelecem os limites dentro dos quais os fenômenos de menor nível de complexidade podem ocorrer. Porém, a determinação social implica aceitar que cada domínio da realidade apresenta processos mediadores que interferem com a emergência de novas características nos níveis de complexidade crescente, de modo que a consequência, em termos de saúde e doença, será sempre a resultante de um processo complexo de determinação-mediação. 
Adotar este tipo de explicação teórica significa romper com a concepção linear de causalidade e abandonar qualquer pretensão de identificar cadeias de causa-efeito entre características ou indicadores sociais e problemas de saúde, bem como entre indicadores de desigualdades sociais e saúde.

\section{Conceito marxista de Classe social}

Na década de 1980 foram feitas várias tentativas de operacionalização do conceito marxista de classe social para uso em investigações empíricas em diferentes campos do conhecimento, incluindo a saúde.

Na concepção marxista, as classes sociais são definidas como grandes grupos de indivíduos que se diferenciam entre si pela posição que ocupam no sistema de produção historicamente determinado, pelas relações que estabelecem com os meios de produção, pelo papel que desempenham na organização social do trabalho e pelo modo como se apropriam de parte da riqueza social. O conceito engloba as dimensões econômicas, sociais, jurídicas, políticas e ideológicas.

Embora difícil de operacionalizar, pois a decomposição das dimensões do conceito em variáveis e sua reagregação para compor as classes empíricas exijam um conjunto amplo de questões, o conceito de classe é visto como capaz de apresentar um grande potencial explicativo exatamente por condensar em si tantas dimensões.

Para efeito das investigações epidemiológicas, o que se pede ao conceito de classe social é que através dele possam ser identificados grupos definidos a partir de seus vínculos sociais 
estruturais, que são os determinantes mais imediatos das condições de vida das famílias e, portanto, da situação de saúde dos indivíduos.

Durante a década de 1980 surgiram diferentes modelos visando à operacionalização do conceito de classes sociais com base, sobretudo, na produção teórica de Poulantzas e outros autores marxistas. A maioria das propostas de operacionalização baseiase na definição leninista de classe social, levando em consideração principal ou exclusivamente o componente econômico do conceito, ou o que se convencionou chamar a "classe em si".

$\mathrm{Na}$ América Latina, destacam-se dois esquemas de operacionalização do conceito de classe social: o modelo de Bronfman e Tuirán e o de Singer. Ambos os modelos constroem classificações hierarquizadas iniciando pela posição na ocupação, ou seja, pela posse ou não dos instrumentos e meios de produção. Esses esquemas já foram utilizados para estudar diferentes problemas de saúde, bem como para avaliar o consumo de bens e serviços em saúde.

Um exemplo empírico pode facilitar a compreensão desses conceitos e de sua utilização nas pesquisas epidemiológicas de desigualdades sociais em saúde. Usaremos dados de estudo realizado por pesquisadores do Departamento de Medicina Social da Faculdade de Medicina, da Universidade de São Paulo (USP) de Ribeirão Preto, para demonstrar a potencialidade do conceito de classe social. O objetivo da investigação era identificar fatores de risco para baixo peso ao nascer.

A incidência de baixo peso foi 1,8 vezes maior em filhos de mães fumantes e 2,4 vezes maior em filhos de mães pobres. A incidência também variou por classe social da mãe. Na burguesia 
a incidência de baixo peso foi de 3,1 casos por 100 nascidos vivos; entre o proletariado, 10,7 e no subproletariado, 13,9, mostrando um gradiente de agravamento do problema conforme piora a situação de classe.

Portanto, classe social e hábito de fumar podem ser considerados fatores de risco para o baixo peso ao nascer. Entretanto, não constituem variáveis da mesma dimensão de análise. $\mathrm{Na}$ Tabela 1, observa-se o resultado da incidência de baixo peso quando ambas as variáveis são consideradas.

Tabela 1 - Incidência de baixo peso ao nascer segundo a classe social e o hábito de fumar materno. Ribeirão Preto (SP) - 1978-1979

\begin{tabular}{l|cc}
\hline Classe social & Fumantes & Não fumantes \\
\hline Burguesia & 4,4 & 2,7 \\
\hline Proletariado & 9,5 & 5,9 \\
\hline Subproletariado & 12,8 & 6,3 \\
\hline
\end{tabular}

Fonte: Adaptado de Silva et al., 1992.

Os dados mostram que em cada classe social o risco de baixo peso é sempre maior para os filhos de mães fumantes. Mas, o mais interessante é notar que o risco para os filhos de mães fumantes que pertencem à burguesia é menor do que o risco para os filhos das mães não fumantes que pertencem ao proletariado ou ao subproletariado. Conclui-se, então, que a determinação de classe social é mais forte e modula o risco representado pelo hábito de fumar.

A distribuição das crianças menores de 5 anos em São Paulo, segundo decis de altura/idade (indicador de estado nutricional) definidos pelo National Center for Health Statistics (NCHS) na 
década de 1980, também revela clara influência da posição de classe. Considerando o primeiro decil, isto é, aquele que define $10 \%$ dos valores mais baixos para a razão altura/idade, a distribuição das crianças residentes em São Paulo aponta significativa desigualdade (Tabela 2).

Se a distribuição fosse equilibrada, isto é, independente da classe social, cada uma deveria ter aproximadamente 10\% das crianças. O excesso relativo de crianças nesse decil entre as famílias da pequena burguesia tradicional, do proletariado e do subproletariado e a ausência de crianças da burguesia mostra a concentração do problema nas classes sociais com inserção mais precária.

Tabela 2 - Proporção de crianças pertencentes ao primeiro decil da distribuição NCHS para a razão altura/idade segundo classe social. São Paulo - 1984

\begin{tabular}{l|c}
\hline Classe social & Proporção \\
\hline Burguesia & 0,0 \\
\hline Nova pequena burguesia & 8,8 \\
\hline Pequena burguesia tradicional & 21,2 \\
\hline Proletariado setor serviço & 20,2 \\
\hline Proletariado setor industrial & 29,0 \\
\hline Subproletariado & 35,8 \\
\hline
\end{tabular}

Fonte: Monteiro, Freitas \& Baratho, 1989.

\section{Conceito Weberiano de Classe Social}

Na concepção weberiana a posição social dos indivíduos decorre da classificação segundo três dimensões: classe econômica, 
prestígio e poder político. Os estratos sociais são compostos por indivíduos que compartilham determinadas características de inserção econômica (ocupação), prestígio social (escolaridade) e poder ou riqueza (renda), características essas utilizadas para alocá-los em uma escala ou gradiente de valores crescentes ou decrescentes.

As teorias de estratificação social tratam as desigualdades de um ponto de vista predominantemente quantitativo, visto que os estratos são categorias eminentemente descritivas, construídas mediante a definição de determinados pontos de corte que repartem séries contínuas. As variáveis utilizadas na definição dos estratos referem-se a características individuais tomadas como indicadoras de condições sociais. Tais variáveis podem incluir a renda, a escolaridade, a ocupação, escalas de prestígio e outras. Eventualmente os estratos podem ser construídos utilizando indicadores compostos nos quais as variáveis são arranjadas por agregação, ponderação ou hierarquização.

As evidências empíricas produzidas pelas investigações das relações entre desigualdades sociais e saúde sugerem que a situação de saúde é afetada pela posição social dos indivíduos e também pelas diferenças socioeconômicas da estratificação social.

Embora os indivíduos façam escolhas que possam implicar comportamentos sadios ou nocivos à sua saúde, estas escolhas estão situadas em contextos familiares, econômicos, culturais, políticos e históricos. Os estilos de vida ou os comportamentos individuais são apenas as evidências mais imediatas de todo o processo de determinação-mediação.

As escalas de estratificação social podem ser úteis na investigação de diferenciais intraclasses ou entre diferentes famílias, 
auxiliando na especificação de relações particulares que possam explicar por meio de que características ou de que mecanismos as desigualdades sociais produzem efeitos sobre a saúde.

A ocupação é uma das variáveis mais utilizadas em pesquisas conduzidas nos países europeus como medida de classe social. A classificação baseada em ocupações, elaborada pelo sistema de estatística vital do Reino Unido, em 1911, vem sendo amplamente utilizada. Esta classificação foi baseada no grau de habilidade e no prestígio social correspondente a cada ocupação, de modo que pudesse servir como indicadora de posição social, o que, no entanto, não garante a correspondência exata entre classe social e ocupação.

A classificação inglesa divide as ocupações em cinco classes: profissionais (formação universitária), técnicos (formação técnica), trabalhadores qualificados manuais ou não manuais, trabalhadores semiqualificados e trabalhadores não qualificados.

Controlando a influência da idade, da classe social na idade adulta, o hábito de fumar e o índice de massa corporal, o risco de morrer por câncer de estômago foi 5,4 vezes maior nos trabalhadores manuais qualificados, e 5,8 vezes maior nos trabalhadores semi e não qualificados quando comparados aos profissionais e técnicos.

Crianças brasileiras prematuras também apresentam distribuição diferenciada por classe ocupacional. O risco de prematuridade é 1, 6 vezes maior entre trabalhadores manuais qualificados e semiqualificados, e 1,8 vezes maior entre trabalhadores manuais não qualificados quando comparados a trabalhadores não manuais.

Mesmo dentro de grupos ocupacionais mais homogêneos, é possível encontrar diferenças entre trabalhadores segundo a 
posição na hierarquia de trabalho, ou seja, segundo a ocupação de postos de trabalho com maior ou menor controle e autonomia. O estudo Whitehall II realizado entre os trabalhadores administrativos do governo britânico mostrou aumento do risco de ausências prolongadas no trabalho ( $>8$ dias) por motivo de doença conforme se descende na escala da hierarquia burocrática. Os funcionários com menor autonomia e submetidos a controle mais rígido por supervisores têm risco três vezes maior de se ausentar do trabalho por períodos longos em decorrência de problemas de saúde. A mesma relação foi observada entre trabalhadores franceses.

Nos exemplos apresentados, os problemas de saúde não estão diretamente relacionados com exposições a agentes nocivos no ambiente de trabalho. A ocupação foi tomada como um marcador da posição social dos indivíduos.

No estudo das desigualdades sociais em saúde, outra variável bastante usada é o nível de escolaridade, isoladamente, ou combinada à ocupação. Para a maioria dos problemas de saúde infantil, a escolaridade materna é um dos determinantes mais importantes, tanto como marcador de posição social quanto como indicador do nível de instrução e da possibilidade de compreender e aplicar corretamente as informações técnicas.

O risco de ter um bebê pequeno para a idade gestacional está inversamente relacionado com o número de anos de escolaridade da mãe. Tomando como referência a incidência para mães com 12 anos ou mais de escolaridade, o risco aumenta 1,5 vezes para mulheres com cinco a oito anos de escolaridade e 1,7 vezes para mulheres com zero a quatro anos de escolaridade. 


\section{Desigualdades nO estado de saúde E NO USO DE SERVIÇOS}

As desigualdades sociais em saúde podem se manifestar em relação ao estado de saúde e ao acesso e uso de serviços de saúde para ações preventivas ou assistenciais. Na população brasileira, segundo dados da Pesquisa Mundial de Saúde, a autoavaliação do estado de saúde varia marcadamente com o nível de escolaridade. Entre os adultos com menos de oito anos de escolaridade, ou seja, com ensino fundamental incompleto, apenas $41 \%$ classificam sua saúde como boa ou muito boa. Este valor sobe para $62,2 \%$ para os adultos que completaram o ensino fundamental e iniciaram o ensino médio, e chega a 72,1\% dos indivíduos com ensino médio completo.

A prevalência de doenças crônicas também varia com os anos de escolaridade após ajuste por idade. Entre os adultos com até três anos de escolaridade, a prevalência referida de doenças crônicas chega a 55,9\%, representando um risco 1,28 vezes maior do que aquele dos indivíduos com 11 anos ou mais de escolaridade. A prevalência diminui gradualmente entre os extremos da distribuição de anos de escolaridade.

O uso de serviço de saúde também é influenciado pelo grau de escolaridade, mas as diferenças são muito menores. A criação do Sistema Único de Saúde (SUS) possibilitou o acesso aos serviços para a grande maioria da população brasileira. A probabilidade de uso é 1,2 vezes maior entre os brasileiros com nove ou mais anos de escolaridade, quando comparados aos que têm entre zero e quatro anos. As taxas de internações hospitalares não mostram diferenças segundo a escolaridade 
e a renda, variando em função do estado de saúde e da presença de problemas crônicos de saúde.

A utilização de serviços preventivos mostra diferenciais mais acentuados segundo a escolaridade e a ocupação. Estas diferenças sugerem que, na procura por serviços preventivos, atuam fatores diferentes daqueles envolvidos na utilização dos serviços assistenciais. É provável que características culturais e o nível de acesso à informação desempenhem um papel mais ativo nesses casos.

Apenas 75\% das mulheres com 25 anos ou mais de idade, na população brasileira, em 2003, fizeram o exame Papanicolau para prevenção do câncer de colo uterino. Esta proporção varia com a escolaridade no sentido esperado, ou seja, as mulheres com maior escolaridade apresentam maior cobertura (Tabela 3).

Tabela 3 - Prevalência de realização do exame Papanicolau nos últimos cinco anos

\begin{tabular}{l|cc}
\hline Escolaridade & Prevalência & $\begin{array}{c}\text { Razão de } \\
\text { prevalência (RP) }\end{array}$ \\
\hline $\begin{array}{l}\text { Analfabeto/ensino } \\
\text { fundamental incompleto }\end{array}$ & 67,5 & $4,4(4,1-4,8)$ \\
\hline $\begin{array}{l}\text { Ensino fundamental } \\
\text { completo/ensino médio } \\
\text { incompleto }\end{array}$ & 83,8 & $1,6(1,5-1,7)$ \\
\hline $\begin{array}{l}\text { Ensino médio completo/ } \\
\text { superior incompleto }\end{array}$ & 86,0 & $1,5(1,4-1,6)$ \\
\hline $\begin{array}{l}\text { Superior completo/ } \\
\text { pós-graduação }\end{array}$ & 91,4 & 1,0 \\
\hline
\end{tabular}

Fonte: Novaes, Braga \& Schout, 2003. 
Enquanto o uso de serviços de saúde em geral, por pessoas com nove anos ou mais de escolaridade, no mesmo inquérito, foi 1,2 vezes mais frequente do que para os indivíduos analfabetos ou com ensino fundamental incompleto, para a realização do exame de Papanicolau a probabilidade de não ter feito o exame foi 4,4 vezes maior entre as mulheres com menor escolaridade. Portanto, parte dessa diferença não deve ser atribuída a dificuldades de acesso.

Apenas 36\% das mulheres com 25 anos ou mais de idade realizaram mamografia nos últimos dois anos. O mesmo perfil de distribuição pode ser observado entre os níveis de escolaridade. Neste caso é possível fazer o mesmo tipo de inferência quanto ao acesso, uma vez que a distribuição dos mamógrafos na rede de serviços é bem menor do que a dos recursos necessários para a realização do exame de Papanicolau.

Em pacientes diabéticos, classificados por ocupação e escolaridade, os comportamentos preventivos diminuíram e a exposição ao fumo aumentou conforme piorou a inserção social. Os pacientes em pior posição foram menos à consulta médica de rotina, tiveram menor probabilidade de realizar um exame de fundo de olho e menor probabilidade de ter o pé examinado e apresentaram, ainda, maior frequência do hábito de fumar.

\section{DESIGUALDADES RELACIONADAS AOS LOCAIS DE MORADIA}

O estudo das desigualdades sociais em saúde deveria, idealmente, ter como variável explicativa a classe social construída com base nas relações fundamentais estabelecidas a partir da 
posição dos indivíduos na estrutura produtiva da sociedade. Entretanto, as dificuldades que cercam a operacionalização desse conceito, bem como a necessidade de contar com muitas informações, raramente disponíveis nos sistemas regulares de registros de dados em saúde, levaram os pesquisadores a buscar outras alternativas.

A estratificação social através de variáveis indicadoras da posição social, tais como ocupação, escolaridade e renda, aparece como uma dessas alternativas. Embora, com menor dificuldade de operacionalização, nem sempre a análise de cada uma das estratificações atende de maneira adequada às necessidades de compreensão de fenômenos complexos, como a produção e a distribuição das doenças e eventos relacionados com a saúde.

Outra alternativa cada vez mais utilizada é a análise dos eventos de saúde em relação ao local de moradia, tomando o espaço geográfico como indicativo das condições de vida da população que nele reside. A vantagem de utilizar espaços geográficos como indicadores de condições de vida está em tomar a complexidade da organização social em seu todo, em vez de fragmentá-la em diferentes variáveis.

As análises que utilizam as características sociopolíticas de diferentes espaços geográficos permitem abordar as desigualdades sociais em saúde no plano de agregados, isto é, tanto as condições de vida quanto os impactos sobre a saúde são avaliados através de valores médios.

Um primeiro nível de comparações pode ser estabelecido entre países (Tabela 4). Apesar de serem consideravelmente heterogêneos em seu interior, as comparações entre eles permitem 
ressaltar a relação entre variáveis macroeconômicas ou macrossociais e seus impactos sobre a saúde populacional.

Tabela 4 - Indicadores socioeconômicos e impactos sobre a saúde em países selecionados - 2006

\begin{tabular}{l|cccccc}
\hline Indicador & Canadá & Espanha & $\begin{array}{c}\text { Nova } \\
\text { Zelândia }\end{array}$ & Brasil & Egito & Índia \\
\hline IDH* & 0,95 & 0,94 & 0,94 & 0,79 & 0,70 & 0,61 \\
\hline $\begin{array}{l}\text { PIB per capita } \\
\text { (US\$) }\end{array}$ & 39.004 & 27.913 & 25.603 & 5.640 & 1.484 & 784 \\
\hline Acesso Internet & $68 \%$ & $40 \%$ & $68 \%$ & $21 \%$ & $7 \%$ & $5 \%$ \\
\hline $\begin{array}{l}\text { Gasto em saúde } \\
\text { (\% PIB) }\end{array}$ & $7 \%$ & $5 \%$ & $6 \%$ & $3 \%$ & $2 \%$ & $1 \%$ \\
\hline $\begin{array}{l}\text { Gasto per capita } \\
\text { (US\$) }\end{array}$ & 2.666 & 1.522 & 1.598 & 189 & 320 & 9 \\
\hline Natalidade & 10,7 & 10,2 & 14,2 & 20,6 & 25,5 & 25,1 \\
\hline EV** ao nascer & 79,9 & 79,4 & 79,0 & 70,3 & 69,6 & 63,1 \\
\hline
\end{tabular}

*IDH - Índice de Desenvolvimento Humano

** EV - Esperança de vida ao nascer

Fonte: IBGE.

Os dados mostram que há correspondência entre os indicadores sociais (IDH e acesso à Internet) e econômicos (PIB per capita e gasto em saúde) e o nível de saúde da população (natalidade e esperança de vida ao nascer - EV). Chama a atenção a grande desigualdade entre a riqueza dos países e os gastos públicos em saúde. Essa desigualdade se reflete tanto no padrão de natalidade com diferença de 15 crianças por mil habitantes entre o Canadá e a Índia, quanto na EV, com diferença de 16,8 anos entre a Índia e o Canadá. As desigualdades sociais em saúde repetem-se também no interior dos países, entre suas regiões e cidades (Tabela 5). 
Tabela 5 - PIB per capita e mortalidade infantil para cinco capitais brasileiras -2005

\begin{tabular}{l|cc}
\hline Capital & PIB per capita & Mortalidade infantil \\
\hline São Paulo & 24.175 & 12,82 \\
\hline Porto Alegre & 20.563 & 12,67 \\
\hline Manaus & 16.528 & 19,64 \\
\hline Campo Grande & 9.528 & 15,14 \\
\hline Salvador & 7.656 & 21,63 \\
\hline
\end{tabular}

Fonte: IBGE.

Há um nítido gradiente na mortalidade infantil que acompanha o PIB per capita em cada capital, mostrando que quanto maior a riqueza, menor a taxa de mortalidade infantil. O PIB per capita de Salvador é três vezes menor do que o de São Paulo, e sua mortalidade infantil é 1,7 vezes maior, indicando, assim, que a correlação não é perfeita, pois na determinação da mortalidade atuam as condições concretas de vida e a oferta de serviços de saúde. A existência do SUS garante maior extensão de cobertura à população mesmo nas áreas mais pobres do país, compensando em certa medida as desigualdades decorrentes da organização social.

A desigualdade em saúde ocorre também no interior das cidades. Quanto mais homogêneo o espaço social considerado, mais evidentes tornam-se as desigualdades entre elas. As diferenças nas condições de vida e seu impacto nas desigualdades sociais em saúde podem ser aquilatadas pela análise de alguns dados referentes a áreas de subprefeituras no município de São Paulo (Tabela 6). 
Tabela 6 - Indicadores socioeconômicos e impactos sobre a saúde em subprefeituras selecionadas. Município de São Paulo - 2005

\begin{tabular}{|c|c|c|c|c|c|}
\hline Indicador & Pinheiros & Butantã & $\begin{array}{l}\text { Casa } \\
\text { Verde }\end{array}$ & $\begin{array}{l}\text { Campo } \\
\text { Limpo }\end{array}$ & Parelheiros \\
\hline $\begin{array}{l}\text { Renda per capita } \\
<0,5 \mathrm{SM}^{*}\end{array}$ & 1,6 & 8,6 & 11,2 & 15,2 & 27,0 \\
\hline $\begin{array}{l}\text { Aglomeração } \\
\text { (> } 3 \text { pessoas/ } \\
\text { dormitório) }\end{array}$ & 2,7 & 14,9 & 19,7 & 22,7 & 30,8 \\
\hline $\begin{array}{l}\text { Responsáveis } \\
\text { com }<4 \text { anos } \\
\text { de escolaridade }\end{array}$ & 9,0 & 30,9 & 37,5 & 42,0 & 54,2 \\
\hline $\begin{array}{l}\text { Moradores em } \\
\text { favela }\end{array}$ & 0,2 & 13,2 & 11,2 & 24,4 & 13,4 \\
\hline $\begin{array}{l}\text { Mortalidade } \\
\text { infantil }\end{array}$ & 8,3 & 9,9 & 15,1 & 13,5 & 15,9 \\
\hline $\begin{array}{l}\text { Taxa de } \\
\text { homicídios }\end{array}$ & 16,9 & 52,2 & 52,9 & 74,6 & 117,2 \\
\hline $\begin{array}{l}\text { Homicídios } \\
15-29 \text { a }\end{array}$ & 23,2 & 92,4 & 177,1 & 199,2 & 260,8 \\
\hline $\begin{array}{l}\text { Menos de sete } \\
\text { consultas de } \\
\text { pré-natal }\end{array}$ & 9,7 & 33,9 & 20,3 & 34,6 & 50,5 \\
\hline
\end{tabular}

* SM - salário mínimo

Fonte: CE-INFO Secretaria Municipal de Saúde de São Paulo, 2005.

A Tabela 6 mostra diferenças muito significativas entre as subprefeituras, tanto nos indicadores socioeconômicos quanto nos indicadores de saúde. Essas desigualdades são mais acentuadas do que aquelas observadas entre os países ou entre as capitais brasileiras. Novamente chama a atenção que as desigualdades na mortalidade infantil e na proporção de gestantes com núme- 
ro insatisfatório de consultas de pré-natal é muito menor - duas e cinco vezes respectivamente - do que as diferenças nos indicadores sociais. A subprefeitura que apresenta as piores condições de vida tem 17 vezes mais pessoas pobres, 11 vezes mais aglomeração intradomiciliar, seis vezes mais responsáveis com baixa escolaridade e 67 vezes mais moradores em favelas. Para os homicídios em geral e os homicídios entre jovens, as diferenças são também bastante acentuadas, visto que o sistema de saúde tem influência muito menor sobre esse tipo de agravo.

A posição social dos indivíduos e grupos sociais, medida por indicadores de classe social, variáveis isoladas como escolaridade e classes ocupacionais, ou a partir das condições de vida em determinados espaços geográficos, é um poderoso determinante do estado de saúde das populações, atuando sobre o perfil de morbidade e mortalidade e também sobre o acesso e utilização dos serviços de saúde.

Há inúmeras investigações científicas demonstrando a existência das desigualdades sociais em saúde e buscando modelos de interpretação para as mesmas, procurando entender os processos sociais e os processos mediadores entre as condições concretas de vida e a saúde no âmbito populacional. 



\section{I Ser Rico faz bem à Saúde?}

A maioria das pessoas responderia afirmativamente à pergunta, baseadas na observação de que indivíduos e países mais ricos conseguem garantir o atendimento das necessidades básicas, essenciais para a manutenção da saúde: moradia adequada, alimentação saudável, trabalho em condições satisfatórias, acesso a bens e serviços relacionados com a educação, a cultura e a saúde.

Tradicionalmente o nível de riqueza tem sido associado à garantia de melhor qualidade de vida e consequentemente a melhores níveis de saúde, refletidos em maior esperança de vida desde o nascimento até as idades mais avançadas, em menor mortalidade por qualquer causa e em qualquer idade, e na ausência de determinadas causas de morbidade associadas com a pobreza, tais como desnutrição e doenças infecciosas relacionadas a precárias condições de higiene e saneamento básico.

Entretanto, a relação entre a riqueza dos países medida pelo PIB ou pelo PIB per capita e os diversos indicadores de saúde não é linear. Não se observa uma relação simples do tipo quanto mais rico um país mais saudável sua população. Desde a década de 1970 pesquisas têm demonstrado que a relação entre PIB per capita e esperança de vida se assemelha a uma parábola, ou seja, a partir de certo limiar os aumentos na riqueza não se traduzem em mais saúde. 
Há vários aspectos a considerar no chamado paradoxo entre riqueza e saúde: a comparação entre os países, a comparação entre regiões de um mesmo país e a comparação entre ricos e pobres em uma mesma região. Além disso, é importante prestar atenção a dois aspectos relacionados à renda e à riqueza: os valores absolutos e a distribuição ou valores relativos.

\section{QUAIS SÃO OS IMPACTOS DO NÍVEL ABSOLUTO DE RIQUEZA SOBRE OS INDICADORES DE SAÚDE?}

Em estudo recente, comparando as tendências temporais de redução da mortalidade na infância e entre adultos, em todos os países membros da Organização das Nações Unidas (ONU), no período de quarenta anos, entre 1960 e 2000, observou-se comportamento distinto entre três grupos constituídos segundo a taxa de mortalidade em 2000.

Foram constituídos três grupos para a mortalidade na infância, correspondendo aos países com mortalidade de menores de cinco anos: baixa (3,9 a 60,0 óbitos por 100 mil habitantes), média (66,0 a 156,0 óbitos por 100 mil habitantes) ou alta (160,0 a 316,0 óbitos por 100 mil habitantes). No primeiro grupo foram classificados 117 países com PIB per capita médio de US\$12.086,00; 8\% da população vivendo na miséria com renda inferior a um dólar por dia; $14 \%$ de população feminina analfabeta e gasto público médio em saúde de US\$650,00 por pessoa/ano.

No segundo grupo foram classificados 45 países com PIB per capita de US\$2.660,00; 26\% da população vivendo na miséria; $38 \%$ da população feminina analfabeta e gasto médio em saúde de US $\$ 56,00$. No terceiro grupo foram classificados 23 países 
extremamente pobres com PIB per capita de US\$1.011,00; 53\% da população vivendo na miséria; $63 \%$ da população feminina analfabeta e gasto médio em saúde de apenas US\$10,00.

A taxa média de mortalidade na infância foi de 20 óbitos por 100 mil no primeiro grupo, 106 óbitos por 100 mil no segundo e 207 óbitos por 100 mil no terceiro, mostrando relação inversa entre a riqueza dos países e a mortalidade na infância. A análise de tendência da mortalidade no período de 1960 a 2000 revelou declínio das taxas nos três grupos, porém com menor aceleração no grupo dos países mais pobres, embora se considere mais fácil, através de medidas de saúde pública, reduzir taxas de mortalidade na infância partindo de patamares mais altos.

As mesmas comparações feitas para a mortalidade de homens adultos mostraram que houve declínio da mortalidade durante todo o período para os países dos grupos um e dois. Nos países do grupo três, a mortalidade aumentou na década de 1990, revertendo a tendência anterior de declínio, atingindo, em 2000, valores mais altos do que os observados em 1960.

As desigualdades na riqueza dos países aumentaram acentuadamente desde o início do século XIX até o final do século XX. Por volta de 1820 o país mais rico era a Grã-Bretanha, com PIB per capita de US $\$ 1.756,00$ (valores ajustados ao dólar de 1990) e o mais pobre era a China, com PIB per capita de US\$523,00. Portanto, a diferença entre os extremos era de cerca de três vezes. Em 1900, essa diferença alcançou dez vezes. Em 2000, chegou a 75 vezes e, em 2006, a 660 vezes. O PIB per capita dos países mais pobres, que, em 1820 , era de US $\$ 523,00$ para a China, em 2006 era de apenas US\$133,00 para o Zimbábue. 
Ainda que se leve em conta o fato de que os dados não eram disponíveis para os países mais pobres nos primeiros anos analisados, é notória a deterioração da situação econômica dos países africanos no final do século XX e início do XXI. De maneira ainda mais espetacular observa-se o crescimento da riqueza dos países mais ricos, cujo PIB per capita passou de US\$1.756,00 para o Reino Unido em 1820, e a US\$ 87.829,00 para Luxemburgo em 2006. Resumo da ópera: os países pobres ficaram cada vez mais pobres e os países ricos cada vez mais ricos durante os últimos dois séculos. A diferença de esperança de vida ao nascer entre a população do Zimbábue e a de Luxemburgo é de 41,2 anos, ou seja, um recém-nascido em Luxemburgo pode esperar viver cerca de quarenta anos a mais do que outro no Zimbábue.

No interior dos países também ocorre grande desigualdade no nível de riqueza, com repercussões sobre a saúde. Por exemplo, no Brasil, em 2005, as diferenças entre os estados do Maranhão - com um dos menores PIB per capita do país $(\mathrm{R} \$ 4.138,90)$ - e o de São Paulo $(\mathrm{R} \$ 18.255,00)$ podem ser observadas na esperança de vida ao nascer, esperança de vida aos 60 anos, mortalidade infantil e mortalidade infantil pós-neonatal, entre outros indicadores de saúde. $\mathrm{Na}$ esperança de vida ao nascer, a diferença é de 6,8 anos; aos 60 anos uma pessoa vivendo em São Paulo pode esperar viver em média mais 21 anos, enquanto outra, vivendo no Maranhão, pode esperar viver em média mais 19 anos. A mortalidade infantil e a mortalidade pós-neonatal são três vezes maiores no Maranhão.

Além dos diferenciais assinalados entre as unidades da federação também são importantes as diferenças entre as cidades e no interior das cidades. A Fundação Sistema Estadual de Análise 
de Dados (Seade), responsável pelos sistemas de informação estatística do governo do estado de São Paulo, desenvolveu o Índice Paulista de Responsabilidade Social para classificar os municípios segundo três eixos: riqueza, longevidade e escolaridade. No grupo I foram incluídos os municípios com elevado nível de riqueza e que apresentavam bons indicadores sociais em educação e saúde; no grupo II, os municípios com bons níveis de riqueza e indicadores sociais ruins. Os municípios do grupo III eram pobres, mas apresentavam bons indicadores sociais; os do grupo IV eram pobres e apresentavam indicadores sociais intermediários e no grupo $\mathrm{V}$ os municípios eram pobres e apresentavam indicadores sociais ruins. O próprio indicador, portanto, permite separar o desempenho nos indicadores sociais do nível de riqueza municipal.

Utilizando esse indicador, observa-se que, embora a proporção de mães adolescentes apresente um gradiente que aumenta conforme diminui a riqueza dos municípios considerados, a proporção de mulheres com sete ou mais consultas de pré-natal é mais alta no município do grupo III: pobre com bons indicadores sociais. A pior situação é observada nos municípios pobres com indicadores sociais ruins ou intermediários. E a situação intermediária ocorre nos municípios ricos. Chama a atenção o fato do IDH ser relativamente próximo entre os municípios dos vários grupos, exceto para o primeiro, em que ele é significativamente mais alto. Estes dados já começam a indicar que a relação entre riqueza e condições de saúde ou uso de serviços de saúde não é simples.

O Centro de Informação em Saúde, da Secretaria Municipal de Saúde de São Paulo, criou um índice de saúde baseado na 
mortalidade infantil, mortalidade proporcional precoce (antes dos 60 anos) por doenças crônicas, incidência de tuberculose e mortalidade por causas externas para estratificar as subprefeituras da capital. Os valores do índice permitem a distribuição das 31 subprefeituras em seis estratos. No grupo I, com índice de saúde acima de 0,80, foram classificadas quatro subprefeituras que apresentavam, em 2005, mortalidade infantil variando entre 6,1 e 10,9 óbitos por mil nascidos vivos; 7,4 a 17,9\% de mortalidade proporcional precoce; 32,5 a 51,6 casos por 100 mil habitantes de incidência de tuberculose e 33,1 a 38,3 óbitos por causas externas para 100 mil habitantes. Para todos os indicadores utilizados os valores são os mais baixos observados.

No grupo II, com índice da saúde entre 0,70 e 0,79, foram classificadas duas subprefeituras com mortalidade infantil de 8,0 e 9,5 óbitos por mil nascidos vivo; 15,3 e 19,8\% de mortalidade proporcional precoce; 49,0 casos de tuberculose por 100 mil habitantes e 44,8 e 48,8 óbitos por causas externas para cada 100 mil habitantes. Comparativamente ao grupo anterior, este apresenta maior mortalidade proporcional precoce e maior mortalidade por causas externas.

No grupo III, havia quatro subprefeituras com índice de saúde entre 0,60 e 0,69. Nessas áreas a mortalidade infantil foi de 12,0 a 14,0 óbitos por mil nascidos vivos; a mortalidade proporcional precoce variou entre 16,4 e $23,7 \%$; a incidência de tuberculose, entre 52,4 e 58,9 casos por 100 mil e a mortalidade por causas externas, entre 43,7 e 57,9 óbitos por 100 mil. Os indicadores são todos mais altos do que aqueles observados nos grupos I e II. 
Três subprefeituras classificaram-se no grupo IV com índices de saúde entre 0,50 e 0,59. A mortalidade infantil variou de 11,7 a 12,9 óbitos por mil nascidos vivos; a mortalidade proporcional precoce, entre 14,8 e $26,2 \%$; a mortalidade por causas externas, de 56,6 a 81,7 óbitos por 100 mil e a incidência de tuberculose, de 59,4 a 72,5 casos por 100 mil. Este grupo apresenta pior situação do que o anterior em relação à incidência de tuberculose e mortalidade por causas externas.

O grupo V reuniu 14 subprefeituras, com índices de saúde entre 0,40 e 0,49 . A mortalidade por causas externas foi muito alta, variando entre 55,1 e 121,6 óbitos por 100 mil habitantes; a incidência de tuberculose também foi muito alta, entre 47,8 e 81,0 casos por 100 mil habitantes; a mortalidade proporcional precoce atingiu 20,1 a 42,1\% dos óbitos e a mortalidade infantil chegou ao valor mais alto: 16,7 óbitos por mil nascidos vivos.

Finalmente o grupo VI reuniu quatro subprefeituras com índices de saúde muito baixos $(<0,40)$. Embora a mortalidade infantil e a mortalidade por causas externas sejam comparáveis àquelas observadas nos demais grupos (11,5 a 15,2 óbitos por mil nascidos vivos e 42,5 a 53,1 óbitos por 100 mil habitantes respectivamente), a mortalidade proporcional precoce chegou a $44 \%$ dos óbitos, e a incidência de tuberculose foi maior do que 70 casos por 100 mil em todas as subprefeituras. Há forte correspondência entre os índices de saúde e a renda média dos responsáveis pelos domićlios, que variou entre 17,67 salários mínimos no grupo I e 3,95 salários mínimos no grupo VI.

Em resumo, as desigualdades no nível de saúde e no uso de serviços de saúde parecem estar relacionadas com o nível absoluto de renda ou de riqueza dos países, estados, municípios e 
divisões intramunicipais. O paradoxo da dissociação entre nível de renda ou riqueza e o estado de saúde começa a ser notado quando as comparações se restringem aos países ricos, ou seja, quando são feitas entre populações de países desenvolvidos, onde as necessidades básicas estão adequadamente supridas para a maioria da população, e mesmo as pessoas mais pobres ultrapassaram os limiares das carências materiais básicas.

\section{A CONCENTRAÇÃO NA DistRiBUiÇÃO RELATIVA DA RIQUEZA}

Ainda na década de 1970 começa a chamar a atenção o fato de que, a partir de certo limiar de renda, os ganhos adicionais na esperança de vida deixam de estar associados aos níveis médios de renda.

Na década de 1980, Richard Wilkinson, estudando nove países desenvolvidos, mostrou que a esperança de vida ao nascer estava associada mais fortemente a indicadores de distribuição de renda do que ao PIB per capita. Na década seguinte, diversos estudos reforçaram as demonstrações empíricas da relação entre nível de saúde e distribuição de renda.

A partir de 1969 observa-se enorme crescimento das desigualdades na distribuição da renda, tanto entre os países como entre diferentes grupos sociais no interior de cada país. Em 2000, cerca de três quintos da população mundial viviam em sessenta países extremamente pobres, apropriando-se apenas de $6 \%$ da riqueza produzida no mundo, recebendo menos de dois dólares por pessoa por dia. Em vinte anos, entre 1977 e 1999, nos Estados Unidos, os $20 \%$ mais pobres da população tiveram redução 
de $9 \%$ em sua renda, enquanto os $20 \%$ mais ricos tiveram um acréscimo de $43 \%$. No topo da pirâmide, o 1\% dos mais ricos teve um aumento de $115 \%$ em sua riqueza. Os quatrocentos cidadãos norte-americanos mais ricos possuem riqueza superior ao PIB da China.

Estudos que buscam explorar a relação entre nível de riqueza, distribuição de renda e satisfação com a vida, ou bem-estar mostram que, embora o nível geral de satisfação e bem-estar aumente com o crescimento do nível de riqueza do país, para o mesmo nível de riqueza, a satisfação e o bem-estar são maiores nos países que apresentam menor desigualdade na distribuição da renda.

\section{PARADOXO DA DISSOCIAÇÃO ENTRE RIQUEZA E NÍVEL DE SAÚDE}

As análises das relações entre PIB per capita e esperança de vida ao nascer mostram que de maneira geral os países mais pobres também apresentam menores esperanças de vida. Entretanto, algumas exceções chamam a atenção e não são fáceis de serem explicadas no marco das teorias materialistas apresentadas no primeiro capítulo. Por exemplo, o Sri Lanka e o Vietnã, países muito pobres com PIB per capita inferior a US\$ 1.500,00, apresentam esperança de vida acima de 70 anos; o Gabão com PIB per capita mais alto que o do Brasil e com esperança de vida cerca de 15 anos mais baixa; a Costa Rica com PIB per capita oito vezes menor do que o dos Estados Unidos e a mesma esperança de vida.

Entre os países pertencentes à Organização para a Cooperação Econômica e o Desenvolvimento (OCED), a correlação 
entre o PIB per capita e a esperança de vida é mediana ( $\mathrm{r}=0,5824)$. Até o PIB per capita de 20 mil dólares, a relação é mais linear. A partir desse limiar, os acréscimos no PIB per capita não estão necessariamente associados a iguais aumentos na esperança de vida. Os países com maior longevidade de suas populações não são os mais ricos.

Cerca de três quartos da diferença na esperança de vida entre os países ricos pode ser explicada pela maior ou menor igualdade na distribuição da renda. As sociedades mais igualitárias compartilham uma característica comum, que é a maior coesão social. A saúde é produzida socialmente e algumas formas de organização social são mais saudáveis do que outras.

A esperança de vida se correlaciona com qualquer uma das medidas de concentração de renda: o coeficiente de Gini, a proporção da riqueza apropriada pelo percentil 70 da distribuição populacional, a proporção da população vivendo em pobreza relativa e outros. O mesmo pode ser observado para outros desfechos de saúde, como taxas de mortalidade infantil, mortalidade geral e específica por causas dentre as quais se destacam as mortes violentas.

Os impactos das desigualdades na qualidade de vida são diretos sobre os mais pobres, mas afetam as demais camadas da sociedade porque provocam deterioração da vida pública, perda do senso de comunidade, bem como aumento da criminalidade e da violência. A vida em sociedades com grandes desigualdades sociais parece menos civilizada, como afirma Wilkinson, importante estudioso do tema.

Wilkinson demonstra que os períodos em que houve maior aumento na esperança de vida na Inglaterra foram os que 
coincidiram com a primeira e a segunda guerras mundiais. Ao contrário do que seria esperado, a escassez a que a população civil foi submetida nessas épocas não foi acompanhada de redução na esperança de vida. No primeiro período, observou-se ganho de 6,6 anos na esperança de vida e, no segundo, 6,5 anos.

Durante as guerras houve piora no padrão de vida e deterioração dos serviços de saúde que foram prioritariamente direcionados para o atendimento aos soldados feridos. No entanto, a esperança de vida cresceu. Em ambos os períodos houve pleno emprego para fazer frente ao esforço de guerra e dramática redução na desigualdade de renda. O salário real da classe trabalhadora cresceu $9 \%$ enquanto na classe média caiu $7 \%$. A coesão social aumentou em decorrência da união frente ao inimigo comum, das mudanças no mercado de trabalho e da política de cooperação para o esforço de guerra.

Além da maior coesão social e dos laços cooperativos que caracterizam o chamado capital social, outras explicações para melhor nível de saúde em situações de menor desigualdade apontam as políticas públicas universalistas como responsáveis por parcela dos resultados.

Os países mais igualitários gastam mais em bens e serviços públicos. Serviços universais de saúde podem reduzir as desigualdades basicamente de duas maneiras: diminuindo as diferenças nas condições de vida, representando um salário indireto para os trabalhadores e oferecendo serviços similares para toda a população. Em contrapartida, a segregação urbana reforça os efeitos negativos da desigualdade de renda, concentrando a pobreza, produzindo isolamento social e diminuição de oportunidades, 
reduzindo a aplicação de recursos públicos nas áreas pobres e provocando o declínio da coesão social.

A menor esperança de vida nos países pobres pode ser o resultado da fome, do consumo de água contaminada e das más condições sanitárias, mas não é possível explicar por esses mesmos motivos a menor esperança de vida das pessoas que vivem nas áreas mais pobres dentro de países ricos. A pobreza é potencialmente fatal para os mais pobres, porém eles representam pequena parcela da população nas nações ricas. A desigualdade, entretanto, afeta todos os grupos sociais e tem maior impacto sobre a mortalidade mesmo entre os mais bem situados socialmente.

O melhor nível de saúde observado nas situações de menor desigualdade pode ser explicado através de comportamentos saudáveis que seriam mais frequentes nessas populações. Entretanto, conforme demonstrado pelo estudo dos funcionários públicos na Inglaterra, os tradicionais fatores de risco explicam menos de metade do excesso da mortalidade por doença isquêmica do coração entre os trabalhadores em diferentes posições ocupacionais.

Tomando como referência a taxa de mortalidade nos funcionários administrativos, os executivos apresentam risco de morrer por doença isquêmica do coração (DIC) 2,1 vezes maior. Desse excesso de risco, apenas 0,3 é explicado pelos fatores de risco tradicionais. Entre os gerentes, o excesso de risco é de 3,2 vezes com apenas 0,9 sendo explicado por exposições aos fatores de risco comportamentais. Para os trabalhadores manuais, o excesso é de quatro vezes e 1,4 é explicado por comportamentos não saudáveis. 
Marmot, um dos autores do estudo, dá mais importância às condições e às relações no trabalho, como determinantes dos riscos observados, do que ao chamado "estilo de vida". Postulase assim um conjunto amplo de determinantes psicossociais, relacionados com o maior ou menor controle sobre a vida, como elementos mediadores entre a posição social e o nível de saúde.

As desigualdades sociais em saúde são manifestações de determinantes sociais do processo saúde-doença. Os desfechos de saúde não são específicos a nenhuma causa em particular, mas o resultado de processos sociais nos quais interferem inúmeras mediações. Portanto, nenhuma resposta médica resolverá o problema, nem intervenções que enfatizem o estilo de vida concebido como fruto de escolhas individuais. O enfrentamento das desigualdades sociais em saúde depende de políticas públicas capazes de modificar os determinantes sociais, melhorar a distribuição dos benefícios ou minorar os efeitos da distribuição desigual de poder e propriedade nas sociedades modernas. 



\section{$4 \mid$ As Desigualdades Étnicas
Necessariamente Significam Racismo?}

A igualdade e a desigualdade são conceitos dimensionais relativos a quantidades mensuráveis, ou seja, referem-se a quantidades equivalentes ou distintas de atributos estudados. Equidade e iniquidade são conceitos políticos que expressam, além da igualdade ou desigualdade quantitativa, uma avaliação moral relacionada com a noção de justiça social.

As iniquidades são desigualdades injustas ou decorrentes de alguma forma de injustiça. A maioria das desigualdades sociais em saúde é injusta porque reflete a distribuição dos determinantes sociais da saúde na sociedade, remetendo, portanto, à distribuição desigual de poder e propriedade. Na perspectiva liberal, as desigualdades sociais em saúde são vistas como reflexo das escolhas pessoais que levam alguns a alcançar posições sociais de prestígio, que lhes conferem poder e posses na sociedade, enquanto outros permanecem em posições desvantajosas sem poder usufruir a riqueza social, sem desfrutar de prestígio ou poder político.

Na perspectiva do materialismo histórico, a posição dos indivíduos na estrutura de classes sociais representa um conjunto de constrangimentos e circunstâncias que acabam por moldar as escolhas individuais, de modo que o pertencimento de classe leva os diferentes indivíduos a compartilharem modos de vida semelhantes. 
Essas visões de mundo que competem na explicação das desigualdades e iniquidades sociais, entretanto, não dão conta das iniquidades relacionadas com o pertencimento a determinados grupos étnicos, uma vez que os indivíduos não são livres para escolher a qual grupo pertencer, nem esta determinação está relacionada diretamente com a posição de classe.

Qualquer consideração das desigualdades sociais em relação a grupos étnicos carrega a dupla determinação: a posição social que tais grupos ocupam na sociedade e a aceitação/rechaço que possam ter frente aos grupos majoritários.

Segundo a teoria ecossocial, apresentada no primeiro capítulo, nossas características biológicas, decorrentes da história evolutiva da espécie, do contexto ecológico em que vivemos e da trajetória de vida de cada indivíduo concreto, somam-se aos arranjos societais de distribuição de poder e propriedade, definindo padrões de produção e consumo próprios de cada classe social. Este conjunto de determinações estrutura exposições e vulnerabilidades distintas, além de definir as opções de resistência e enfrentamento das agressões e vicissitudes ao longo da vida.

Nesse contexto teórico, a discriminação praticada contra determinados grupos étnicos é um meio de expressar e institucionalizar relações sociais de dominação e repressão. É um fenômeno sancionado socialmente, justificado pela ideologia e expresso em relações pessoais e institucionais, visando ao privilégio dos grupos dominantes às custas da exclusão e dominação dos outros. 


\section{Mas afinal 0 que é raça?}

Nas ciências biológicas raça é sinônimo de uma divisão dentro de uma mesma espécie. Entre os humanos, a noção de raça aparece como uma construção ideológica relacionada com a crença dominante na inferioridade inata de certos grupos, como os judeus, os ciganos, os indígenas, os negros e os imigrantes.

Durante o século XIX e o princípio do século XX, com a expansão econômica e política do modo de produção capitalista e a formulação das teorias evolutivas, esta visão relativa a certos grupos sociais foi bastante reforçada como expressão da lei natural da "sobrevivência dos mais adaptados". Evidentemente os povos dominantes eram os considerados mais adaptados e capazes de exercer não apenas seu domínio sobre a natureza como também sobre os povos considerados inferiores.

Esta perspectiva considerada científica na época ainda persiste entre muitos teóricos, embora o desenvolvimento da genética tenha demonstrado que todos os seres humanos são idênticos em mais de $75 \%$ do seu material genético, sendo totalmente impossível identificar, através da análise das características genéticas da espécie, qualquer indicador seguro da existência de raças ou subespécies humanas.

Nos últimos tempos os avanços da genética permitiram demonstrar que mais de 95\% das variações genéticas humanas são observadas no interior dos grupos 'raciais', de modo que há mais variação genética dentro da mesma raça do que entre elas.

Os traços físicos externos, que em todos os tempos permitiram a identificação de grupos com particularidades em relação aos outros, representam o resultado das interações entre o 
genótipo e o ambiente e a trajetória histórica de cada grupo. Está bastante demonstrado que a expressão fenotípica de qualquer gene, ou conjunto de genes, é extremamente variável segundo o ambiente no qual o organismo vive e se desenvolve.

Assim, não há, do ponto de vista estritamente biológico, nenhuma sustentação científica para a noção de raça. Embora esta noção não seja útil como marcador de diferenças biológicas, ela pode ser um importante marcador de iniquidades e injustiças sociais. Oficialmente, portanto, a noção de raça/ etnia é um construto sociopolítico, e não uma categoria baseada cientificamente em diferenças biológicas intrínsecas.

Com o avanço científico, a noção de raça passa a ser vista como equivalente ao conceito de grupo étnico, definido, principalmente, com base em características socioculturais próprias de certos grupos sociais, que, por diferentes motivos, mantém um isolamento relativo a outros grupos e populações, conservando seus hábitos e costumes mesmo quando deslocados em relação a seu país ou região de origem.

Raça ou etnia é uma importante dimensão da estratificação social que se relaciona de maneira complexa com a classe social, refletindo principalmente a distribuição de poder entre os grupos sociais no interior de uma dada sociedade. Frequentemente as diferenças entre os grupos raciais estão fortemente associadas às condições socioeconômicas e tendem a desaparecer quando essas são controladas para efeito de análise. Entretanto, na maioria dos estudos de desigualdades sociais aparece um efeito independente da raça sobre a saúde após controlar para variáveis socioeconômicas. 
Alguns autores consideram que raça é um poderoso construto social com profundas implicações sobre a saúde e que é fundamental utilizar a categoria etnia como variável social para melhor compreender o modo como as relações raciais produzem desigualdades sociais em saúde.

Nos Estados Unidos a raça tem sido usada como variável de classificação no lugar da classe social desde o censo de 1790. Ela é definida com base na ancestralidade, isto é, na origem africana de qualquer um dos progenitores ou antepassados dos indivíduos, independentemente das características fenotípicas atuais.

Quanto mais miscigenada uma população, mais difícil é a aplicação dessa concepção. Nestes casos o mais comum é a substituição do critério de ancestralidade pela classificação baseada na cor da pele, admitindo-se diferentes gradações entre os tipos não miscigenados e os demais. No Brasil a classificação sempre esteve baseada no critério de cor e traços fisionômicos.

O significado concreto da raça como variável social preditora de estados de saúde é modelado pelo contexto histórico, socioeconômico, cultural e epidemiológico, sendo praticamente impossível estabelecer regras universais sobre as relações entre raça e saúde. Dito de outra maneira, não é possível afirmar, sem levar em conta o contexto, que determinados grupos étnicos apresentarão inexoravelmente determinados problemas de saúde.

Os determinantes sociais de saúde são mais bem compreendidos em contextos particulares do que como variáveis independentes com vida própria. Ser homem ou mulher, jovem ou idoso, pobre ou rico, sérvio ou croata, tem diferentes significados e diferentes consequências para a saúde em diferentes contextos 
históricos e sociais. Ou seja, as relações entre essas categorias intermediárias e a posição social de classe são sempre complexas e subordinadas.

De qualquer modo, a raça ou etnia, como dimensão particular da estratificação social, é um importante determinante dos processos de reprodução social, condicionando as possibilidades de acesso aos bens e serviços, modelando a dimensão dos processos sociais e estabelecendo os limites para a repartição do poder.

\section{Relações entre etnia e saúde}

Embora as raças não tenham expressão biológica, como construto social elas têm importante impacto sobre as condições de saúde e o acesso e utilização de serviços de saúde.

Nas pesquisas em desigualdades sociais em saúde, as desigualdades raciais ou étnicas são geralmente atribuídas a diferentes condições socioeconômicas ou valores culturais resultantes da pior inserção social desses grupos na sociedade. Entretanto, mesmo após controlar o efeito dessas variáveis, as diferenças permanecem demonstrando o efeito independente que o pertencimento a determinado grupo étnico ou racial pode ter sobre o estado de saúde.

Há pelo menos três aspectos dessa relação que são normalmente subavaliados nas pesquisas epidemiológicas: o efeito da acumulação de desvantagens ao longo da trajetória de vida, os efeitos contextuais decorrentes da concentração de grupos étnicos minoritários em áreas residenciais pobres e deterioradas do ponto de vista urbano e os efeitos deletérios de viver em uma sociedade percebida como racista. 
No Brasil, embora nunca tenha havido um sistema consolidado de segregação racial, a população negra sofre sistematicamente maior desvantagem social. A concentração desta população é maior nas regiões mais pobres do país, seu nível de desenvolvimento humano é inferior ao da população em geral, o acesso a saneamento básico, educação e postos de trabalho também é significantemente menor.

O efeito das desigualdades étnicas sobre a saúde pode ser modificado pela inserção ocupacional, conforme demonstrado em investigação sobre tabagismo em diferentes grupos étnicos e ocupacionais na população norte-americana. Os pesquisadores verificaram que as maiores prevalências de tabagismo ocorreram em quatro grupos sociais: trabalhadores manuais ou do setor de serviços; brancos com escolaridade secundária ou inferior; trabalhadores agrícolas negros com escolaridade secundária ou inferior; indígenas e esquimós em todos os grupos exceto aqueles com formação universitária e em hispânicos trabalhando no setor de serviços.

Entre funcionários de uma universidade pública brasileira, o ganho excessivo de peso mostrou associação com a cor apenas para mulheres, para os homens não existem diferentes por cor. A associação se reduziu após o controle das variáveis socioeconômicas, mas permaneceu significante.

No estado de Nova York, no período de 1988 a 1992, praticamente não se observaram diferenças raciais na mortalidade por doenças coronarianas em homens, entre trabalhadores não manuais, independentemente das características dos municípios de residência. Entre os trabalhadores manuais, o risco era sempre maior para trabalhadores negros e diretamente proporcional à 
desigualdade de renda existente no município de residência. Assim, para os municípios com maior desigualdade, a diferença na mortalidade entre negros e brancos chegou a 1,8 vezes, caindo para 1,3 nos municípios com menor desigualdade. Esses dados demonstram os efeitos complexos da interação entre distintas variáveis sociais, reforçando a concepção de raça como construto social.

$\mathrm{O}$ risco de mortalidade prematura, ou seja, anterior ao indivíduo completar 65 anos, é sempre maior em negros e menor em hispânicos, em comparação às taxas observadas para os brancos, nos mesmos grupos de setores censitários, agrupados segundo proporção de pobres, concentração de renda e percentual de riqueza.

Os índios Maoris na Nova Zelândia morrem em média dez anos mais cedo do que os descendentes de europeus, provavelmente em decorrência da pobreza e das menores oportunidades socioeconômicas, além das dificuldades de acesso e utilização dos serviços de saúde. A demora na busca de tratamento possivelmente contribui para a maior mortalidade por doenças cerebrovasculares, câncer, doenças cardíacas, diabetes e enfermidades mentais.

No Brasil a probabilidade de ter um recém-nascido de baixo peso, pequeno para a idade ou prematuro, é significantemente maior entre mães pretas ou mulatas quando comparadas a mães brancas, mesmo após anular o efeito da renda e da escolaridade, ou seja, tornando esses grupos de mães comparáveis com relação a essas variáveis.

Há muitas evidências empíricas das relações entre etnia e saúde, entretanto, a maioria dos estudos não consegue separar 
adequadamente os efeitos decorrentes da posição social, do nível socioeconômico, das características culturais, de aspectos que poderiam ser decorrentes da discriminação e do racismo. Há uma tendência a considerar qualquer desigualdade como reflexo das condições de discriminação, porém não é tão simples assim. Como todos esses aspectos são socialmente determinados e todos eles têm implicações uns sobre os outros, as questões de etnia e saúde carregam um conjunto complexo de determinações nem sempre passíveis de tratamento estatístico, ou mesmo qualitativo, adequado nas pesquisas populacionais.

\section{Diferenças nO ACESSO A SERVIÇOS DE SAÚdE}

As diferenças no acesso a serviços de saúde têm outro tipo de determinantes. Além das condições socioeconômicas já assinaladas em relação ao estado de saúde, nas desigualdades no acesso a serviços importa também a configuração da política nacional de saúde, isto é, quais são os princípios que a constituem, a forma de organização dos serviços e as formas de relação que se estabelecem entre clientela e profissionais de saúde.

No âmbito da política de saúde, os princípios de universalidade, integralidade e equidade que orientam a constituição do sistema de saúde brasileiro podem garantir acesso mais igualitário aos diferentes grupos sociais. Como evidência, podemos comparar a situação observada em dois momentos distintos: um anterior à criação do SUS e outro posterior à sua existência.

Em relação ao primeiro momento, podemos comparar a probabilidade de acompanhamento pré-natal em mulheres brancas, mulatas e pretas, em Ribeirão Preto (SP), no final da década de 1970. É interessante utilizar nesse exemplo dados do estado 
de São Paulo, onde a rede de atenção básica sempre foi bastante extensa, não constituindo um obstáculo ao acesso. Tomando como referência as mulheres brancas, a probabilidade de não ter tido acompanhamento pré-natal para as mulheres mulatas era 1,82 vezes maior e para mulheres pretas, 3,47 vezes maior.

Após a criação do SUS, dados de internações hospitalares, de uma amostra significativa da população brasileira em 1998, mostram que não há diferença nas taxas entre brancos e negros. A probabilidade de ter sido internado no último ano é diretamente proporcional à idade, maior entre os indivíduos mais pobres e com menor escolaridade e com pior estado de saúde, independentemente da cor.

Isto não significa que não existam mais diferenças por grupos étnicos no acesso e utilização dos serviços de saúde nem a inexistência de discriminação, mas demonstra que uma política pública de acesso universal pelo menos pode possibilitar acesso ampliado para todas as camadas da população. Certamente continua havendo diferenciais na qualidade da assistência e na possibilidade de utilização de determinados bens e serviços.

Com relação à organização dos serviços, estudo realizado no Rio de Janeiro, sobre a qualidade da assistência pré-natal e ao parto, mostrou probabilidades distintas de obter um cuidado pré-natal adequado para mulheres brancas, mulatas ou pretas. A proporção de mulheres sem assistência pré-natal, embora baixa em todos os grupos, foi significativamente mais alta em pardas $(4,7 \%)$ e pretas $(6,7 \%)$ quando comparadas às gestantes brancas $(2,5 \%)$.

Nessa mesma pesquisa, as autoras encontraram diferenças significativas na probabilidade de receber anestesia durante o 
parto para as gestantes brancas $(86,5 \%)$ quando comparadas a gestantes negras $(78,2 \%)$. Menor proporção de mulheres brancas $(18,5 \%)$ teve de procurar mais de uma maternidade até ser atendida quando comparadas a mulheres pardas $(28,8 \%)$ ou pretas $(31,8 \%)$.

Parte dessas diferenças pode ser atribuída a diferentes condições socioeconômicas, porém, mesmo após levar em conta o nível de escolaridade como indicativo da posição social, as diferenças permanecem.

\section{RACISMO E DISCRIMINAÇÃO}

O termo racismo refere-se a uma ideologia social de inferioridade, que é usada para justificar o tratamento diferencial concedido a membros de grupos raciais ou étnicos, por indivíduos e instituições, usualmente acompanhados por atitudes negativas de depreciação com relação a esses grupos. As manifestações de racismo variam consideravelmente segundo tempo e lugar, sendo geralmente produzidas por sociedades nas quais a distribuição desigual do poder está baseada não apenas na posição de classe, mas são atravessadas também pela noção de raça ou etnia.

A discriminação racial ou étnica é um fenômeno estruturado e sancionado socialmente, justificado pela ideologia e expresso através de interações entre indivíduos e instituições; baseada na dominação, visa a manter privilégios para os grupos dominantes à custa de privação e exclusão dos demais.

Uma sociedade racista acaba por reproduzir a discriminação em toda a estrutura social, limitando e restringindo o desenvolvimento econômico e social não apenas dos grupos discriminados, mas da sociedade como um todo. Os integrantes dos grupos 
étnicos ou raciais discriminados sofrem vários tipos de desvantagens, acumulando-se os efeitos da discriminação econômica, segregação espacial, exclusão social, destituição do poder político e desvalorização cultural.

A segregação significa restrição das possibilidades de acesso a oportunidades de educação e emprego, resultando em inserção social desvantajosa e ausência de mobilidade social. As diferenças em relação à riqueza são particularmente marcantes no caso da segregação racial contra os negros norte-americanos. A riqueza mediana das famílias brancas, em 1994, era de aproximadamente 44 mil dólares enquanto para as famílias negras era de apenas quatro mil dólares, portanto 11 vezes menor.

O racismo significa também maior probabilidade de exposição a experiências pessoais de discriminação. A percepção de discriminação varia com o nível socioeconômico dos indivíduos, sendo maior entre aqueles mais bem posicionados na escala social. Com relação ao gênero, a discriminação é proporcionalmente mais percebida pelos homens, enquanto a relação com a idade é bastante variável nas diferentes sociedades.

Alguns problemas e comportamentos de saúde apresentam maior associação com a exposição a situações de discriminação e racismo: transtornos mentais, hipertensão arterial, baixo peso e prematuridade, doenças cardíacas, diabetes e obesidade, abuso de álcool e drogas e tabagismo. Os efeitos do racismo e da discriminação sobre a saúde podem ser agudos ou crônicos, agindo provavelmente através dos mecanismos fisiopatológicos do estresse. A experiência de exposição a atos racistas e discriminatórios pode funcionar como um estressor agudo, enquanto viver em uma sociedade racista pode funcionar como um estressor 
crônico. Os efeitos podem ser modificados pelos estilos pessoais de adaptação a situações de estresse (coping), bem como pelas expectativas dos indivíduos, estrutura comunitária, fatores históricos e políticos de resposta e enfrentamento ao racismo.

No Mississipi, após a abertura dos hospitais públicos aos negros, entre 1965 e 1971, a mortalidade pós=neonatal caiu 50\%, demonstrando o impacto da aprovação da lei dos direitos civis sobre a saúde populacional. De forma geral, entre 1950 e 2004, houve acentuada redução da mortalidade infantil entre os negros, como resultado de distintos processos sociais: migrações do sul para o norte e consequente urbanização, crescimento econômico sustentado no país e movimento pelos direitos civis garantindo acesso à educação e saúde.

Os efeitos da discriminação sobre a saúde decorrem de diferentes mecanismos que envolvem a segregação residencial e ocupacional, com aumento da probabilidade de viver em bairros sem acesso a condições mínimas de vida saudável; aumento do risco de exposições a contaminantes ambientais; acumulação das sensações de medo e raiva; aumento de comportamentos insalubres como o consumo de álcool, drogas e tabaco; diagnósticos e tratamentos tardios ocasionados pela menor possibilidade de acesso aos serviços, agravada pela discriminação institucional.

Mesmo em sociedades em que o racismo não é institucionalizado, ou seja, não está legalmente sancionado, a prevalência da experiência de exposição a agressões motivadas pelo racismo pode ser impressionantemente alta. Em pesquisa realizada no Reino Unido no final dos anos 90, com grupos étnicos minoritários, foram relatadas agressões físicas motivadas pelo racismo por 3\% dos entrevistados, $12 \%$ de agressões verbais, e $64 \%$ deles 
acreditavam que os empregadores exerciam algum tipo de discriminação nas contratações de trabalho.

Um aspecto que tem sido observado nas pesquisas empíricas sobre racismo e discriminação é a chamada dissociação pessoa/ grupo. Os entrevistados tendem a identificar e reconhecer maior discriminação contra o grupo ao qual pertencem do que contra si mesmos. Este aspecto é visto como um recurso adaptativo que leva à negação da discriminação, visando a limitar ou conter os efeitos nocivos dessa percepção sobre a saúde.

A proporção de recém-nascidos com menos de 1.500 gramas de peso ao nascer é três vezes maior entre mães negras de Chicago que referem experiências de discriminação racial. Este aumento de risco não é explicado pela idade, número de filhos anteriores, assistência pré-natal, tabagismo, consumo de álcool, uso de drogas ou pela inexistência de rede social de apoio. Pesquisa comparando a chance de ter um bebê com peso muito baixo mostra que ela varia com a composição racial do casal. Casais com pais e mães brancos têm menor chance de terem bebês com menos de 1.500 gramas. Em seguida, em ordem crescente de risco, vêm os casais formados por mães brancas e pais negros, mães negras e pais brancos e mães e pais negros.

A discriminação pode assumir muitas formas, embora o racismo seja uma das mais importantes. O direito a receber tratamento igual, isto é, não-discriminação, é um dos aspectos fundamentais dos direitos humanos. Ninguém deve ser tratado de maneira diferente e negativa com base nas diferenças de gênero, etnia, crença religiosa, orientação sexual ou incapacidade.

Em termos operacionais, a discriminação pode ser captada com a investigação de ocorrência de tratamento ofensivo. No 
inquérito nacional de saúde realizado na Suécia, em 2006, 6,7\% da população relatou ter sido vítima de tratamento ofensivo. Destes, $35 \%$ relacionaram o fato a alguma forma de discriminação. A maioria das mulheres atribuiu esse tratamento ofensivo a questões de gênero ou idade, ao passo que os homens referiram mais a questões étnicas.

As pessoas que relataram ter sofrido algum tipo de discriminação apresentaram maior prevalência de saúde mental ruim, ansiedade e depressão, estresse, problemas graves de sono, ideação suicida, tentativas de suicídio, baixa autoestima e doenças físicas.

A discriminação percebida também está relacionada com comportamentos de saúde e busca por assistência médica. O mesmo inquérito realizado na Suécia analisou a probabilidade de refrear a busca por serviço de saúde na presença de uma necessidade sentida entre indivíduos que referiram ou não discriminação. Após controlar por idade, escolaridade, presença de doenças crônicas e viver sozinho, os pesquisadores observaram que quanto maior a frequência de exposição a situações de discriminação, maior a probabilidade de refrear a busca a serviços de saúde, ainda que o comportamento ofensivo não estivesse relacionado com esses serviços.

Os autores do inquérito citado analisaram ainda o efeito da interação entre desvantagem econômica e percepção de discriminação, encontrando que homens que não apresentavam desvantagem econômica, sujeitos a tratamentos ofensivos atribuídos à discriminação, tiveram 5,6 vezes maior probabilidade de não procurar um serviço de saúde, do que os que não sofreram nenhum tipo de tratamento ofensivo. Para as mulheres em igual 
situação, a probabilidade de refrear a busca a serviços foi 4,2 vezes maior. Para os indivíduos com desvantagem econômica e percepção de tratamento discriminatório, a probabilidade de não procurar serviços de saúde foi 12,0 vezes maior entre os homens e 11,6 vezes maior entre as mulheres.

Um achado interessante desse inquérito é que se a pessoa que referia ter sofrido algum tipo de tratamento ofensivo não fosse capaz de identificar uma razão para o mesmo, não se observava maior probabilidade de não procurar serviços de saúde. Para os homens as razões de discriminação que estiveram mais associadas com a diminuição da procura destes serviços foram, em ordem decrescente de risco: religião, etnia ou raça, gênero e idade. Para as mulheres as razões foram: etnia ou raça, religião, gênero e idade.

Embora só recentemente as pesquisas em saúde tenham começado a se interessar pela questão da discriminação e de suas repercussões nas condições de vida e no perfil de morbimortalidade dos grupos sociais, já existem evidências importantes sobre esses aspectos.

Geralmente as pessoas que vivenciam situações de discriminação são mais vulneráveis também porque, com maior probabilidade, não podem contar com uma rede de suporte social, emocional, afetivo e prático, não confiam nas instituições nem nas pessoas com as quais convivem. Uma demonstração da importância da rede de suporte social é fornecida pela análise de uma situação limite de discriminação, como foi o extermínio dos judeus durante a ocupação nazista na Holanda. Estudo feito a partir das informações do censo da população judaica, realizado pelas autoridades nazistas, e das informações de mortalidade nos 
campos de extermínio permitiu verificar que a sobrevivência estava associada a ter familiares não judeus, pertencer a famílias não ortodoxas em questões religiosas, pertencer a famílias convertidas a outras religiões ou ter domínio da língua alemã.

Estudo conduzido em instituições andaluzas para menores infratores encontrou piores condições de saúde entre crianças e adolescentes de origem cigana nascidas na própria Espanha, quando comparadas com crianças imigrantes de outros países europeus e não europeus com situações socioeconômicas piores, sugerindo, assim, a existência de efeitos deletérios decorrentes da discriminação social contra esse grupo na sociedade espanhola.

Embora comecem a haver estudos de desigualdades sociais em saúde, enfocando especificamente os efeitos deletérios das situações em que a distribuição de poder é assimétrica entre diferentes grupos sociais, seja por questões relacionadas à idade, gênero, etnia, religião, seja por questões relacionadas à classe social ou às condições materiais de vida, ainda há um longo caminho a percorrer na compreensão de fenômenos com essa complexidade. 



\section{$5 \mid \begin{aligned} & \text { Relações de Gênero e Saúde: } \\ & \text { desigualdade OU discriminação? }\end{aligned}$}

\section{Afinal 0 que é 0 COnCeito de gênero?}

$\mathrm{Na}$ língua portuguesa a palavra 'gênero' apresenta inúmeros sentidos dependendo do campo do conhecimento em cujo discurso se insere. Entretanto, em termos gerais, gênero significa o conjunto de seres ou objetos que possuem mesma origem ou que se acham ligados pela similitude de uma ou mais particularidades. Em biologia, o termo se refere à categoria taxonômica que agrupa espécies relacionadas filogeneticamente, distinguíveis das outras por características marcantes que permitem assim a subdivisão das famílias. Na gramática, gênero se refere a classes de palavras que permitem estabelecer o contraste entre masculino e feminino, nem sempre referido a diferenças de sexo.

$\mathrm{Na}$ área de saúde o conceito de gênero retém algumas das características de sentido que a palavra tem tanto na biologia quanto na gramática. Assim, ele é utilizado para marcar características próprias aos comportamentos de grupos de sujeitos sociais e para estabelecer o contraste entre masculino e feminino, mas, principalmente, para enfocar as relações que se estabelecem entre masculino e feminino no âmbito social e que apresentam repercussões para o estado de saúde e para o acesso e utilização dos serviços de saúde.

Definitivamente, gênero não é sinônimo de sexo. Em biologia, e também na área médica, sexo é um marcador de diferenças 
biológicas entre indivíduos da espécie humana, relacionadas com aspectos anatômicos e fisiológicos do aparelho reprodutivo e eventualmente com características genéticas vinculadas aos cromossomos $x$ ou $y$. Entretanto, é muito comum atualmente os textos publicados em periódicos científicos utilizarem gênero como substituto para sexo mesmo em situações nas quais o termo correto seria sexo, pois se está fazendo referência a características biológicas de homens e mulheres. Nestes tempos do 'politicamente correto' parece que os médicos e pesquisadores em geral passaram a considerar de 'bom tom' não utilizar a palavra sexo.

Segundo a epidemiologista Nancy Krieger, o termo gênero foi introduzido nas pesquisas em saúde para ajudar a clarear o pensamento em face do ressurgimento do movimento feminista em meados no século XX. Uma das preocupações do movimento foi debater as diferenças observadas na inserção e nos papéis sociais de homens e mulheres nas sociedades capitalistas do Ocidente. Dentre os aspectos e as desigualdades enfocadas estavam, desde o início, as desigualdades em saúde. O centro do debate feminista nesta questão estava na indagação sobre os motivos ou as explicações para essa diferença: elas eram todas derivadas de diferenças inatas ligadas ao sexo ou poderiam ser atribuídas a convenções culturais construídas socialmente no processo de educação e aculturação dos homens e das mulheres, que acabavam por moldar não apenas as características masculinas e femininas, mas também determinavam os padrões de relação estabelecidos entre homens e mulheres? Para diferenciar este último aspecto foi proposto o conceito de gênero.

Como afirma Krieger, todos nós somos sexo e gênero, isto é, temos um sexo, biologicamente determinado, que influencia 
algumas das nossas condições de saúde, mas também somos gênero, isto é, produto do processo sociocultural que molda na sociedade os papéis femininos e masculinos e define as pautas de relação entre homens e mulheres. Há, assim, uma relação de mútua determinação entre sexo e gênero no qual este último adquire a maior hierarquia na produção dos estados de saúde. Portanto, as desigualdades em saúde observadas entre homens e mulheres devem ser analisadas a partir dessa dupla determinação: as relações de gênero e as peculiaridades do sexo biológico.

A confusão entre os termos sexo e gênero presente em parte da pesquisa epidemiológica e de saúde em geral é sinal de um grave erro conceitual. Além do problema já assinalado de utilizar gênero como sinônimo de sexo, outro aspecto desse uso inadequado é a utilização do conceito para denotar exclusivamente problemas relacionados com as mulheres, especialmente aqueles ligados à saúde reprodutiva.

Embora na pesquisa epidemiológica clássica, a variável sexo já fosse vista como indicadora de diferentes padrões de exposição relacionados aos comportamentos específicos de homens e mulheres e às distintas situações de vida de uns e outros, a complexidade e as múltiplas facetas das relações de gênero não estavam presentes. Esta ausência se faz sentir principalmente no âmbito das explicações teóricas para as diferenças encontradas, quando se analisa qualquer evento de saúde segundo o sexo dos indivíduos.

A variável sexo, entretanto, não dá conta das questões de gênero, pois um dos aspectos mais salientes dessas relações é a assimetria de poder que se estabelece entre homens e mulheres na maioria das sociedades e praticamente em todos os âmbitos da vida social. Por isso, a abordagem de gênero em seus aspectos 
mais complexos está presente principalmente em pesquisas com abordagens qualitativas. Porém, as diferenças observadas na distribuição do estado de saúde, das doenças e outros agravos à saúde e as desigualdades no acesso e uso de serviços de saúde podem indiretamente apontar as consequências dessas relações assimétricas de poder, permitindo o desvelamento das questões de gênero ainda que a variável de classificação utilizada seja sexo.

\section{RELAÇÃO ENTRE GÊNERO E OUTRAS CATEGORIAS NO ESTUDO DAS DESIGUALDADES}

Um aspecto muito discutido desde o surgimento do enfoque de gênero é a relação entre esta categoria de análise para a compreensão de problemas de saúde e sua distribuição social e categorias tradicionais, tais como classe social ou renda, escolaridade e ocupação, como variáveis de estratificação social.

A segunda metade do século XX assistiu à emergência de movimentos sociais diversos, centrados principalmente na defesa de interesses específicos de determinados grupos sociais definidos com base em questões de identidade cultural, diferentemente dos movimentos sociais anteriores, fortemente marcados por questões de classe, ou seja, vinculadas à posição dos sujeitos na estrutura produtiva. É nesse novo contexto que o movimento feminista ressurge e dele emerge a questão de gênero.

Parte da militância desses movimentos vai considerar que as determinações de gênero são mais importantes do que aquelas decorrentes da posição dos indivíduos na estrutura social, conferindo às relações de gênero o maior grau de determinação nos processos de saúde-doença e em outros processos sociais. 
O principal argumento dessa corrente é que ao nascer o indivíduo já passa a ter toda sua existência determinada pelas relações de gênero e, portanto, elas serão as mais importantes na hierarquia de determinações e mediações que acabam por moldar o perfil epidemiológico. Outros, entretanto, dão maior peso aos determinantes de inserção social dos indivíduos, vale dizer, à classe social, tendo nas relações de gênero um dos mediadores importantes da relação entre a posição social e o perfil epidemiológico dos grupos sociais.

$\mathrm{Na}$ realidade é muito difícil desembaraçar as diferentes dimensões de determinação e mediação presentes nos processos sociais. As relações sociais que se expressam na divisão sexual do trabalho, a divisão sexual do poder na sociedade, assim como a própria construção social do feminino e do masculino são diversas modalidades de manifestação da organização social e do papel dos homens e das mulheres nessa organização, seja na dimensão predominantemente econômica, seja nas dimensões sociais, culturais ou políticas propriamente ditas.

As relações de gênero atravessam todas as dimensões da vida social, possuem dinâmica própria independente de outros processos sociais e são marcadas pelo antagonismo na relação de dominação das mulheres pelos homens. A idealização do papel do trabalho remunerado, como elemento de fortalecimento da identidade e da liberdade feminina, desaparece face à constatação da pouca ou nenhuma qualificação da maioria dos postos de trabalho ocupados pelas mulheres, dos salários inferiores para as mesmas funções e da dupla jornada, representada pelo trabalho doméstico ou pelas tarefas de cuidado destinado a membros da família das quais invariavelmente são as mulheres que se ocupam. 
Ignorar a importância da estrutura social em todos os seus aspectos acarreta o enfraquecimento do poder explicativo da categoria gênero e impede a compreensão de diferentes fenômenos, nos quais cada um dos múltiplos aspectos das relações de gênero pode assumir proeminência temporária. Por exemplo, o fenômeno da violência doméstica contra as mulheres não pode ser entendido em toda sua extensão com base apenas na perspectiva de classe social, uma vez que ele extrapola amplamente as divisões de classe. Entretanto, as formas de manifestação dessa violência podem estar fortemente marcadas por aspectos relativos às classes sociais.

Portanto, não há como estabelecer de maneira unívoca e permanente uma hierarquia rígida entre as diferentes categorias de determinação do processo saúde-doença. Em cada tipo de problema analisado, haverá a necessidade de elaborar modelos explicativos específicos nos quais a categoria gênero pode tanto ocupar a posição de determinação, quanto a posição de mediação entre diferentes aspectos da organização social.

Do mesmo modo que se compreende raça como construto social, é possível pensar nas questões de gênero como construções sociais baseadas nas diferenças de sexo, mas cujo alcance ultrapassa largamente os aspectos exclusivamente biológicos.

\section{Gênero e estado de saúde}

Para a maioria das populações, a mortalidade é maior entre os homens em todas as faixas etárias a partir do nascimento. Apenas em culturas que praticam o infanticídio feminino, ou em sociedades onde a assistência à gestação e ao parto é muito precária, a mortalidade pode ser maior entre as mulheres em certos 
grupos etários. Este fato é geralmente atribuído à diferença na exposição a fatores e situações de risco ao longo da vida, que costuma ser maior entre os homens, seja na exposição a situações insalubres de trabalho, seja em relação a comportamentos nocivos para a saúde, tais como o consumo exagerado de álcool, cigarros e outras drogas, e a exposição mais frequente a situações de risco para acidentes e violências (Gráfico 1).

Gráfico 1 - Razão de mortalidade geral por sexo e idade. São Paulo - 2005

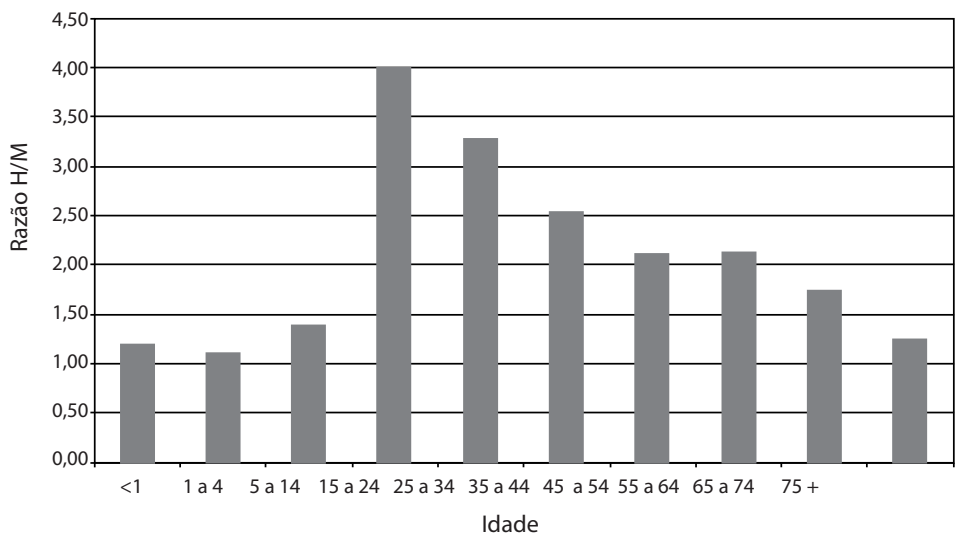

Fonte: Datasus.

O Gráfico 1 mostra que para todas as idades a mortalidade geral foi maior para os homens do que para as mulheres no estado de São Paulo, em 2005. Para os menores de cinco anos a diferença é pequena e a razão é ligeiramente maior do que 1. A partir dos cinco anos a diferença começa a se acentuar, atingindo valor máximo no grupo de 15 a 24 anos, em que a razão chega a 4. A partir dos 25 anos a diferença torna-se progressivamente menor, porém mantendo-se sempre acima de 1 . 
O excesso de mortalidade masculina entre jovens e adultos jovens reflete o impacto não só das mortes violentas, mais frequentes nessas faixas etárias e entre os homens, mas também dos óbitos por Aids.

Com a maior mortalidade masculina em todas as idades, a esperança de vida das mulheres cresce mais aceleradamente do que a esperança de vida dos homens. No Brasil, entre 1960 e 2006 a esperança de vida foi maior para as mulheres, e a diferença entre as curvas masculina e feminina tende a aumentar a cada ano. Em 1960 a diferença era de três anos e em 2006 ela chega a 7,6 anos.

Esses dados, embora classificados por sexo dos indivíduos afetados, podem indicar diferenças de gênero, pois não há razões estritamente biológicas para que os homens apresentem maior mortalidade geral em todas as idades e, consequentemente, menor esperança de vida ao nascer, nem para que os homens jovens apresentem risco de morrer tão acentuado em comparação com o risco das mulheres. As diferenças mencionadas certamente refletem diferenças de gênero, isto é, decorrentes da divisão sexual do trabalho, da construção social e cultural do masculino e do feminino em nossa sociedade, bem como dos distintos modos de vida determinados pela inserção social dos indivíduos, mas modulados pela posição e pelas relações de gênero.

$\mathrm{O}$ excesso de mortalidade masculino também se manifesta em relação aos grupos de causas, conforme pode ser observado no Gráfico 2. 
Gráfico 2 - Razão de mortalidade hospitalar segundo sexo. São Paulo - 2007

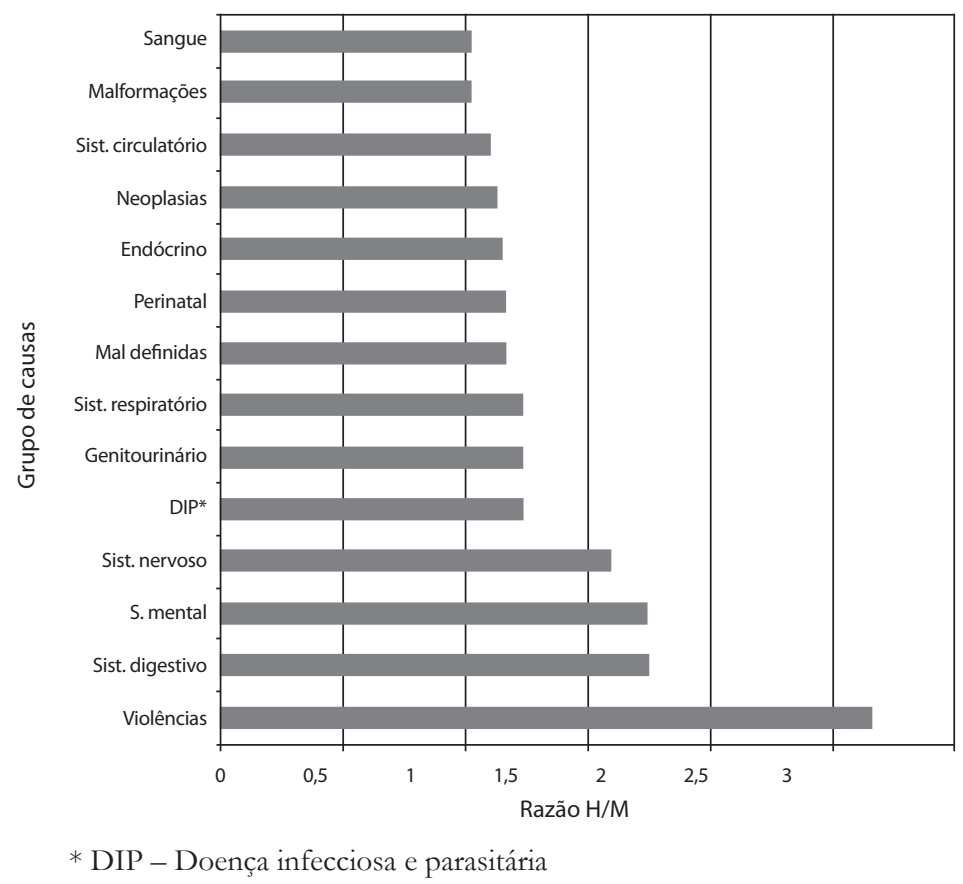

Fonte: Datasus.

Para todos os grupos há um excesso de mortes masculinas, entretanto, a diferença é muito pequena para os óbitos por malformações congênitas e problemas do sangue e dos órgãos hematopoiéticos. O excesso é significativo para doenças do sistema nervoso, problemas mentais e sistema digestivo. A maior diferença é observada para as mortes violentas. Novamente não existem razões biológicas capazes de explicar essas constatações. 
Paradoxalmente, as mulheres, em praticamente todas as populações estudadas, referem pior avaliação do próprio estado de saúde e maior frequência de morbidade do que os homens. Algumas explicações para a morbidade mais acentuada nas mulheres baseiam-se nas diferenças hormonais e genéticas entre os sexos, considerando estritamente o ponto de vista biológico. $\mathrm{O}$ enfoque nas relações de gênero, entretanto, assinala os diferentes papéis sociais dos homens e mulheres que acabam por determinar diferentes percepções sobre o processo saúde doença, assim como comportamentos distintos em relação à doença.

O papel universal e histórico conferido às mulheres como responsáveis pelos cuidados dos filhos e de outros membros da família provavelmente determina a maior atenção para as questões de saúde e doença e, portanto, percepção mais aguçada para os próprios problemas.

Inquéritos populacionais mostram diferenças na morbidade referida pelas mulheres que permaneceram significantes mesmo após controlar o efeito da idade, renda, educação, classe social, estado civil, desemprego e raça. As mulheres com maior frequência referiram sintomas em geral, sintomas graves, problemas crônicos, estado de saúde regular ou ruim, distúrbios psiquiátricos maiores e presença de três ou mais sintomas simultaneamente. A constatação da maior morbidade entre as mulheres, mesmo após a anulação do efeito da idade e de variáveis socioeconômicas, sugere, assim, o efeito independente da condição de gênero sobre o estado de saúde.

Certamente, parte do excesso de morbidade apresentado pelas mulheres pode estar relacionado com as características do trabalho feminino, uma vez que as condições de trabalho são 
determinantes muito relevantes do estado de saúde. O trabalho feminino geralmente está concentrado em certos setores de atividade e em certas profissões predominantemente mal remuneradas. Em algumas sociedades como a brasileira, para empregos semelhantes com o mesmo grau de exigência em termos de qualificação, é comum as mulheres receberem salários menores em comparação com os homens.

No estado de São Paulo, em 2006, 55,4\% das mulheres entre 15 e 59 anos estavam no mercado de trabalho. A renda média feminina era $R \$ 869,00$, enquanto a masculina era $R \$ 1.291,00$. Entretanto, a jornada média de trabalho era menor para as mulheres - em torno de 39 horas - ao passo que para os homens a jornada média era de 45 horas. Assim, a comparação mais adequada é através do valor da hora trabalhada. Novamente o valor é menor para as trabalhadoras: $R$ \$ 5,21 contra $R \$ 6,70$ dos trabalhadores.

$\mathrm{O}$ valor da hora é sempre menor para as mulheres, qualquer que seja a inserção no trabalho. Em 2005, para a posição de empregador, as mulheres ganharam $\mathrm{R} \$ 9,01$ por hora, enquanto os homens ganharam $\mathrm{R} \$ 13,14$. Entre os trabalhadores autônomos, a diferença foi de $\mathrm{R} \$ 3,94$ a hora feminina para $\mathrm{R} \$ 5,77$ a hora masculina. $\mathrm{O}$ trabalho assalariado no setor privado remunerou a hora feminina em $\mathrm{R} \$ 5,24$ e a masculina em $\mathrm{R} \$ 6,10$. Finalmente, o trabalho assalariado no setor público pagou $\mathrm{R} \$ 9,52$ a hora de trabalho das mulheres e R $\$ 11,09$ a dos homens. No caso do setor público, em função das características do emprego, em que para mesma função a remuneração é obrigatoriamente a mesma, a diferença na remuneração média só pode ser atribuída ao fato das mulheres ocuparem predominantemente postos pior remunerados. 
O censo britânico de 2001 também mostrou maior proporção de percepção de saúde regular ou ruim entre as mulheres nas diferentes condições de classe ocupacional. As condições no estado de saúde são piores para mulheres em praticamente todas as classes, exceto para as ocupações intermediárias na hierarquia gerencial, pequenos empregadores e autônomos com negócio e ocupações semiqualificadas. Nas demais, o estado de saúde referido foi pior entre as mulheres. A diferença na proporção de indivíduos com saúde regular ou ruim, entre os extremos do espectro de posições na ocupação, foi mais acentuada entre os homens, com razão de prevalências de 2,7 vezes entre os trabalhadores em ocupações não qualificadas e os profissionais e altos executivos. Para as mulheres essa diferença foi de 2,2 vezes, principalmente pelo excesso de risco apresentado pelas profissionais e ocupantes de postos executivos de alta hierarquia, sugerindo maior pressão sobre as mulheres em posições de status social mais elevado.

Os empregos femininos, além dos salários menores, geralmente são mais monótonos, com pequeno ou nenhum grau de autonomia na execução das tarefas, menores perspectivas de progressão, vínculos trabalhistas mais precários, movimentos repetitivos, contato com o público e outras características de desgaste psicológico e emocional. Eventualmente as trabalhadoras ainda estão sujeitas a assédio psicológico ou sexual, agravando as condições de precariedade e desgaste.

Às condições muitas vezes nocivas no trabalho remunerado acrescem-se às demandas do trabalho doméstico não pago. Karen Giffin chama a atenção para o fato de que para grande parte das mulheres a dupla jornada, representada pela somatória entre trabalho doméstico e trabalho remunerado desqualificado e mal 
pago, acaba por anular os potenciais benefícios que eventualmente o trabalho fora das atividades domésticas poderia representar.

Distúrbios psiquiátricos menores estão associados com a dupla jornada das mulheres pobres e também com jornadas de trabalho de mais de dez horas diárias. A maioria delas tinha o trabalho doméstico fora de casa como ocupação principal. A associação entre ter dupla jornada, ser casada e ter filhos em idade pré-escolar dobrou o risco de apresentarem sintomas psiquiátricos. Esta relação desaparece para mulheres sem a dupla jornada. Os dados reforçam a hipótese de que o trabalho remunerado pode representar uma sobrecarga para a saúde das mulheres quando a qualidade do emprego é baixa e se associa com o trabalho doméstico para a própria família.

Há maior risco para transtornos mentais comuns em mulheres desempregadas ou trabalhadoras do setor informal, donas de casa ou inativas, em comparação a mulheres empregadas no setor formal. Entre os homens, a prevalência também é maior para os desempregados e inativos, mas não há diferença entre trabalho formal e informal. Comparando a prevalência de transtornos mentais entre homens e mulheres, com a mesma posição no mercado de trabalho, observa-se prevalência sempre maior para as mulheres.

A inserção da mulher no mercado formal desempenhou papel protetor em relação à saúde mental, entretanto, comparativamente com os homens inseridos no mercado formal ou informal, a situação de saúde mental das mulheres se mostrou pior, refletindo provavelmente o efeito da dupla jornada de trabalho.

Como para a maioria dos processos sociais, a inserção feminina no mundo do trabalho é contraditória. Por um lado, pode representar a oportunidade de construção da autoestima, 
independência financeira, confiança na capacidade decisória e de liderança, rede de suporte social extrafamiliar, realização profissional, maior poder nas relações de gênero; por outro, pode significar exposição a situações de desgaste biopsíquico e acúmulo de desvantagens. Esse jogo contraditório entre aspectos positivos e negativos para a saúde acaba por definir e modelar o perfil epidemiológico no qual as mulheres geralmente apresentam maior frequência de doenças e agravos à saúde e menor mortalidade, em comparação com os homens.

As desigualdades na autopercepção do estado de saúde indicam que as mulheres tendem a considerar sua saúde pior em comparação com a percepção que os homens têm de sua própria saúde. Os dados empíricos reforçam o conceito de gênero com construto social que determina como homens e mulheres experimentam os eventos vitais de modo particular.

Inquérito realizado em amostra representativa da população brasileira, exceto para a população rural da região Norte do país, mostrou diferença significativa na autopercepção do estado de saúde entre homens e mulheres. As mulheres apresentam maior proporção de saúde regular ou ruim, em todos os grupos de idade, estratos de renda e níveis de escolaridade.

As diferenças entre o estado de saúde de homens e mulheres se tornam ainda mais acentuadas após o ajuste por variáveis socioeconômicas, como escolaridade e renda, sugerindo que os determinantes estruturais não são capazes de explicar a variação encontrada. Do mesmo modo, a cor da pele e a idade não modificam essa relação.

As quatro variáveis mencionadas explicam pouco mais de $10 \%$ da desigualdade observada no estado de saúde entre homens 
e mulheres. Portanto, outros aspectos, além das condições diretamente materiais e biológicas (expressas pela idade), interferem na determinação do estado de saúde de homens e mulheres, sendo necessário recorrer a outras dimensões da vida social para compreender as desigualdades de gênero.

Um problema de saúde com importância crescente e no qual a determinação das relações de gênero ocupa uma posição central é a violência. Por um lado, a violência urbana afeta de maneira desproporcional os homens; por outro, a violência doméstica afeta desproporcionalmente as mulheres. Além de vários determinantes socioeconômicos, políticos e culturais, as relações de gênero desempenham papel fundamental na produção desses agravos à saúde.

As mortes e traumatismos decorrentes da violência vêm aumentando de maneira alarmante a partir da década de 1980, convertendo-se em problema de saúde pública, seja por sua magnitude e transcendência social, seja pelo volume de gastos que o atendimento das vítimas representa para o setor saúde. A mortalidade por homicídios representa uma das facetas do crescimento da violência urbana, ocupando lugar de destaque entre as causas básicas de óbito, principalmente entre adolescentes e adultos jovens do sexo masculino, em muitos países da América, constituindo, ao lado dos acidentes de trânsito, os principais motivos das mortes por causas externas.

Na cidade de São Paulo, no período de 1996 a 2005, a taxa de mortalidade por homicídio para homens apresentou valores extremamente altos até 2003, quando então começou a declinar. Em 1999 a taxa atingiu seu valor mais alto: 129,07 óbitos por 100 mil habitantes. Em 2005 foi registrado o valor mais baixo: 49,85 
óbitos por 100 mil habitantes. Para as mulheres, no mesmo período, as taxas foram em média 14 vezes menores. $\mathrm{O}$ valor mais alto também foi registrado em 1999, chegando a 9,20 óbitos por 100 mil habitantes, e o valor mais baixo em 2005 foi de 3,95 óbitos por 100 mil. Durante esse período, a razão de mortalidade por homicídios variou entre 12,62 em 2005 e 15,66 em 2001.

Estudo que realizamos em amostra de homicídios ocorridos em 1998 mostrou que a razão entre os óbitos por homicídio de homens e mulheres varia segundo os estratos socioeconômicos das áreas de residência das vítimas. No estrato de melhores condições de vida, a relação observada foi de cinco óbitos masculinos para cada óbito feminino, enquanto no estrato de piores condições de vida a relação foi de 32 óbitos masculinos para cada óbito feminino.

Estas marcadas diferenças no risco para homens e mulheres não podem ser explicadas exclusivamente pelos processos macrossociais. Os fenômenos sociais e econômicos, que estão na gênese do crescimento da violência urbana e que se traduzem no aumento sem precedentes dos óbitos por homicídio, são mediados pelas relações de gênero, determinando riscos bastante diferenciados para homens e mulheres nas mesmas condições sociais.

Para as camadas da população vivendo em condições de exclusão social, os comportamentos violentos aparecem muitas vezes como reafirmadores de identidade. A frustração das expectativas, associada ao desemprego crônico e à falta de participação na vida social, acaba por produzir sentimentos de marginalização e diminuição da autoestima, potencializados pela vivência da extrema situação de desigualdade, concorrendo para maior exposição e vitimização dos moradores das áreas periféricas mais pobres. 
Nessas áreas os homicídios ocorrem majoritariamente no espaço público, geralmente na rua ou em bares ou salões de baile, e estão relacionados com brigas e desavenças e também com o tráfico de drogas. O consumo de álcool e outras drogas ilegais estão frequentemente associados com essas mortes, sendo comum que a vítima e o agressor estejam sob o efeito do álcool ou de outras drogas quando o homicídio é praticado.

No estrato mais pobre predominam, como circunstâncias em que os homicídios são cometidos, as brigas entre conhecidos ou amigos e em boa parte dos casos são utilizadas armas brancas. Nos três estratos intermediários no espectro socioeconômico são mais frequentes as execuções relacionadas com o tráfico de drogas na cobrança de dívidas, disputa por pontos de vendas e diversas situações relacionadas com vingança. $\mathrm{Na}$ quase totalidade dos casos, os homicídios foram cometidos com armas de fogo e as pessoas foram alvejadas na cabeça, havendo pouca ou nenhuma chance de sobrevida.

Nas camadas da população vivendo em melhores condições de vida, os homicídios estão mais relacionados a situações de assaltos seguidos de homicídio ou a crimes passionais. Parte significativa dos casos ocorre no domić́lio da vítima, explicando assim o aumento proporcional do risco para as mulheres.

Os homens se tornam vítimas de homicídio mais frequentemente do que as mulheres, tanto por apresentarem maior exposição a situações de risco, quanto pelo maior consumo de álcool e drogas ilícitas. Mas provavelmente há outros aspectos mais diretamente relacionados à construção do papel masculino na sociedade que acabam por favorecer a maior exposição dos homens. 
Do mesmo modo a vitimização das mulheres é mediada pela construção do papel feminino na sociedade. Exemplar desse tipo de situação é o homicídio praticado pelo companheiro, seja como vingança por abandono ou traição amorosa, seja como decorrência de situações de crescente violência na relação de casal.

Alguns estudos realizados no âmbito da psicologia social têm demonstrado que homens e mulheres apresentam diferentes atitudes em relação à igualdade nas relações de gênero e que estas atitudes podem influenciar a qualidade da relação entre casais. As mulheres tendem a endossar atitudes mais igualitárias nas relações de gênero, independentemente de terem ou não sido vítimas de agressões físicas ou psicológicas. Nos homens a ideologia do papel de gênero parece estar mais vinculada às próprias experiências. Homens que não foram vítimas de agressões tendem a aprovar atitudes mais igualitárias do que aqueles que foram vitimizados em algum momento da vida.

No Brasil, em dois inquéritos nacionais representativos da população urbana, os pesquisadores encontraram alta prevalência de violência sexual praticada por companheiro ou companheira $(8,6 \%)$. O risco para as mulheres foi duas vezes maior do que para os homens. A prevalência foi extremamente alta para indivíduos de ambos os sexos, com prática homo ou bissexual, correspondendo ao dobro da observada entre as mulheres heterossexuais e cinco vezes maior do que para os homens heterossexuais.

Os dados revelam que, além das relações de gênero, a preferência sexual dos indivíduos também atua como mediadora nas questões de violência doméstica por parceiro íntimo. A prevalência de violência sexual foi maior nos indivíduos mais velhos, 
com menor renda e menor grau de escolaridade, mostrando assim a influência da posição social nesse tipo de violência.

\section{AS QUESTÕES DE GÊNERO E 0 USO DE SERVIÇOS DE SAÚDE}

A utilização dos serviços de saúde apresenta um conjunto de determinantes, dentre os quais a necessidade de saúde ou a existência de um problema de saúde é aquele que impulsiona o indivíduo a buscá-los. Há uma série de fatores predisponentes que alteram a percepção das necessidades de saúde e, portanto, desempenham papel decisivo na concretização da demanda por serviços. Estes fatores incluem a idade, o gênero, a etnia e a condição socioeconômica. A partir da demanda, a utilização dos serviços irá se realizar na dependência da disponibilidade de serviços e recursos humanos, da facilidade de acesso, das formas de financiamento e remuneração aos prestadores.

A utilização de consulta médica, em todos os estratos de renda familiar, apresenta maior frequência entre as mulheres, tanto para os indivíduos com bom estado de saúde, quanto para aqueles com saúde regular ou ruim, segundo os dados das pesquisas nacionais por amostra de domicílios.

O uso de consulta médica aumenta proporcionalmente com a renda familiar, tanto para homens quanto para mulheres, havendo redução progressiva da desigualdade relativa entre eles à medida que se vai da faixa de menor para a de maior renda e com o aumento da idade. A maior desigualdade por gênero é observada entre os jovens com bom estado de saúde e com renda familiar de até dois salários mínimos. Observa-se maior desigualdade de gênero entre as pessoas com bom estado de saúde, em 
todos os grupos de idade, sugerindo utilização diferencial de consultas preventivas segundo gênero. Entre as pessoas com estado de saúde regular ou ruim, as desigualdades entre gêneros são menores, tendendo a desaparecer para os grupos com maior renda. Este comportamento sugere que, em face da necessidade sentida, essas diferenças tendem a exercer menor influência no comportamento de busca por serviços de saúde.

A taxa de utilização de consultas médicas no último ano também aumentou com a idade e com o nível de escolaridade, tanto para homens quanto para mulheres. As desigualdades entre homem e mulheres quanto a este dado apresentam-se mais altas entre os mais jovens e entre aqueles com menor escolaridade e bom estado de saúde. Para as pessoas com condições de saúde regulares ou ruins, as desigualdades não se alteram em função dos níveis de escolaridade, reproduzindo os achados relativos aos níveis de renda.

Para o estado de saúde, a desigualdade indica desvantagem relativa das mulheres que sempre apresentam pior estado de saúde autorreferido, enquanto para a utilização de serviços de saúde a desigualdade se mostra favorável às mulheres que sempre referem maior consumo, em consonância com a autopercepção do estado de saúde.

A desigualdade de gênero na prevalência de estado de saúde regular ou ruim foi observada também para a presença de doença crônica, restrição de atividades e procura por serviços de saúde nos últimos 15 dias, nesta mesma população.

Dados do inquérito nacional de saúde do Canadá mostram que parcela maior das variações no estado de saúde dos homens e mulheres é explicada por determinantes estruturais (19,23\% e 
$19,47 \%$ respectivamente) mais do que por determinantes comportamentais $(14,95 \%$ e $10,92 \%$ respectivamente), reforçando a concepção de gênero como uma construção social. Homens e mulheres têm suas experiências de vida diversificadas em um mesmo contexto, conforme indicado pela diferença entre determinantes estruturais bem menor do que a diferença entre os determinantes comportamentais, ainda que os primeiros sejam preditores mais importantes do estado de saúde.

Homens e mulheres diferenciam-se marcadamente nos papéis sociais dentro da família e na sociedade em geral. Diferentes sociedades também podem produzir diferentes graus de desigualdade entre homens e mulheres.

Tendo em vista que as necessidades de saúde constituem o principal determinante do uso de serviços de saúde, e que a autoavaliação do estado de saúde das mulheres tende a ser pior do que a dos homens, a frequência maior de utilização de consultas médicas pelas mulheres poderia ser explicada apenas por esta maior necessidade percebida. Entretanto, a diferença nas taxas de utilização de consultas entre homens e mulheres é mais acentuada para as pessoas com bom estado de saúde do que para aquelas com saúde regular ou ruim.

O número médio de consultas/ano também é maior para as mulheres, e elas utilizam proporcionalmente mais consultas para prevenção ou exames de rotina e menos consultas por motivo de doença do que os homens. O consumo de consultas médicas mostra padrão inverso à necessidade de saúde nos diferentes estratos socioeconômicos, e parte dessa utilização diferencial é decorrente do maior uso de consultas preventivas pelos estratos sociais privilegiados, denotando maior preocupação com a saúde, 
incorporação da ideia de risco não como fatalidade, mas como uma possibilidade de ocorrência evitável através de intervenções preventivas.

Para as internações hospitalares o sistema de saúde parece propiciar maior equidade, visto que as taxas de utilização têm distribuição coerente com a do estado de saúde, sugerindo que o maior determinante da utilização é a necessidade de saúde.

As desigualdades de gênero no estado de saúde e na utilização de serviços resultam da ação complexa de diversos determinantes que incluem desde a dimensão biológica, com a carga de problemas relacionados à função reprodutiva, até a dimensão política relacionada à divisão do poder na sociedade.

Gênero, como construção social, consiste em um sistema multinível, incluindo arranjos econômicos e políticos e crenças culturais na dimensão macrossocial, padrões de comportamento na dimensão intermediária e aspectos ligados à identidade individual na dimensão microssocial. Esta estrutura multidimensional se traduz para os indivíduos em identidades de homens e mulheres que estão engajados em papéis familiares e sociais diversos.

A equidade de gênero não implica a igualdade entre homens e mulheres, seja no estado de saúde, seja no consumo de serviços de saúde, mas o atendimento equitativo das necessidades de homens e mulheres. Para a população brasileira não parece haver discriminação dos serviços de saúde quanto ao gênero, visto que a maior utilização pelas mulheres parece acompanhar o estado de saúde e a maior atenção que elas costumam dar à sua saúde. Entretanto, caberia investigar até que ponto a existência de políticas de saúde voltadas principalmente para a saúde reprodutiva das mulheres pode estar influenciando essa maior utilização. 


\section{$6 \mid$ Políticas para o Enfrentamento
Das Desigualdades}

A abordagem coletiva ou populacional do processo saúdedoença na perspectiva da epidemiologia social implica fazer algumas perguntas básicas sobre como são produzidas as doenças na população, que forças determinam sua distribuição, por que alguns indivíduos adoecem e outros não, e quais são as maneiras pelas quais as políticas públicas podem interferir nesses processos.

Para compreender o processo de determinação das doenças e ter elementos para a intervenção através de políticas públicas desenhadas para alcançar a modificação das condições de produção e de distribuição dos problemas de saúde, é necessário inicialmente tratar dos modelos de causalidade em uso pela epidemiologia.

$\mathrm{Na}$ abordagem convencional dos modelos multicausais, cada variável ou fator de risco é analisado inicialmente em sua associação com o desfecho de interesse, ou seja, com a doença ou problema de saúde em estudo. Na pesquisa anteriormente citada da associação entre idade materna, hábito de fumar das mães e classe social como fatores de risco para baixo peso ao nascer, a abordagem multicausal - que não foi a adotada pelos autores, mas que podemos utilizar apenas a título de exemplificação indicaria ao final dos ajustes a importância de cada uma dessas variáveis (Tabela 7). 
Tabela 7 - Incidência de baixo peso e risco relativo segundo características maternas. Ribeirão Preto (SP) - 1978-1979

\begin{tabular}{l|cc}
\hline Fatores de risco & $\begin{array}{c}\text { Incidência } \\
\text { (casos por 100) }\end{array}$ & RR \\
\hline Idade materna & \multicolumn{2}{l}{} \\
\hline$<20$ anos & 9,38 & 1,52 \\
\hline$\geq 20$ anos & 6,15 & 1,00 \\
\hline Hábito de fumar da mãe & & 1,77 \\
\hline Fumante & 9,62 \\
\hline Não fumante & 5,43 \\
\hline Pobreza & & \\
\hline Pobres & & \\
\hline Não pobres & 7,35 & 2,35 \\
\hline
\end{tabular}

Fonte: Silva et al., 1992.

A análise dos dados permite afirmar que as mães adolescentes que fumam e são pobres apresentam maior risco de ter recémnascidos com baixo peso quando comparadas a mães com 20 anos ou mais de idade, não fumantes e não pobres. Consequentemente, se a idade materna é um fator de risco, as políticas para redução do baixo peso ao nascer devem incluir ações visando a diminuir a gravidez na adolescência. Do mesmo modo, se o hábito de fumar é um fator de risco, será necessário que as mães deixem de fumar para reduzir a incidência de baixo peso e, finalmente, se a pobreza também está relacionada, será preciso usar políticas compensatórias que possibilitem melhor alimentação durante a gestação para evitar o baixo peso. Teríamos assim um conjunto de intervenções educativas, de controle da gravidez na 
adolescência, redução do hábito de fumar e de suplementação alimentar para enfrentar o problema.

Sabemos que na realidade as mesmas mães podem apresentar as três características analisadas, e que tratá-las separadamente pode não ser a melhor estratégia para o enfrentamento do problema.

Segundo Leonard Syme, do Departamento de Epidemiologia Social de Berkeley (EUA), há três problemas principais na prática em saúde pública. Primeiro, gastamos muito tempo tentando identificar fatores de risco, mas todos somados explicam menos da metade da ocorrência das doenças. Além disso, mesmo quando as pessoas conhecem os fatores de risco, elas têm dificuldade em mudar seu comportamento e, ainda que algumas delas mudem o comportamento, haverá sempre outras pessoas entrando na população. Em segundo lugar não podemos imaginar que a promoção de saúde seja possível com enfoque exclusivo nos fatores de risco e nas doenças. O terceiro aspecto é que a tarefa mais importante é a identificação dos determinantes de saúde, e o principal determinante é a classe social.

No modelo de determinação social do processo saúde-doença, as variáveis seriam tratadas através de um modelo hierárquico, no qual o principal determinante é a classe social (em vez do nível de pobreza). A inserção de classe determina igualmente as chances de ocorrência de uma gravidez na adolescência (idade materna) e a de ser fumante, e ambas as variáveis intermediárias determinam a probabilidade de ter um recém-nascido de baixo peso. Deste modo, as variáveis são tratadas de maneira articulada (Tabela 8). 
Tabela 8 - Incidência de baixo peso ao nascer segundo a classe social e o hábito de fumar maternos. Ribeirão Preto (SP) - 1978-1979

\begin{tabular}{l|cc}
\hline Classe social & Mães fumantes & Mães não fumantes \\
\hline Burguesia & 4,36 & 2,67 \\
\hline Proletariado & 9,52 & 5,93 \\
\hline Subproletariado & 12,77 & 6,27 \\
\hline
\end{tabular}

Fonte: Silva et al., 1992.

Ambos os fatores são considerados determinantes, entretanto, se observarmos a combinação de ambas as variáveis, veremos que a determinação exercida pela classe social subordina a atuação do hábito de fumar como fator de risco. Assim, mesmo que todas as mães deixassem de fumar, continuaria havendo desigualdade no risco de ter recém-nascidos de baixo peso, na medida em que as diferenças de classe social continuariam a existir.

Comparando os resultados obtidos em cada uma das abordagens, verificamos que ambas apontam os fatores analisados como fatores de risco, mas o modelo multicausal não permite detectar a hierarquia entre eles e induz à adoção de medidas que não serão totalmente eficazes, exatamente por ignorar a complexidade das relações entre as variáveis.

Dentre os modelos de determinação social do processo saúde-doença, duas formulações atuais merecem destaque pela abordagem complexa dos distintos níveis de organização da vida social que representam: o modelo do modo de vida elaborado por Naomar de Almeida Filho e o proposto pela comissão de Determinantes Sociais em Saúde da Organização Mundial da Saúde (OMS). 
O primeiro modelo reúne as esferas de produção e da reprodução material e simbólica da sociedade, o modo de vida dos grupos sociais, o processo de trabalho, a estrutura de classes, as práticas cotidianas e a construção cultural como determinantes das configurações de risco que se acoplam ao perfil de saúdedoença-cuidado no âmbito populacional.

O segundo modelo destaca cada um dos aspectos mais relevantes das dimensões apontadas no modelo do modo de vida, visando a facilitar a identificação de possíveis áreas de intervenção para as políticas sociais que busquem a redução das desigualdades.

A Comissão de Determinantes Sociais em Saúde define estes determinantes como o conjunto das condições sociais nas quais as pessoas vivem e trabalham e que podem ser alteradas pela ação das políticas públicas. Uma sociedade justa é aquela que é capaz de prover a todos os cidadãos um alto grau de liberdade para escolher dentre as opções de vida aquelas que se ajustem à concepção de 'vida boa'. A meta de qualquer política equânime não deve ser simplesmente igualar o estado de saúde para os diferentes grupos sociais, mas sim buscar igualdade de oportunidades de saúde.

O contexto social determina a cada indivíduo sua posição e esta, por sua vez, determina as oportunidades de saúde segundo exposições a condições nocivas ou saudáveis e segundo situações distintas de vulnerabilidade.

Há pelo menos três níveis distintos de ação política para a redução das desigualdades, dependendo do contexto político e social em cada país. O enfrentamento das desigualdades sociais em saúde pode incluir políticas macrossociais, tais como políticas 
econômicas e sociais que modifiquem a estratificação social; políticas que modifiquem as condições de exposição e vulnerabilidade dos grupos sociais; ou políticas de saúde que atuem sobre as consequências negativas das desigualdades, buscando minimizar o impacto de seus efeitos.

Navarro e colaboradores demonstram que, dependendo da duração dos governos e das características dos partidos no governo, nos países europeus, entre 1950 e 2000, os gastos sociais e com saúde, bem como as consequências sobre o nível de saúde das populações foram bastante diversos (Tabela 9).

Tabela 9 - Concentração de renda, gasto social e gasto em saúde dos países europeus segundo partidos que permaneceram por mais tempo no governo. Europa - 1950-2000

\begin{tabular}{l|ccc}
\hline Governos & $\begin{array}{c}\text { Coeficiente } \\
\text { Gini }\end{array}$ & $\begin{array}{c}\text { Gasto social } \\
(\%)\end{array}$ & $\begin{array}{c}\text { Gasto em } \\
\text { saúde }(\%)\end{array}$ \\
\hline Social-democratas & 0,225 & 30,0 & 7,2 \\
\hline Democracia cristã & 0,306 & 28,0 & 6,4 \\
\hline $\begin{array}{l}\text { Liberal } \\
\text { conservadores }\end{array}$ & 0,320 & 24,0 & 5,8 \\
\hline Ditatoriais & 0,420 & 14,0 & 4,8 \\
\hline
\end{tabular}

Fonte: Navarro et al., 2006.

As políticas redistributivas, praticadas principalmente pelos governos social-democratas, estão positivamente associadas com menor mortalidade infantil e maior esperança de vida. A taxa de mortalidade infantil apresenta correlação negativa com a quantidade de anos de governo social-democrata e com o nível de distribuição da renda; a implementação de políticas sociais desenhadas para reduzir desigualdades está 
associada com baixas taxas de mortalidade infantil; e existe correlação negativa entre desigualdade de renda e esperança de vida para homens e mulheres.

Os princípios para a ação política devem ser o compromisso ético com a equidade; a abordagem baseada em evidências científicas; a preocupação com todo o gradiente de desigualdades, e não apenas com os extremos da distribuição ou com as diferenças individuais; a atuação na vida cotidiana, pois é nela que experimentamos o impacto da estrutura social; e a consciência de que as evidências são importantes, mas há outros ingredientes na tomada de decisão, dentre as quais talvez a mais relevante seja a vontade de transformar as evidências disponíveis em estratégias para a ação.

As experiências levadas a efeito para promover a equidade em saúde incluem políticas de redução da desigualdade de renda e de redução da pobreza, políticas fiscais progressivas, controle sobre o capital volátil, perdão da dívida e novas fórmulas de cálculo baseadas na atenção às necessidades básicas, políticas de redução da vulnerabilidade e investimentos em saúde.

A definição da saúde como bem público significa que o consumo dos serviços e práticas de saúde não é exclusivo de um indivíduo, nem seu uso por um indivíduo rivaliza com o consumo por outros. Há inúmeros exemplos de bens públicos nas ações de saúde, tais como os programas de controle das doenças transmissíveis, a produção de conhecimentos científicos em saúde, a regulação de produtos com impacto sobre a saúde, e a organização de sistemas universais de saúde.

No nível de atuação intermediário, estão as intervenções que têm como objetivo a modificação das condições de exposição e vulnerabilidade dos diferentes grupos sociais. Como exemplo de 
atuação setorial para reduzir a vulnerabilidade social dos grupos em piores condições socioeconômicas, podemos analisar o efeito dos investimentos realizados no Programa de Saúde MaternoInfantil, tanto na atenção primária quanto na assistência hospitalar, pela prefeitura de Belo Horizonte, visando a reduzir os diferenciais intraurbanos na mortalidade infantil (Tabela 10).

Tabela 10 - Gastos do orçamento participativo e administrativo, diferenciais de mortalidade infantil (MI) segundo distritos de saúde (DS) ordenados por condições de vida. Belo Horizonte 1994 e 1997

\begin{tabular}{|c|c|c|c|c|c|}
\hline \multirow[t]{2}{*}{ DS } & \multirow{2}{*}{$\begin{array}{c}\text { Gasto per } \\
\text { capita } \\
(\mathrm{R} \$)\end{array}$} & \multirow{2}{*}{$\begin{array}{c}\text { Orçamento } \\
\text { participativo } \\
\text { per capita } \\
\text { (R\$) }\end{array}$} & \multirow{2}{*}{$\begin{array}{c}\text { Orçamento } \\
\text { administrativo } \\
\text { per capita } \\
(\mathrm{R} \$)\end{array}$} & \multicolumn{2}{|c|}{$\begin{array}{c}\text { Diferenciais } \\
\text { de MI }\end{array}$} \\
\hline & & & & 1994 & 1997 \\
\hline Pampulha & 23,00 & 21,00 & 2,00 & 0,61 & \\
\hline & & & & & $0,00^{*}$ \\
\hline Nordeste & 33,00 & 17,00 & 16,00 & 0,74 & 0,64 \\
\hline Barreiro & 47,00 & 14,00 & 33,00 & 0,78 & 0,06 \\
\hline $\begin{array}{l}\text { Venda } \\
\text { nova }\end{array}$ & 34,00 & 21,00 & 14,00 & 0,90 & 0,09 \\
\hline
\end{tabular}

* Taxa de referência

Fonte: Junqueira et al., 2002.

Os dados apresentados na Tabela 10 referem-se exclusivamente a quatro dos distritos sanitários. Os diferenciais de mortalidade infantil foram calculados com relação à taxa de mortalidade infantil observada no distrito da Pampulha em 1997 (taxa de 17,7 óbitos por 1.000 nascidos vivos). Os diferenciais calculados para 1994 mostram gradiente nítido entre os distritos segundo as condições de vida. Com vistas a reduzir essas 
brechas, o governo municipal optou por realizar investimentos diferenciados, destinando mais recursos para os distritos com maiores necessidades (orçamento administrativo). Simultaneamente, a distribuição de recursos para as diferentes políticas sociais foi objeto de discussão e deliberação pelo orçamento participativo. Chama a atenção o fato de que no orçamento participativo foram destinados mais recursos para o Programa Materno-Infantil, tanto no distrito com piores condições de vida quanto naquele com as melhores condições de vida.

Após quatro anos, houve redução nas brechas de mortalidade para os dois distritos com piores condições de vida e também para o distrito com melhores condições de vida, enquanto o distrito em situação intermediária mostrou pequena redução. Este tipo de política setorial redistributiva logrou reduzir as desigualdades sociais em saúde, diminuindo a vulnerabilidade de grupos sociais que apresentavam inserção social mais precária.

O Programa Nacional de Imunizações (PNI) pode ser tomado como outro exemplo de política setorial voltada para esse fim. Ele associa uma atuação universal através do fornecimento de vacinas de forma continuada nos serviços de atenção primária com a realização de 'dias nacionais de vacinação', promovidos para abranger parcelas da população que, por diferentes motivos, não conseguem utilizar de maneira apropriada os serviços regulares de saúde.

O programa fornece gratuitamente vacinas contra dez doenças através de uma ampla rede de serviços distribuídos em todo o território nacional. Apesar do PNI ser bastante abrangente e totalmente gratuito, a cobertura vacinal apresenta diferença entre os estratos socioeconômicos da população. Ela é satisfatória para 
os estratos B, C e D, com valores médios acima de 95\%, mas é significativamente menor nos extremos da distribuição, ficando abaixo de $90 \%$ nos estratos A e E.

No estrato A, mais da metade das crianças é vacinada em serviços privados de saúde, sugerindo que a menor cobertura não é motivada por dificuldades de acesso. Nesse estrato os pais escolhem as vacinas que desejam aplicar nos filhos, ponderam entre o risco de adquirir a doença e o risco de efeitos colaterais após a aplicação da vacina. Além disso, têm acesso a informações pela Internet ou em revistas de vulgarização do conhecimento científico e geralmente valorizam negativamente as vacinas tradicionais, considerando-as desnecessárias em sua classe social.

No estrato E, as razões para a menor cobertura são muito diferentes. Parte das famílias é constituída por migrantes, recém-chegados à cidade, com inserção social precária, o que dificulta o uso dos equipamentos sociais existentes, sem documentação das crianças, sem conhecimento sobre os direitos sociais e a gratuidade dos serviços. Uma parte dessas famílias é chefiada por mulheres que necessitam trabalhar para o próprio sustento e o de seus filhos, não dispondo de tempo para frequentar os serviços de atenção primária e manter os filhos adequadamente vacinados.

Assim, mesmo um programa de ampla abrangência como o de imunizações não consegue em sua execução superar todas as desigualdades geradas na estrutura social. $\mathrm{O}$ fato de pertencer a uma determinada classe ou estrato social significa não apenas poder desfrutar de determinadas condições materiais, mas também acaba por moldar toda uma visão de mundo com complexas implicações para a saúde. 
Finalmente, é preciso considerar iniciativas que, não tendo abrangência suficiente para modificar a estratificação social, nem para modificar as condições de vulnerabilidade dos diferentes grupos, destinam-se a mitigar as desigualdades sociais através da oferta de serviços de saúde.

Há uma preocupação crescente não apenas em desenhar e implementar sistemas de saúde capazes de proteger as famílias dos efeitos catastróficos das doenças, mas também em que a atuação dos serviços e profissionais de saúde não aumentem ainda mais as desigualdades sociais, através de ações que estigmatizem ou discriminem grupos de indivíduos segundo idade, sexo, etnia, preferência sexual, religião, condição econômica ou outras características.

Na pesquisa mundial de saúde realizada no Brasil, a proporção de indivíduos que disse haver sido vítima de comportamentos discriminatórios nos serviços ambulatoriais de saúde foi relativamente pequena, exceto para discriminação de classe social ou econômica. Cerca de 11\% das pessoas atendidas em serviços do SUS e $5 \%$ das pessoas atendidas em serviços privados de saúde mencionaram ter sofrido discriminação por falta de dinheiro, enquanto $9 \%$ e $5 \%$, respectivamente, citaram discriminação de classe social.

A discriminação relacionada à cor da pele, idade, sexo ou tipo de doença foi referida por menos de $2 \%$ dos indivíduos nos dois grupos, não apresentando diferenças significantes entre eles. Apenas $0,3 \%$ dos entrevistados mencinou haver sido discriminado por sua nacionalidade.

A existência de um sistema nacional de saúde com acesso universal é uma precondição para buscar a redução das desigualdades 
sociais através do atendimento às necessidades de saúde de todos os grupos da população.

O Gráfico 2 mostra a proporção de mulheres que iniciaram o atendimento pré-natal no primeiro trimestre de gestação segundo a cor da pele, no Brasil e na África do Sul. Pode-se notar que, embora no Brasil existam diferenças nas proporções observadas para brancas, negras e mulatas, elas são bem menores do que aquelas observadas na África do Sul. Após o ajuste por variáveis sociodemográficas, disponibilidade de serviços e necessidades percebidas, as diferenças por cor deixam de ser significantes no Brasil.

Gráfico 2 - Início do pré-natal no primeiro trimestre segundo cor. Brasil e África do Sul - 1996

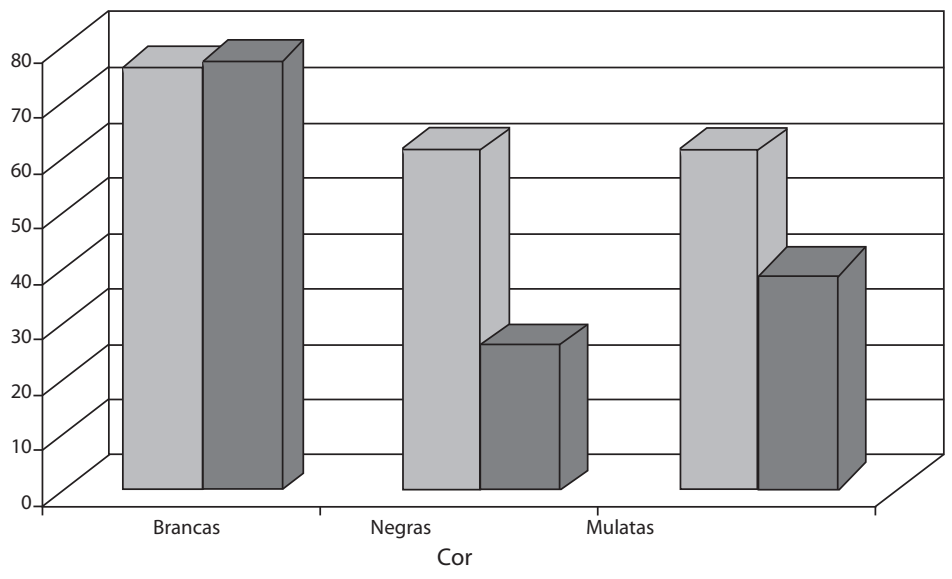

$\square$ Brasil $\square$ África do Sul

Fonte: Adaptado de Burgard, 2004. 
Além do sistema nacional de saúde com acesso universal, é preciso que exista distribuição adequada de serviços e de equipamentos no território, para que os mesmos possam ser utilizados pelos indivíduos que deles necessitam independentemente das condições socioeconômicas, gênero, etnia e outras particularidades.

Os profissionais de saúde precisam estar adequadamente habilitados para garantir a qualidade técnica e humana do atendimento, e os serviços precisam estar organizados para responder às necessidades de saúde. 



\section{CONSIDERAÇões Finais}

A redução das desigualdades sociais em saúde não é uma tarefa fácil, e nem sempre as boas intenções resultam em intervenções com o impacto esperado. Como afirma Fernando Lolas, diretor do programa de bioética da Organización Panamericana de la Salud (OPS) e professor da Universidade do Chile,

embora cada indivíduo separadamente não possa conseguir ou garantir a equidade, valor que se realiza e aperfeiçoa no coletivo, pode não obstante reconhecer e estimular sua manifestação (...) e assim encontrará um sentido para ser feliz, de ordem superior e distinto daquele que nos dá a satisfação de nossas próprias necessidades.

Reconhecer as desigualdades sociais em saúde, buscar compreender os processos que as produzem e identificar os diferentes aspectos que estabelecem a mediação entre os processos macrossociais e o perfil epidemiológico dos diferentes grupos sociais é uma condição indispensável para que seja possível buscar formas de enfrentamento, sejam elas no âmbito das políticas públicas, sejam elas no âmbito da vida cotidiana.

A epidemiologia é apenas uma das disciplinas do campo da saúde coletiva a se preocupar com a temática das desigualdades sociais. Há diversas abordagens dessa mesma temática no âmbito das ciências sociais em saúde e também relativas ao financiamento e à organização dos serviços de saúde. 
A confluência desses saberes de distintas fontes, aliada ao imperativo ético de buscar a construção de uma sociedade mais justa, na qual os indivíduos não sejam inferiorizados em função de qualquer diferença que apresentem em relação à norma, pode resultar em maior comprometimento dos profissionais da saúde coletiva com a formulação e implementação de políticas de saúde mais equânimes.

Há inúmeros desafios relacionados com a questão das desigualdades sociais em saúde. Em primeiro lugar, podemos assinalar o desafio, no plano teórico, de formular explicações consistentes para os dados empíricos obtidos em nossas pesquisas. Em segundo lugar, podemos mencionar o desafio metodológico. Todas as categorias de análise utilizadas no estudo das desigualdades sociais em saúde - classe social, estratificação ocupacional, educacional ou de renda, etnia, gênero - necessitam permanente desenvolvimento conceitual e aprimoramento em sua operacionalização para utilização em pesquisas empíricas.

Ainda enfocando desafios relacionados com a produção de conhecimentos, constata-se a necessidade de desenvolver indicadores apropriados, seja para mensurar os fenômenos sociais, seja para mensurar os resultados deles sobre a saúde, bem como de elaborar técnicas de análise estatística capazes de refletir a complexidade e a estrutura hierárquica desses processos.

No âmbito das práticas, os desafios são ainda maiores em decorrência da natural limitação do campo de atuação do setor saúde. Evidentemente, a superação das desigualdades sociais em saúde requer um conjunto de políticas e processos de transformação social que vão muito além do escopo de atuação do setor. No entanto, é possível iniciar pela própria política de saúde, a 
transformação necessária visando pelo menos a minorar os efeitos danosos da desigualdade gerada na organização social.

A implementação e o aprimoramento contínuo do SUS, com o fim de tornar realidade os princípios da universalidade, integralidade e equidade, fazem parte deste esforço para minorar as desigualdades sociais em saúde

Como cidadãos, entretanto, outras frentes de luta podem-se abrir com o objetivo de repudiar todas as formas de preconceito e discriminação. A atuação política - desde o plano cotidiano até o exercício do direito do voto, na escolha de dirigentes comprometidos com princípios verdadeiramente democráticos e de respeito às diferenças, e que considerem inaceitável o perpetuar das enormes desigualdades sociais na população brasileira também é uma forma de tentar realizar o ideal expresso na citação de Fernando Lolas com a qual iniciamos estas considerações finais. 



\section{Bibliografia}

ALMEIDA-FILHO, N. Modelos de determinação social das doenças crônicas não-transmissíveis. Ciência \& Saúde Coletiva, 9 (4): 865-884, 2004.

BRAVEMAN, P. Health disparities and health equity: concepts and measurement. Annual Review of Public Health, 27(18): 1-28, 2006.

BURGARD, S. Race and pregnancy-related care in Brazil and South Africa. Social Science \& Medicine, 59: 1127-1146, 2004.

COOPER, H. Investigating socio-economic explanations for gender and ethnic inequalities in health. Social Science \& Medicine, 54: 693706, 2002.

JUNQUEIRA, V. et al. Equidad en la salud: evaluación de políticas públicas en Belo Horizonte, Minas Gerais, Brasil, 1993-1997. Cadernos de Saúde Pública, 18(4): 1087-1101, 2002.

KAWACHI, I.; SUBRAMANIAN, S. V. \& ALMEIDA-FILHO, N. A glossary for health inequalities. Journal of Epidemiol. Community Health, 56: 647-652, 2002.

KRIEGER, N. Theories for social epidemiology in the $21^{\text {st }}$ century: an ecosocial perspective. International Journal of Epidemiology, 30: 668-677, 2001.

KRIEGER, N. \& DAVEY-SMITH, G. Bodies count and body counts: social epidemiology and embodying inequality. Epidemiol. Rev., 26:92-103, 2004.

LEAL, M. C.; GAMA, S. G. N. \& CUNHA, C. B. Desigualdades raciais, sociodemográficas e na assistência ao pré-natal e ao parto, 19992001. Revista de Saúde Pública, 39(1): 100-107, 2005. 
MECHANIC, D. Population health: challenges for science and society. The Milbank Quarterly, 85(3):533-559, 2007.

MONTEIRO, C. A.; FREITAS, I. C. M. \& BARATHO, R. M. Saúde, nutrição e classes sociais: o nexo empírico evidenciado em um grande centro urbano, Brasil. Revista de Saúde Pública, 23(5): 422-428, 1989.

NAVARRO, V. \& SHI, L. The political context of social inequalities and health. International Journal of Health Services 31(1): 1-21, 2001.

NAVARRO V. et al. Politics and health outcomes. The Lancet, 368: 1033-1037, 2006.

NOVAES, H. M. D.; BRAGA, P. E. \& SCHOUT, D. Fatores associados à realização de exames preventivos para câncer nas mulheres brasileiras, Pnad 2003. Ciência \& Saúde Coletiva, 11(4): 1023-1035, 2006.

ROHLFS, I. et al. The incorporation of gender perspective into Spanish health surveys. Journal of Epidemiol. Community Health, 61(suppl. II): 20-25, 2007.

SCHRAIBER, L. B. et al. Prevalência da violência contra a mulher por parceiro íntimo em regiões do Brasil. Revista de Saúde Pública, 41(5): 797-807, 2007.

SILVA, A. A. M. et al. Associação entre idade, classe social e hábito de fumar maternos com peso ao nascer. Revista de Saúde Pública, 26(3): 150-154, 1992.

STARFIELD, B. Pathways of influence on equity in health. Social Science \& Medicine, 64: 1355-1362, 2007.

STEPKE, F. L. \& DRUMMOND, J. G. F. Fundamentos de uma Antropologia Bioética. São Paulo: Edições Loyola, 2007.

SYME, S. L. Social determinants of health: the community as an empowered partner. Preventing Chronic Disease, 1(1): 1-5, 2004.

WILLIANS, D. R. Patterns and causes of disparities in health. In: MECHANIC, D.; LYNN, B. R. \& COLBY, D. C. (Eds.) Policy Challenges in Modern Health Care. New Jersey: Rutgers University Press, 2005. 


\section{Sugestões de Leituras}

BARATA, R. B. Desigualdades sociais em saúde. In: CAMPOS, G. W. S. et al. (Orgs.) Tratado de Saúde Coletiva. São Paulo, Rio de Janeiro: Hucitec, Editora Fiocruz, 2006.

Apresenta de forma didática as principais questões relativas às desigualdades sociais em saúde. Cada tópico é ilustrado com exemplos, e o caráter didático do texto facilita a compreensão de questões teóricas e metodológicas para aqueles que estão fazendo uma primeira aproximação com o tema.

BREILH, J. La Inequidady la Perspectiva de los Sin Poder: construcción de lo social y del género-cuerpos, diferencias y desigualdades. Bogotá: Utópica Ediciones, 1998.

Aborda a questão da determinação social do processo saúdedoença, destacando principalmente os desequilíbrios de poder entre as distintas classes sociais e entre gêneros.

CASTELLANOS, P. L. Epidemiologia, saúde pública, situação de saúde e condições de vida: considerações conceituais. In: BARATA, R. B. (Org.) Condições de Vida e Situação de Saúde. Rio de Janeiro: Abrasco, 1997.

Discute aspectos conceituais centrais para questão das desigualdades em saúde, não apenas em sua dimensão descritiva, mas, principalmente, na dimensão interpretativa. $\mathrm{O}$ autor apresenta claramente a diferença entre uma abordagem populacional e a 
abordagem individuada, que tem predominado nas pesquisas epidemiológicas

HOFRICHTER, R. (Ed.) Health and Social Justice. San Francisco: John Wiley \& Sons, 2003.

Pode ser visto como um tratado de epidemiologia social em que as várias dimensões das desigualdades são abordadas por diferentes autores. É um balanço da produção nos países desenvolvidos selecionando pesquisadores mais críticos. Num certo sentido pode ser considerado como um contraponto ao livro organizado por Kawachi e Berkman.

KAWACHI, I. \& KENNEDY, B. P. The Health of Nations: why inequality is harmful to your health. New York: New Press, 2002.

Escrito numa linguagem acessível e agradável, apresenta dados muito interessantes sobre o processo acelerado de crescimento das desigualdades entre países a partir da década de 1990.

MARMOT, M. \& WILKINSON, R. G. Social Determinants of Health. London: Oxford Press, 1999.

É um clássico do tema dos determinantes sociais em saúde, embora haja algum desequilíbrio entre seus capítulos. De todo modo, tenta abarcar, com uma visão pragmática, as várias dimensões da determinação da saúde e da doença.

PAIM, J. S. Abordagens teórico-conceituais em estudos de condições de vida e saúde: notas para reflexão e ação. In: BARATA, R. B. (Org.) Condições de Vida e Situação de Saúde. Rio de Janeiro: Abrasco, 1997.

Escrito para um seminário da Comissão de Epidemiologia da Abrasco, este capítulo é um excelente material sobre questões conceituais no campo dos determinantes sociais em saúde. A leitura é densa, mas bastante clara. 
POULANTZAS, N. As Classes Sociais no Capitalismo de Hoje. São Paulo: Zahar Editores, 1978.

Embora relativamente antigo, é um clássico da discussão das classes sociais nas sociedades ocidentais. Este texto tem iluminado a produção no campo da sociologia e também foi muito utilizado por autores da epidemiologia social latino-americana, nas diversas tentativas de operacionalização do conceito para uso em estudos epidemiológicos

SAMAJA, J. A Reprodução Social e a Saúde: elementos teóricos e metodológicos sobre a questão das relações entre saúde e condições de vida. Salvador: Casa da Saúde, 2000.

Estimulado por uma reunião realizada na cidade de Salvador com o objetivo de aprofundar aspectos teóricos e metodológicos dos estudos de desigualdades sociais em saúde, Juan Samaja escreveu esta pequena jóia para compreender o conceito de reprodução social. Além de um filósofo muito culto e inspirado, era também um excelente metodólogo. A leitura é densa mas vale a pena.

WILKINSON, R. G. Unhealtby Societies: the afflictions of inequality. London: Routledge, 1996.

Outro clássico dos estudos de determinação social, este livro traz uma série de evidências que ajudam a compreender por que as desvantagens relativas são tão importantes para a saúde quanto o nível de privação econômica e social.

WHO (World Health Organization). Commission on Social Determinants of Health. A Conceptual Framework for Action on the Social Determinants of Health. Discussion Paper, 2007.

Este documento da Comissão de Determinantes Sociais em Saúde da WHO/OMS, embora não constitua uma publicação 
formal, é acessível no site da organização e apresenta a discussão mais conceitual que orientou os trabalhos da mesma. Além disso, traz a discussão das alternativas de políticas públicas possíveis no enfrentamento das desigualdades. 
Formato: $12,5 \times 18 \mathrm{~cm}$

Tipologia: Letter Gothic e Garamond

Papel: Off Set $75 \mathrm{~g} / \mathrm{m} 2$ (miolo)

Cartão Supremo $250 \mathrm{~g} / \mathrm{m} 2$ (capa)

CTP, impressão e acabamento: Imo's Gráfica e Editora Ltda.

Rio de Janeiro, maio de 2012

Não encontrando nossos títulos em livrarias, contactar a Editora Fiocruz:

Av. Brasil, 4036 - térreo - sala 112 - Manguinhos

21040-361 - Rio de Janeiro - RJ

Tel.: (21) 3882-9039 e 3882-9041

Telefax: (21) 3882-9006

http://www.fiocruz.br/editora

e-mail: editora@fiocruz.br 
